\title{
COMPARAÇÃO DE RESULTADOS DE UMA COORTE SOB AS ABORDAGENS PROSPECTIVA E HISTÓRICA: AMAMENTAÇÃO NO PRIMEIRO ANO DE VIDA
}

GIZELTON PEREIRA AlENCAR

Dissertação apresentada à Faculdade de Saúde Pública da Universidade de São Paulo para obtenção do grau de Mestre.

Área de concentração: Epidemiologia

ORIENTADOR: PROF. DR. JosÉ MARIA PACHECO DE SOUZA

São Paulo 2003 


\section{Agradecimentos}

Os meus sinceros agradecimentos ao meu orientador José Maria Pacheco de Souza que, com paciência e atenção, auxiliou-me nos meus passos.

À minha querida Célia, aos meus pais e irmãs: o apoio da família sempre esteve presente.

Às professoras Marcia Furquim e Denise Bergamaschi que sempre deram força na vida e no meio acadêmico.

Ao Departamento que ofereceu estrutura para estudar e aos funcionários que ajudavam sempre que possível.

À banca examinadora pelas valiosas contribuições.

À FAPESP (Fundação de Amparo à Pesquisa do Estado de São Paulo) pela bolsa de estudo concedida (processo 00/04081-5). 


\section{Resumo}

Alencar GP. Comparação de resultados de uma coorte sob as abordagens prospectiva e histórica: amamentação no primeiro ano de vida. São Paulo; 2003. [Dissertação de Mestrado - Faculdade de Saúde Pública da USP].

Objetivo. Uma coorte de crianças foi observada sob duas abordagens: coorte prospectiva e coorte retrospectiva (histórica) e o objetivo foi comparar as estimativas da função de riscos do modelo de Cox entre as duas abordagens e a mesma comparação com o modelo complemento log-log. Além disso, comparar as estimativas da função de riscos pelos modelos de Cox e complemento log-log para cada uma das abordagens, separadamente. Métodos. Quando se estuda o tempo de sobrevida da amamentação sem as covariáveis, foram obtidas as estimativas pela técnica atuarial e modelo complemento $\log -\log$ da informação retrospectiva e a técnica de Kaplan-Meier para a informação prospectiva. Os modelos de Cox e complemento log-log foram utilizados para estimar a razão de riscos (HR) com covariáveis para as duas abordagens. Resultados. Sem as covariáveis, a comparação entre as duas abordagens mostrou que as estimativas de $S(t)$ pela informação retrospectiva estão um pouco defasadas em relação à medida prospectiva. Com as covariáveis, os resultados dos modelos de Cox e complemento log-log são semelhantes tanto para os dados prospectivos quanto para os retrospectivos. Foram semelhantes, também, os resultados de um mesmo modelo para cada uma das fontes de informação. Conclusões. Em geral, as estimativas foram bastante próximas em quaisquer das comparações. Somente a variável hábito de fumar da mãe durante a gravidez permaneceu nos modelos finais para todas as técnicas utilizadas, com estimativas próximas, reforçando semelhança entre as várias abordagens.

Descritores: estudos longitudinais, Kaplan-Meier, modelo de Cox, modelo complemento log-log, amamentação. 


\section{Summary}

Alencar GP. Comparação de resultados de uma coorte sob as abordagens prospectiva e histórica: amamentação no primeiro ano de vida. [Comparison between results of a cohort under prospective and historical approaches: breastfeeding in the first year of age]. São Paulo (BR); 2003. [Dissertation - Faculdade de Saúde Pública da Universidade de São Paulo, Brazil].

Objective. A cohort of children was observed under two approaches: prospective cohort and retrospective (historical) cohort and the objective was to compare the estimates of the hazard ratio from Cox model between the two approaches and do the same comparison using the complementary log-log model. Moreover, to compare the estimates of the hazard ratio from the two models to each one of the approaches, separately. Methods. When the survival time for breastfeeding is studied without the covariates, the comparison between the results of actuarial technique and the complementary log-log model has been made for the recorded information. The Kaplan-Meier technique has been used with the daily notebook measures. The Cox and complementary log-log models can estimate the risk rate of covariates categories to both approaches. Results. Without the covariates, the comparison between the two information resources showed that retrospective measures give lower estimates than that from the prospective measures. With covariates, the estimates are not so different and led to the same results. Conclusions. The estimates of each one of the comparisons were too close. Just the variable mother's smoking during the pregnancy stayed in the final models for every techniques used, with close estimates, reinforcing likeness between the several approaches.

Descriptors: longitudinal studies, Kaplan-Meier, Cox model, complementary log-log model, breastfeeding. 


\section{ÍNDICE}

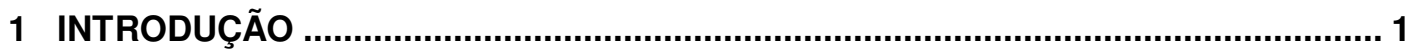





3.1 A PESQUISA “ALIMENTAÇÃO NO PRIMEIRO ANO DE VIDA"......................................... 7

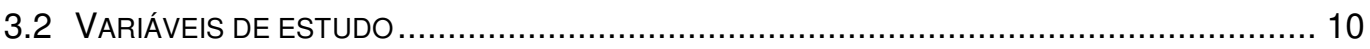

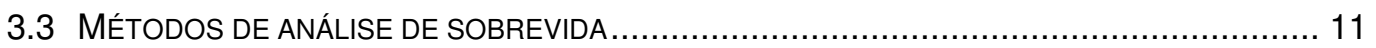

3.3.1 A função de sobrevida e a função de risco ................................................ 11



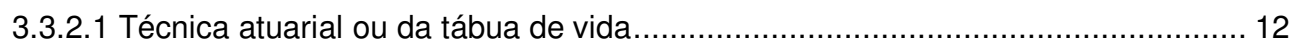

3.3.2.2 Modelo complemento log-log ................................................................... 12

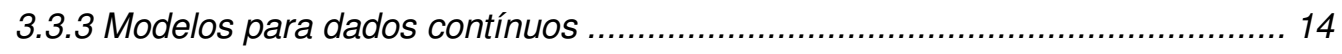



3.3.3.2 Modelo de riscos proporcionais de Cox ..................................................... 15

3.4 PROCEDIMENTO DE OBTENÇÃO E VERIFICAÇÃO DOS MODELOS................................... 17



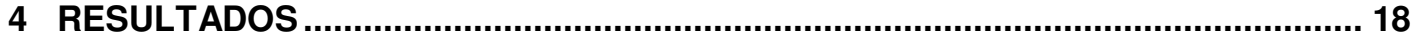

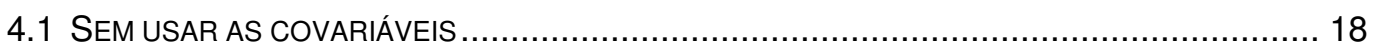

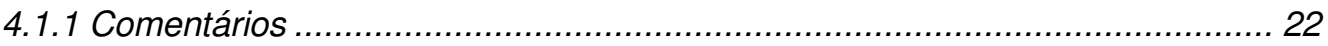

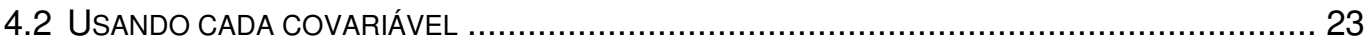



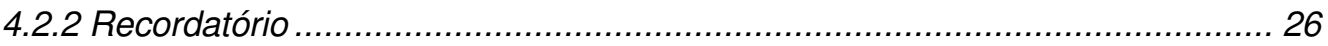

4.3 USANDO AS COVARIÁVEIS EM UM MODELO MULTIVARIADO …................................... 29



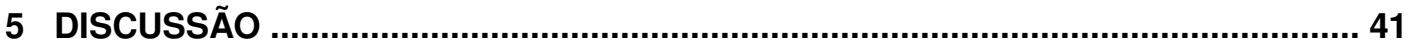



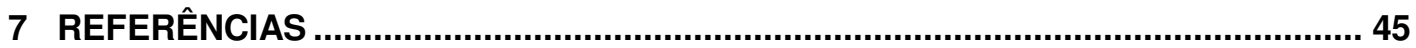

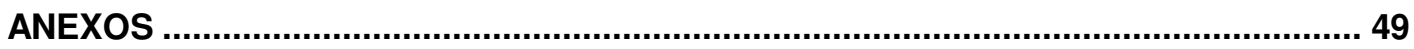

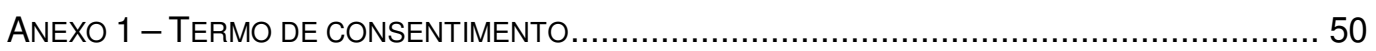

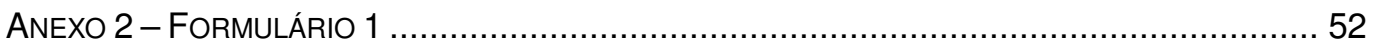



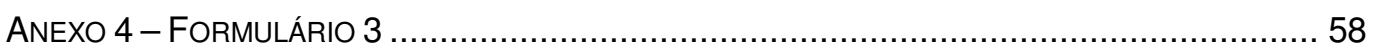


ANEXO 5 - QUESTIONÁRIO RECORDATÓRIO

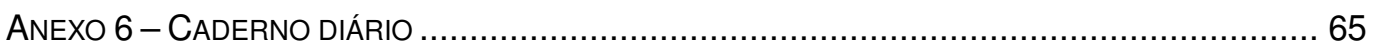

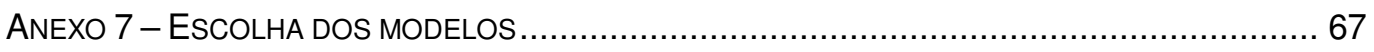

ANEXO 8 - PROGRAMA NO STATA PARA O MODELO COMPLEMENTO LOG-LOG E ALTERAÇÕES NO

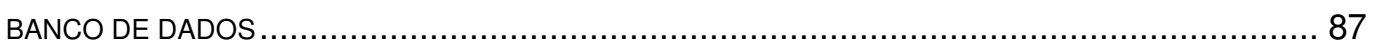

ANeXo 9 - Parecer do Comitê de Ética em Pesquisa dA FSP - COEP ......................... 90 


\section{Introdução}

A alimentação no primeiro ano de vida de uma criança é importante para seu desenvolvimento satisfatório. Essa alimentação envolve a amamentação e a introdução de outros alimentos (RADRIGAN 1989; HITCHCOCK 1985).

Uma possível forma de caracterizar a amamentação das crianças desde o nascimento é por meio de um estudo epidemiológico do tipo coorte. Pode-se considerar duas abordagens. Uma, denominada coorte prospectiva, acompanha as crianças no decorrer do tempo e registra o instante em que cessa a amamentação, no momento de sua ocorrência. Outra abordagem depende da obtenção de informações já registradas ou de inquéritos que as tornem disponíveis, baseando-se na memória das pessoas (KLEINBAUM 1982). Pode-se chamar esta abordagem de coorte retrospectiva ou histórica.

\section{Estudos prospectivos, retrospectivos e de corte transversal}

Os estudos epidemiológicos observacionais podem ter duas referências de tempo: transversal e longitudinal. O estudo do tipo coorte, tanto prospectivo como retrospectivo, é um estudo longitudinal.

$\mathrm{Na}$ coorte prospectiva, as medidas da exposição e demais covariáveis são tomadas antes da ocorrência do evento. No caso retrospectivo, as medidas da exposição, as demais covariáveis e a ocorrência do evento são avaliadas após a ocorrência do mesmo (PEREIRA 1999; ROTHMAN e GREENLAND 1998).

Embora sejam bastante usados, os termos prospectivo e retrospectivo podem ser encontrados com outras denominações. Na literatura, a coorte retrospectiva é também chamada de coorte histórica ou coorte prospectiva não concorrente. A coorte prospectiva é, por vezes, chamada de coorte prospectiva concorrente (KELSEY 1986; LILIENFELD 1976).

Em diversas situações, estudos de corte transversal podem fornecer informações retrospectivas a respeito da ocorrência de um evento e podem ser utilizadas como se fosse uma coorte retrospectiva. Em um estudo de coorte, existe a aleatorização dos indivíduos a participar da pesquisa, o que não ocorre, em muitos casos, com o estudo 
de corte transversal. Os casos desse último estudo podem representar um viés de seleção e interferir nas estimativas produzidas no que se refere às relações causais que podem ser feitas em estudos de coorte (KLEINBAUM 1982).

\section{Vieses}

Um possível viés que pode surgir em estudos que envolvem a anotação diária de um formulário é provocado pelo indivíduo participar de uma pesquisa. A pesquisa pode fazer com que o participante aumente a atenção para um determinado evento que se quer estudar, provocando uma alteração dos resultados. Assim, o fato de se fazer parte de uma pesquisa sobre alimentação, pode influenciar na conduta da amamentação da criança. Além disso, o entrevistador pode, também, causar um viés. A presença de um entrevistador pode, por exemplo, influenciar sistematicamente os resultados sobre a anotação como um todo. Já o viés de recordação, ou de memória, pode ocorrer mais em um estudo de abordagem retrospectiva (PEREIRA 1999). Uma comparação entre os resultados das abordagens prospectiva e histórica pode apontar diferenças devidas a vieses. Para que se considere a comparação como um instrumento para medir o viés de memória, deve-se supor que a abordagem prospectiva é a que mais se aproxima da medida real - dela é obtida a medida padrão. Essa suposição surge da idéia de que essa abordagem apresenta menos problemas de memória, pois o registro é feito no momento da ocorrência do evento, não se considerando os possíveis problemas no preenchimento desse registro.

\section{Estudos de sobrevida em coortes}

O tempo pode ser a variável de maior interesse em um estudo. De uma forma geral, nesses estudos existe o interesse de se identificar fatores que influenciam o tempo até a ocorrência do evento.

Em um estudo de coorte, o início de observação do indivíduo é feito a partir de um momento definido como, por exemplo, o nascimento. A partir daí, o indivíduo é observado até ocorrer um evento de interesse e quando esse acontece diz-se que ocorreu uma falha. Quando não é possível se observar a ocorrência de um evento, diz-se que ocorre uma censura na observação e é considerado o tempo até aquele 
momento. Isso ocorre por algumas razões: o indivíduo ultrapassa o tempo limite estabelecido para o estudo sem que a falha ocorresse; ocorre algo que se impossibilita a continuação da observação (como o óbito, o abandono do estudo ou a perda de localização).

A sobrevida é definida como o tempo desde o início da observação do indivíduo no estudo até a ocorrência do evento de interesse (falha) ou até a censura. Define-se, a partir daí, a probabilidade de sobrevida acumulada a partir de um tempo $t$ por meio da função probabilidade de sobrevida acumulada que para facilitar chamaremos de função de sobrevida. Uma outra função utilizada é a função de riscos que representa a taxa de falhas em um certo intervalo curto de tempo, dado que o indivíduo não teve falha em um momento anterior a esse intervalo. A partir dessa função, pode-se comparar duas funções de riscos a partir da medida da razão das funções de riscos de falha (HR: hazard ratio).

Em estudos epidemiológicos, a estimativa da função de sobrevida, da função de riscos e da razão de riscos das covariáveis estudadas é bastante utilizada e pode ser obtida por meio de técnicas estatísticas que serão apresentadas na Seção Material e Métodos com mais detalhes.

Duas técnicas são bastante utilizadas para se obter as estimativas da função de sobrevida: a técnica atuarial e a técnica de Kaplan-Meier. Por meio dessas técnicas, é possível estimar a sobrevida para um conjunto de indivíduos e considerar essas estimativas segundo categorias de uma covariável (KLEIN e MOESCHBERGER 1997; LEE 1992; LAWLESS 1982; KAPLAN e MEIER 1958).

Outras duas técnicas de análise de sobrevida são os modelos de Cox e complemento log-log, que podem ser utilizados para se avaliar o efeito de covariáveis em um modelo multivariado (HOSMER e LEMESHOW 1999; COLLETT 1994).

O modelo de Cox pressupõe riscos proporcionais e modela seus coeficientes por meio da verossimilhança parcial (COX 1972). O modelo complemento log-log estima os seus coeficientes maximizando-se a verossimilhança da forma usual (LAWLESS 1982) e considera, da mesma forma que no modelo de Cox, a proporcionalidade entre as funções de riscos de falha. 


\section{Análise de sobrevida em estudos que envolvem o tempo de amamentação}

A amamentação é entendida, de acordo com a Organização Mundial da Saúde (OMS), como o processo pelo qual o lactente recebe leite materno independentemente de consumir outros alimentos (OPAS/OMS 1991).

Em estudos de amamentação, a técnica atuarial surge com bastante freqüência para se calcular o tempo mediano de amamentação em estudos de coorte.

Rea et al. (1997) utilizaram a técnica atuarial para avaliar o efeito do trabalho formal, em uma coorte de mulheres, na duração da amamentação, da amamentação exclusiva e da predominante e observadas, respectivamente, as medianas de 150, 10 e 70 dias.

Kummer et al. (2000) utilizaram a técnica atuarial para obter a função de sobrevida entre duas coortes (uma de 1987 e outra de 1994), comparando-as com o teste de log-rank, sem encontrar diferenças. Além disso, utilizaram a regressão logística para avaliar o efeito de covariáveis como renda, escolaridade, cor da mãe, assistência pré-natal e estado civil, ressaltando-se maior chance de deixar de amamentar mães de baixa renda e cor branca. O estudo utilizou curvas de sobrevida atuarial considerando-se cortes, em meses, até 6 meses.

Assis et al. (1994) avaliaram o tempo de amamentação e de amamentação exclusiva de uma coorte provinda de comunidades rurais do semi-árido baiano e utilizou a técnica atuarial para obter estimativas da sobrevida da amamentação até 1 ano de idade. A duração mediana da amamentação ficou em 90,28 dias e nenhuma das mães amamentou exclusivamente no peito durante mais do que um dia.

Hardy et al. (1982) avaliaram a amamentação em Paulínia, SP, e utilizaram a técnica atuarial para o tempo de amamentação e amamentação exclusiva obtendo 3,3 e 2,2 meses de tempo mediano, respectivamente. Utilizaram, ainda, a técnica atuarial separadamente por idade da mãe (até 27 anos; 28 e mais), sexo e lugar de residência (urbano; rural).

Passos et al. (2000) usaram a técnica atuarial para obter a duração mediana do aleitamento materno em Ouro Preto em um estudo de corte transversal.

Diversos artigos trabalham com a abordagem prospectiva e apresentam fatores de risco para o desmame. Alguns estudos têm o ponto de partida em hospitais (Scott 
JA et al. 1999; Escamilla et al. 1997) e, no seguimento, as casas dos entrevistados foram visitadas até um determinado tempo, que varia de 1 a 12 meses. Nesses trabalhos, é utilizadas a técnica de Kaplan-Meier para se selecionar variáveis para posterior aplicação do modelo de Cox e se estudar, a partir dessa modelagem, os fatores associados à duração da amamentação.

Abada et al. (2001) estudaram por meio de um modelo de Cox o efeito de variáveis socioeconômicas, demográficas de saúde e alimentos suplementares. A modelagem foi feita por meio de um modelo hierarquizado levando-se em consideração uma estrutura de causalidade a partir de fatores sócio-econômicos, de alimentos suplementares e variáveis relacionadas à saúde. As variáveis mais importantes foram nível de educação da mãe, número de filhos tidos, ocupação da mãe, cuidado pré-natal e idade de introdução de fórmulas infantis. Neste trabalho, a suposição da proporcionalidade dos riscos foi verificada para a variável de localidade (urbano; rural) e como essa suposição não foi satisfeita, o modelo utilizado foi então estratificado.

Rutishauser et al. (1992) detectaram por meio do modelo de Cox o efeito das seguintes covariáveis: hábito de fumar da mãe na gravidez, idade materna, IMC, um escore relacionado às atividades da mãe e momento do primeiro aleitamento.

Levy et al. (2000) avalia principalmente o efeito de chupeta, chupar o dedo, além da atenção e cuidado dispensados à criança sobre a duração da amamentação.

No estudo de Gigante et al. (2000), a análise estimou a prevalência de amamentação aos 6 meses e a associou às covariáveis por meio do modelo de Cox e de regressão logística. Idade materna até 20 anos, não ter tido filhos anteriormente, hábito de tabagismo na gestação e idade gestacional até 37 semanas estiveram relacionadas à maior chance de desmame.

Weiderpass et al. (1998) avaliaram uma coorte durante três meses e usou o modelo de Cox para avaliar o tipo de parto (normal, cesariana eletiva, cesariana emergencial), a classe social e a educação materna, mas não apresentaram significância estatística.

No levantamento bibliográfico para o presente trabalho, não foi encontrado nenhum trabalho que utilize o modelo complemento log-log em amamentação. Serão 
citados alguns exemplos, aplicados a outros tipos de dados, para ilustrar o uso dessa técnica.

Chalita et al. (2000) exemplificaram o uso do modelo complemento log-log para estimar a função de sobrevida quanto à resistência de mangueira períodos de seca, acompanhadas em diversos anos entre 1973 a 1992.

Lancelot et al. (2002) utilizaram o modelo complemento log-log para estimar o efeito de algumas variáveis na mortalidade de fêmeas de cabras em cinco coortes diferentes, acompanhadas até 1 ano de vida.

Kosterman et al. (2000) acompanharam uma amostra de uma coorte de 808 jovens, com entrevistas anuais nas idades de 10 a 16 e 18 anos, para identificar as covariáveis relacionadas ao tempo de início do uso de álcool e maconha. Foi utilizado o modelo complemento log-log e foram consideradas covariáveis dependentes do tempo.

No presente estudo foram utilizados dados da pesquisa "Alimentação no primeiro ano de vida" (FAPESP 96/06073-2) que gerou um conjunto de dados com informações de um caderno de registro diário e de um recordatório. O caderno diário gera as informações da coorte prospectiva e o recordatório atua como fonte de informações do passado para simular a coorte retrospectiva.

Supõe-se que estudos de coorte prospectiva tenham boa confiabilidade quanto à informação obtida, pois a observação estaria mais próxima da ocorrência do evento. Por outro lado, pesquisas com coortes retrospectivas são mais rápidas e mais baratas, mas não se conhece o quanto seus resultados se aproximam dos obtidos em um estudo com coorte contemporânea de fato. A proposta deste trabalho é fazer um estudo que compare os resultados dessas duas abordagens, a partir de informações obtidas de um mesmo grupo de mães/crianças.

\section{Objetivos}

Comparar os resultados da abordagem de coorte retrospectiva com os resultados de coorte prospectiva, usando as técnicas de análise de sobrevida atuarial e de Kaplan-Meier e os modelos de risco proporcional de Cox e complemento log-log, 
com as informações de amamentação no primeiro ano de vida. Mais especificamente, objetiva-se:

1) Obter as estimativas da função de sobrevida, aplicando as técnicas atuarial e de Kaplan-Meier, considerando-se fonte de informação retrospectiva e fonte prospectiva, respectivamente;

2) comparar as estimativas da função de risco, obtidas pelo modelo proporcional de Cox, ao se utilizar uma fonte de informação retrospectiva e uma fonte prospectiva;

3) comparar as estimativas da função de risco, obtidas pelo modelo complemento log-log, ao se utilizar uma fonte de informação retrospectiva e uma fonte prospectiva;

4) comparar os resultados obtidos com o uso dos modelos de riscos proporcionais de Cox e complemento log-log, com a fonte de informação retrospectiva;

5) comparar os resultados obtidos com o uso dos modelos de riscos proporcionais de Cox e complemento log-log, com a fonte de informação prospectiva.

\section{Material e métodos}

\subsection{A pesquisa "Alimentação no primeiro ano de vida"}

Na Faculdade de Saúde Pública da Universidade de São Paulo foi desenvolvida a pesquisa "Alimentação no primeiro ano de vida". É um estudo de coorte com recém-nascidos selecionados na maternidade do Hospital Universitário (HU) da Universidade de São Paulo, situado na Cidade Universitária no Município de São Paulo, seguidos desde o nascimento até completarem o primeiro ano de vida. A coleta de dados da coorte foi realizada para crianças nascidas no período de outubro de 1998 a outubro de 1999. Como o acompanhamento de cada dupla mãe/criança teve duração de um ano, a coleta de informações foi concluída em outubro de 2000.

No HU nascem, em média, sete crianças por dia, cujas mães podem ser classificadas como da comunidade USP (alunas, funcionárias docentes e não docentes, dependentes de funcionários) e de fora da comunidade (residentes na região do bairro do Butantã). 
Estudantes de nutrição da Faculdade de Saúde Pública e outras pessoas indicadas pela participação anterior em outras pesquisas foram treinadas para fazer o contato e dar orientações às mães em todas as etapas da pesquisa.

A seleção das mães era feita um dia após o nascimento dos bebês conforme registrado na ficha de nascimentos, enquanto as mães ainda estavam na enfermaria. Eram entrevistadas as primeiras quatro mães que satisfizessem ao protocolo, que consistia em nascimentos de crianças sem intercorrências, mães residentes no município de São Paulo e que concordassem em participar da pesquisa assinando um termo de consentimento (Anexo 1). Não foram incluídas no estudo crianças com malformação congênita, nascidas de parto gemelar, que necessitassem de internação hospitalar por um período superior a cinco dias, com morte materna ou com a mãe necessitando internação por mais de cinco dias.

O Formulário 1 (Anexo 2), preenchido na entrevista inicial no HU, quando a mãe/criança era selecionada, apresenta características da criança, da gestação, do parto e da família. O Formulário 2 (Anexo 3) era preenchido pela mãe na primeira visita, aos 15 dias de idade da criança, e trata de condições do domicílio e posse de bens para a caracterização sócio-econômica.

No Formulário 3 (Anexo 4) eram anotadas informações sobre o crescimento e cuidados da saúde (onde se incluem situações de imunização), consultas médicas, razões para o desmame quando este ocorresse, além de medidas antropométricas e de desenvolvimento da criança. Esse formulário era aplicado em todas as visitas.

No Anexo 5 encontra-se uma ficha, utilizada pela entrevistadora nas visitas de 12 meses, que contém perguntas relativas à recordação da mãe (recordatório) no que se refere à amamentação e outras medidas como peso e comprimento da criança ao nascer e aos 6 meses.

Para o seguimento, as mães foram entrevistadas no HU e receberam um conjunto inicial de fichas formatadas para leitura ótica com informações diárias (Anexo 6) no qual elas próprias, dia a dia, marcavam os eventos relacionados à alimentação da criança. Esse conjunto de fichas é chamado de caderno diário. Foram, também, programadas visitas domiciliares de entrevistadores para as idades de 15, 30, 60, 90, 180, 270 e 360 dias da criança. Nessas visitas, o entrevistador recolhia o 
caderno diário preenchido pela mãe, dava um novo caderno diário e obtinha informações adicionais sobre a alimentação, o crescimento, desenvolvimento e saúde da criança, em cada período, mediante o preenchimento de questionários estruturados. Cada ficha ótica permitia o registro de 60 dias de eventos (Anexos de 2 a 4).

O Esquema 1 apresenta o fluxo da coorte. As perdas ocorridas durante o seguimento foram motivadas pela não aceitação da mãe em continuar no estudo (35), não-preenchimento do primeiro caderno diário mesmo com a presença dos cadernos seguintes (19), falecimento da criança até 15 dias (1), internação da criança até 15 dias (1).

Esquema 1. Dinâmica da coorte do início ao término da pesquisa

CONVITE PARA PARTICIPAR - HU

609 crianças

21 exclusões por endereço

Endereços não encontrados na primeira entrevista 82 crianças

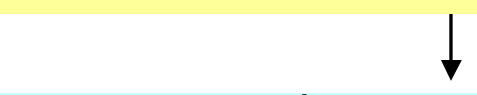

COORTE NO INÍCIO DAS VISITAS DOMICILIARES

COORTE EFETIVA

506 crianças $(100 \%)$

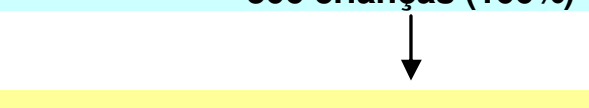

Perdas ocorridas durante o seguimento 56 crianças

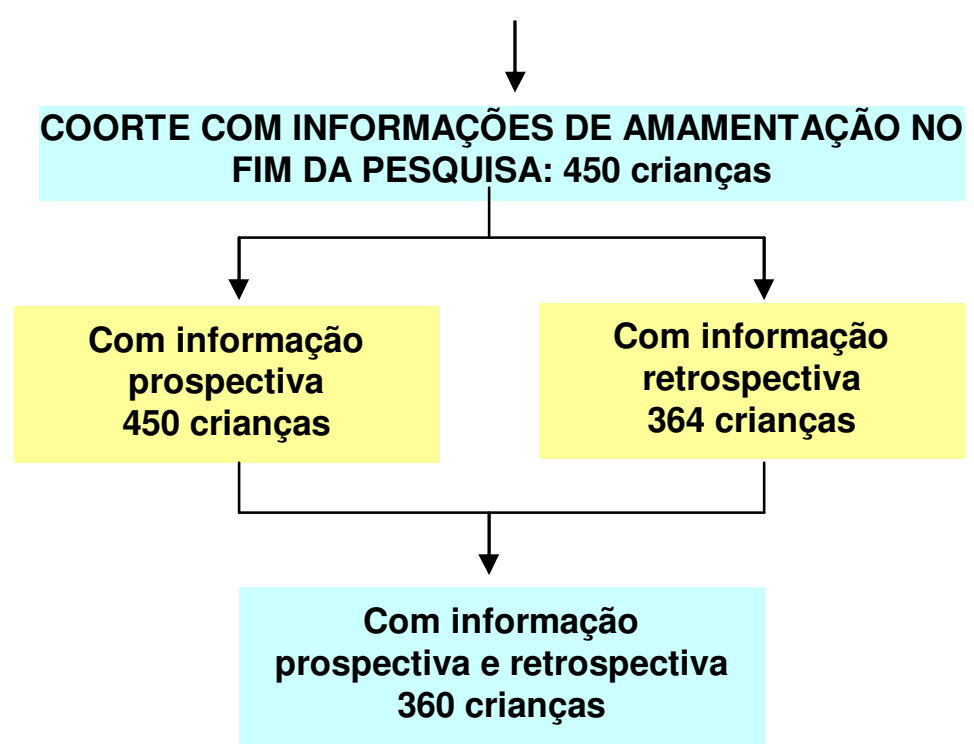


Para ser possível a comparação entre os resultados foram consideradas 360 pares de mães/crianças que possuem as informações completas até 360 dias, nas duas fontes de informação, para a variável que se refere ao tempo de amamentação. Não foram consideradas, portanto, as situações em que alguma das fontes de informação não estava preenchida.

\subsection{Variáveis de estudo}

As variáveis consideradas e suas categorias foram:

- sexo da criança;

- tipo de parto:

normal, fórceps, cesárea;

- cor da pele: branca, não branca (preta, parda/mulata, amarela/oriental);

- idade da mãe: até 19 anos (jovem), de 20 a 34 anos (ideal); acima de 34 anos (madura);

- escolaridade da mãe: universitário, secundário, fundamental;

- condição marital da mãe: casada, não casada;

- hábito de fumar da mãe: sim, não;

- o pai da criança morar com a mãe: sim, não;

- posse de bens: indicador de posse de nenhum (0 itens, categorizado como "não"), um ou mais itens (pelo menos 1 item, categorizado como "sim"): computador, carro, televisão paga e telefone;

- amamentação e tempo de amamentação:

No caderno, exemplificado no Anexo 6, o tempo de amamentação foi obtido por meio da contagem dos alvéolos marcados pela mãe. Admitiu-se que todas as crianças ao nascer iniciaram a amamentação. $O$ final da amamentação corresponde à última marcação após pelo menos três marcações (que podem ou não ter interrupções entre elas) em um período de 60 dias no campo "Leite de peito", independentemente da freqüência anterior observada.

O questionário recordatório de 12 meses está apresentado no Anexo 5. O campo que corresponde à amamentação está representado na questão “Até quando recebeu leite de peito?" que pode ser preenchido com o tempo em meses ou em dias. 


\subsection{Métodos de análise de sobrevida}

A duração da amamentação é a principal variável resposta a ser considerada e gera a variável aleatória $\mathrm{T}>0$, que representa o tempo até a ocorrência do desmame. O tempo observado pode representar: o tempo de ocorrência do evento; o tempo em que o indivíduo esteve em observação sem acontecer o evento; ou o tempo de ocorrência do evento dado na forma de um intervalo.

Os dados provenientes do caderno podem apresentar um tipo de censura denominado censura à direita e indica que a informação sobre o tempo de amamentação só é conhecida até um determinado momento e não se sabe o que acontece com a amamentação além desse tempo.

Os dados do recordatório apresentam um tipo de censura denominado censura por intervalos e está representando o intervalo de tempo no qual o término da amamentação ocorreu. Pode-se, ainda, ter casos de censura à direita no recordatório representados por aqueles questionários que não apresentam resposta porque a amamentação ainda não se encerrou até o momento da pergunta da entrevista. A informação produzida pelo recordatório é chamada intervalar ou agrupada.

\subsubsection{A função de sobrevida e a função de risco}

A função probabilidade de sobrevida acumulada (chamada aqui de função de sobrevida), $\mathrm{S}(\mathrm{t})$, é definida como a probabilidade de o tempo $\mathrm{T}$ ser maior que um dado tempo t, e está representada por

$$
\mathrm{S}(\mathrm{t})=\mathrm{P}(\mathrm{T}>\mathrm{t})
$$

Uma outra função que pode ser utilizada é a função distribuição dos tempos de falha e é dada por

$$
\mathrm{F}(\mathrm{t})=\mathrm{P}(\mathrm{T} \leq \mathrm{t})=1-\mathrm{S}(\mathrm{t}),
$$

que indica a probabilidade de o evento ocorrer até o tempo t.

A função de risco é definida por

$$
\mathrm{h}(\mathrm{t})=\lim _{\Delta \mathrm{t} \rightarrow 0} \frac{\mathrm{P}(\mathrm{t} \leq \mathrm{T}<\mathrm{t}+\Delta \mathrm{t} \mid \mathrm{T} \geq \mathrm{t})}{\Delta \mathrm{t}},
$$

e representa a taxa de falha instantânea no tempo t. 
Essa função é também chamada de hazard function, hazard rate, taxa de falha ou força de mortalidade, para cada tempo t.

A probabilidade de ocorrer a falha no intervalo $[\mathrm{t}, \mathrm{t}+\Delta \mathrm{t})$ pode ser, então, dada por $\mathrm{h}(\mathrm{t}) \Delta(\mathrm{t})($ COLLETT 1994).

\subsubsection{Modelos para dados agrupados}

Muitas vezes, não é possível precisar o tempo em que o evento de falha (fim da amamentação) ou a censura ocorreu, mas se conhece o respectivo intervalo de tempo de sua ocorrência. Esses dados são chamados de agrupados.

\subsubsection{Técnica atuarial ou da tábua de vida}

A técnica atuarial (LEE 1992; LAWLESS 1982) ou da tábua de vida, de certa maneira limitada quanto a testes de hipóteses, estima $\mathrm{S}(\mathrm{t})=\mathrm{P}(\mathrm{T}>\mathrm{t})$, mediante a equação

$$
\hat{\mathrm{S}}\left(\mathrm{t}_{\mathrm{i}}\right)=\prod_{\mathrm{j}=1}^{\mathrm{i}}\left(1-\hat{\theta}_{\mathrm{j}}^{\mathrm{A}}\right) \text {, onde }
$$

i representa o número de intervalos considerados;

$\hat{\theta}_{\mathrm{j}}^{\mathrm{A}}$ é o estimador da probabilidade de ocorrer o evento no intervalo j e pode ser escrito como

$$
\hat{\theta}_{\mathrm{j}}^{\mathrm{A}}=\frac{\mathrm{d}_{\mathrm{j}}}{\mathrm{n}_{\mathrm{j}}-\frac{1}{2} \mathrm{w}_{\mathrm{j}}}, \text { onde }
$$

$\mathrm{d}_{\mathrm{j}}$ representa o número de falhas no intervalo $\mathrm{j}$;

$\mathrm{n}_{\mathrm{j}}$ é o número de indivíduos em risco no início do intervalo $\mathrm{j}$;

$\mathrm{w}_{\mathrm{j}}$ é o número de indivíduos censurados no intervalo $\mathrm{j}$.

Nessa representação, supõe-se que as censuras ocorrem uniformemente no intervalo. O denominador $\mathrm{n}_{\mathrm{j}}-\frac{1}{2} \mathrm{w}_{\mathrm{j}}$ é chamado número efetivo de indivíduos expostos a sofrer falha.

\subsubsection{Modelo complemento log-log}

O modelo complemento log-log é um modelo de regressão que trabalha com resposta binária. Utilizar este modelo viabiliza considerar dados de censura intervalar 
em modelo de riscos proporcionais (PRENTICE e GLOECKER 1978). Esse modelo é também denominado modelo de riscos proporcionais com dados agrupados (HOSMER e LEMESHOW 1999; LAWLESS 1982).

Consideramos $\mathrm{n}$ indivíduos com os tempos $\mathrm{T}_{\mathrm{i}}, \mathrm{i}=1, \ldots, \mathrm{n}$, agrupados em $\mathrm{k}$ intervalos $I_{j}=\left[a_{j-1}, a_{j}\right), j=1, \ldots, k$ e seja $\mathbf{x}_{i}$ o vetor de covariáveis do indivíduo i. Seja $D_{j}$ o conjunto de indivíduos que falharam no intervalo $I_{j}$; e $R_{j}$, o conjunto de indivíduos que estavam em risco no intervalo $\mathrm{I}_{\mathrm{j}}$.

A probabilidade do i-ésimo indivíduo falhar até $a_{j}$ dado que não falhou até $a_{j-1}$ é

$$
\theta_{\mathrm{ij}}=\theta_{\mathrm{j}}\left(\mathbf{x}_{\mathrm{i}}\right)=\mathrm{P}\left(\mathrm{T}_{\mathrm{i}} \leq \mathrm{a}_{\mathrm{i}} \mid \mathrm{T}_{\mathrm{i}} \geq \mathrm{a}_{\mathrm{j}-1}, \mathbf{x}_{\mathrm{i}}\right) .
$$

Reescrevendo-se em termos da função de sobrevida, temos

$$
\theta_{j}\left(\mathbf{x}_{\mathrm{i}}\right)=1-\mathrm{P}\left(\mathrm{T}_{\mathrm{i}} \geq \mathrm{a}_{\mathrm{j}} \mid \mathrm{T}_{\mathrm{i}} \geq \mathrm{a}_{\mathrm{j}-1}, \mathbf{x}_{\mathrm{i}}\right)=1-\frac{\mathrm{S}\left(\mathrm{a}_{\mathrm{j}} \mid \mathbf{x}_{\mathrm{i}}\right)}{\mathrm{S}\left(\mathrm{a}_{\mathrm{j}-1} \mid \mathbf{x}_{\mathrm{i}}\right)},
$$

onde $\frac{\mathrm{S}\left(\mathrm{a}_{\mathrm{j}} \mid \mathbf{x}_{\mathrm{i}}\right)}{\mathrm{S}\left(\mathrm{a}_{\mathrm{j}-1} \mid \mathbf{x}_{\mathrm{i}}\right)}$ representa a probabilidade do i-ésimo indivíduo não falhar até $a_{j}$, dado que não falhou até $a_{j-1}$.

A função de verossimilhança é dada por:

$$
\ell(\beta)=\prod_{j=1}^{k} \prod_{i \in R_{i}}\left[\left(\theta_{j}\left(\mathbf{x}_{\mathrm{i}}\right)\right)^{c_{\mathrm{ij}}}\left(1-\theta_{\mathrm{j}}\left(\mathbf{x}_{\mathrm{i}}\right)\right)^{\left(1-c_{\mathrm{ij}}\right)}\right],
$$

onde $c_{i j}$ é variável indicadora da ocorrência de falha para o indivíduo i no intervalo $\mathrm{j}$.

Essa é a verossimilhança para variáveis com distribuição Bernoulli com probabilidade de sucesso (no caso, de ocorrência do evento) $\theta_{\mathrm{j}}\left(\mathbf{x}_{\mathbf{i}}\right)$ e variável resposta $\mathrm{c}_{\mathrm{ij}}$.

A idéia é permitir usar modelos de regressão binária para modelar uma regressão com riscos proporcionais para dados com censura por intervalo.

Mostra-se algebricamente que $\theta_{\mathrm{j}}\left(\mathbf{x}_{\mathrm{i}}\right)=1-\exp \left\{-\exp \left(\mathbf{x}_{\mathrm{i}} \beta+\tau_{\mathrm{j}}\right)\right\}$, onde $\tau_{j}=\ln \left[-\ln \left(\frac{S_{0}\left(a_{j}\right)}{S_{0}\left(a_{j-1}\right)}\right)\right]$ representa a razão entre $S_{0}$ do início e $S_{0}$ do fim do intervalo i e representa o efeito de intervalo de tempo.

Assim, o modelo de regressão é dado por: 


$$
\ln \left[-\ln \left(1-\theta_{\mathrm{j}}\left(\mathbf{x}_{\mathrm{i}}\right)\right)\right]=\mathbf{x}_{\mathrm{i}}^{\prime} \beta+\tau_{\mathrm{j}}
$$

Esse modelo é denominado complemento log-log (CARSTENSEN 1996; FARRINGTON 1996). Neste modelo, dados com censura intervalar podem ser modelados considerando o problema como se fosse um problema de regressão com resposta binária. No contexto de modelos lineares generalizados (McCULLAGH e NELDER 1989), esse modelo corresponde a um modelo de regressão da família binomial com função de ligação complemento log-log.

Deve-se notar que na construção do banco de dados é necessário que, para cada indivíduo em cada intervalo, exista uma linha que indique o resultado para a resposta $\mathrm{c}_{\mathrm{ij}}$, definida anteriormente. Ela indica se o evento ocorreu ou não no intervalo j. Por exemplo, o indivíduo que tem falha no terceiro intervalo terá três linhas no banco de dados: as duas primeiras onde constam a resposta $\mathrm{c}_{\mathrm{ij}}=0$ e a terceira, a resposta $\mathrm{c}_{\mathrm{ij}}=$ 1. O indivíduo que é censurado no intervalo 2 tem duas linhas no banco de dados, ambos com $c_{i j}=0$. O programa no STATA que promove a construção do banco da forma descrita e um exemplo do resultado desse programa estão no Anexo 8.

Para cada intervalo j, o estimador de $S_{0}$ em $t_{j}$, é

$$
\hat{\mathrm{S}}_{0}\left(\mathrm{t}_{\mathrm{j}}\right)=\hat{\mathrm{S}}_{0}\left(\mathrm{t}_{\mathrm{j}-1}\right) \exp \left(-\exp \left(\hat{\tau}_{\mathrm{j}}\right)\right) \text {. }
$$

Para o primeiro intervalo, $\mathrm{I}_{1}, \hat{\mathrm{S}}_{0}\left(\mathrm{t}_{1}\right)=\exp \left(-\exp \left(\hat{\tau}_{1}\right)\right)$ e para o último intervalo $\mathrm{I}_{7}, \hat{\mathrm{S}}_{0}\left(\mathrm{t}_{7}\right)=\hat{\mathrm{S}}_{0}\left(\mathrm{t}_{6}\right) \exp \left(-\exp \left(\hat{\tau}_{7}\right)\right)$.

Para obter estimadores considerando as covariáveis, o estimador fica como no modelo de riscos proporcionais

$$
\hat{\mathrm{S}}\left(\mathrm{t}_{\mathrm{j}}, \mathbf{x}_{\mathrm{i}}, \hat{\beta}\right)=\left[\hat{\mathrm{S}}_{0}\left(\mathrm{t}_{\mathrm{ji}-1}\right)\right]^{\exp \left(\mathbf{x}_{\mathrm{i}}^{\prime} \hat{\beta}\right)} .
$$

\subsubsection{Modelos para dados contínuos}

O tempo pode ser tratado como variável contínua dependendo da freqüência de sua observação como, por exemplo, quando se observa dia a dia.

Será utilizado um índice que representa a ordenação dos tempos de falha. Primeiramente, os tempos de falha de cada um dos $\mathrm{n}$ indivíduos são ordenados e temse o primeiro tempo de falha, o segundo tempo de falha, e assim por diante:

$$
\mathrm{T}_{(1)}<\mathrm{T}_{(2)}<\mathrm{T}_{(3)}<\ldots<\mathrm{T}_{(\mathrm{j}-1)}<\mathrm{T}_{(\mathrm{j})}<\ldots<\mathrm{T}_{(\mathrm{n})}, \text { onde }
$$


$\mathrm{T}_{(\mathrm{j})}$ identifica o j-ésimo tempo de falha que ocorre no decorrer do período.

\subsubsection{Modelo de Kaplan-Meier}

Kaplan e Meier (KLEIN e MOESCHBERGER 1997; KAPLAN e MEIER 1958) estimam a função de sobrevida $S\left(t_{(j)}\right)$ por meio da equação

$$
\hat{S}\left(t_{(j)}\right)=\hat{S}\left(t_{(j-1)}\right) \hat{P}\left[T>t_{(j)} I T \geq t_{(j)}\right],
$$

onde a segunda parte da expressão representa uma estimativa da probabilidade de sobrevida até o tempo ordenado de falha anterior $\left(\mathrm{t}_{(\mathrm{j}-1)}\right)$ multiplicado pela probabilidade condicional de sobrevida até o tempo de falha ordenado $t_{(j)}$, dada a sobrevida até pelo menos o tempo $\mathrm{t}_{(\mathrm{j})}$.

A função de sobrevida estimada para $S(t)$, que indica a probabilidade de $o$ tempo de sobrevida ser superior a um determinado tempo t, pode ser escrita como

$$
\hat{S}(t)=\prod_{t(j) \leq t}\left(1-\frac{d_{j}}{n_{j}}\right)=\prod_{t(j) \leq t} \frac{n_{j}-d_{j}}{n_{j}}=\prod_{t(j) \leq t}\left(1-\hat{\theta}_{j}\right),
$$

em que $\mathrm{n}_{\mathrm{j}}$ é o número de indivíduos em risco de falha no tempo $\mathrm{t}_{(\mathrm{j})} ; \mathrm{d}_{\mathrm{j}}$ é o número de falhas e $\hat{\theta}_{\mathrm{j}}$ é uma estimativa da probabilidade de ocorrer o evento no tempo $\mathrm{j}$, dado que não ocorreu o evento até o tempo j-1. No índice do somatório, utilizam-se os tempos ordenados que são menores do que $\mathrm{t}$.

Deve-se notar que esse estimador considera os indivíduos com censura para o cálculo do número de indivíduos até o tempo $\mathrm{j}, \mathrm{n}_{\mathrm{j}}$.

Teste de hipóteses no qual se consideram as hipóteses de igualdade de duas curvas de sobrevida $\mathrm{S}_{0}$ e $\mathrm{S}_{1}\left(\mathrm{H}_{0}: \mathrm{S}_{0}(\mathrm{t})=\mathrm{S}_{1}(\mathrm{t}) \times \mathrm{H}_{1}: \mathrm{S}_{0}(\mathrm{t}) \neq \mathrm{S}_{1}(\mathrm{t})\right.$, para todo o período) é feito mediante o teste log-rank (PETO e PETO 1972) ou, de forma mais geral, o teste de Wilcoxon generalizado (BRESLOW 1970; GEHAN 1965), que propõe pesos diferentes para diferentes instantes de falha e engloba o teste log-rank.

\subsubsection{Modelo de riscos proporcionais de Cox}

O modelo de riscos proporcionais de Cox (COX 1972), tem a forma

$$
\mathrm{h}(\mathrm{t}, \mathbf{x}, \beta)=\mathrm{h}_{0}(\mathrm{t}) \cdot \mathrm{HR},
$$


em que $\mathrm{h}(\mathrm{t}, \mathbf{x}, \boldsymbol{\beta})$ : função de risco (hazard function) dependente das covariáveis; $\mathrm{h}_{0}(\mathrm{t})$ : função de risco dependente somente do tempo;

$\mathrm{HR}=\exp \left(\sum_{\mathrm{i}=1}^{\mathrm{p}} \beta_{\mathrm{i}} \mathbf{X}\right)$ : relação entre as funções de risco e que é depende das covariáveis, representadas por $\mathbf{x}$, constante no tempo. Pode ser chamada de razão de risco de falhas (hazard ratio).

O modelo gera uma expressão para a relação de funções de riscos, em qualquer tempo $\mathrm{t}$, entre indivíduos com as suas covariáveis $\left(\mathrm{x}_{1}, \mathrm{x}_{2}, \ldots, \mathrm{x}_{\mathrm{p}}\right)$ representadas por um vetor $\mathbf{x}$.

A verossimilhança desse modelo não é construída de forma usual. Foi proposta por Cox (1972) e é baseada na probabilidade de um indivíduo, com covariáveis $\mathbf{x}$, falhar em um determinado tempo $t_{j}$ dada a ocorrência de falha em $t_{j}$. Considerando-se os tempos ordenados de falha $\mathrm{t}_{(1)}<\mathrm{t}_{(2)}<\ldots<\mathrm{t}_{(\mathrm{j})}<\ldots<\mathrm{t}_{(\mathrm{n})}$ e $\mathrm{R}\left(\mathrm{t}_{(\mathrm{j})}\right)$ o conjunto de indivíduos em risco de falha ou censura até o momento imediatamente anterior a $\mathrm{t}_{(\mathrm{j})}$, tem-se

$P\left[\right.$ indivíduo com covariáveis $x_{(j)}$ falhar em $t_{(j)}$ l houve falha em $\left.t_{(j)}\right]=$

$$
=\frac{\exp \left(\mathrm{x}_{(\mathrm{j})}^{\prime} \beta\right)}{\sum_{l \in \mathrm{R}(\mathrm{t}(\mathrm{j}))} \exp \left(\mathrm{x}_{(\mathrm{j})}^{\prime} \beta\right)} .
$$

Tomando-se o produto das probabilidades para o total de $\mathrm{d}$ falhas, tem-se

$$
\mathrm{L}(\boldsymbol{\beta})=\prod_{\mathrm{j}=1}^{\mathrm{d}} \frac{\exp \left(\mathbf{x}_{(\mathrm{j})}^{\prime} \boldsymbol{\beta}\right)}{\sum_{\mathrm{l} \in \mathrm{R}(\mathrm{t}(\mathrm{j}))} \exp \left(\mathbf{x}_{(\mathrm{j})}^{\prime} \boldsymbol{\beta}\right)} .
$$

Quando ocorrem empates nos tempos de falha, algumas aproximações para a verossimilhança podem ser feitas.

A mais simples de ser programada é a aproximação proposta por Breslow (1974) e é dada por

$$
\mathrm{L}(\boldsymbol{\beta})=\prod_{\mathrm{j}=1}^{\mathrm{d}} \frac{\exp \left(\mathbf{s}_{(\mathrm{j})} \boldsymbol{\beta}\right)}{\left(\sum_{\mathrm{l} \in \mathrm{R}(\mathrm{t}(\mathrm{j}))} \exp \left(\mathbf{x}_{(\mathrm{j})}^{\prime} \boldsymbol{\beta}\right)\right)^{\delta_{\mathrm{i}}}} \text {, onde }
$$

$\mathbf{s}_{(\mathrm{j})}$ é o vetor das somas de cada uma das covariáveis daqueles indivíduos que falharam no tempo $\mathrm{j}$. 
Efron propõe uma aproximação que é razoavelmente fácil de se programar, mas que apresenta problemas quando a proporção de censuras com relação ao número de falhas é muito grande (THERNEAU 2000).

Um método exato foi proposto por Kalbfleisch e Prentice (1980), mas necessita de grande quantidade de cálculos. Uma outra forma de calcular é por meio da verossimilhança média que é semelhante à aproximação proposta por Efron (THERNEAU 2000).

\subsection{Procedimento de obtenção e verificação dos modelos}

As covariáveis utilizadas nos modelos, todas categóricas por natureza ou categorizadas, foram definidas de forma que a razão das funções de riscos (HR) aparecesse com valor maior que 1 para facilitar a interpretação. Foi levado em consideração, para algumas variáveis, o que diz a literatura a respeito de qual a categoria de referência a ser utilizada.

Para obtenção dos modelos, os procedimentos utilizados foram os seguintes:

1. Foram feitas as curvas de Kaplan-Meier para cada variável e aplicado o teste de log-rank;

2. Foram aplicados os modelos univariados;

3. Para selecionar quais variáveis seriam incluídas em um único modelo, foram selecionadas aquelas que possuíssem um nível descritivo de até $15 \%$ para o teste de Wald dos modelos do passo anterior. Após ter definido o modelo, pode-se avaliar a permanência de cada uma das variáveis do modelo por meio do teste de razão de verossimilhanças. O nível de significância utilizado para a permanência das variáveis foi de $5 \%$.

4. O modelo com todas as variáveis também foi feito para se observar as estimativas segundo as técnicas e fontes de informação.

No modelo de Cox, foi sempre utilizada a aproximação pelo método de Breslow para a estimação do modelo na ocorrência de empates entre os tempos de falha por ser disponível em muitos softwares.

Para se verificar a proporcionalidade dos riscos, foi utilizado um gráfico no qual se colocam os valores da função de sobrevida obtidos pelo modelo e por um modelo 
empírico. Para as estimativas do modelo de Cox foi utilizado como modelo de comparação o de Kaplan-Meier. Para as estimativas do modelo complemento log-log foi utilizado o modelo atuarial. Quanto mais próximos os valores da medida de Kaplan-Meier daqueles obtidos pelo modelo de Cox, mais se satisfaz a suposição de proporcionalidade dos riscos. Da mesma forma, isso pode ser visualizado para os valores do modelo complemento log-log e da técnica atuarial (HESS 1995).

\subsection{Questões éticas}

O desenvolvimento do estudo está seguindo os requisitos da Resolução 196/96 do Conselho Nacional de Saúde/Ministério da Saúde do Brasil (COMISSÃO NACIONAL DE ÉTICA EM PESQUISA 2000) e as normas do Comitê de Ética da Faculdade de Saúde Pública da Universidade de São Paulo, que regulamentam pesquisas envolvendo seres humanos. O projeto foi avaliado e aprovado em 4 de junho de 2001 (Anexo 9).

\section{Resultados}

\subsection{Sem usar as covariáveis}

A comparação é feita por meio da observação das estimativas, $\hat{\mathrm{S}}(\mathrm{t})$, segundo as diversas técnicas e fontes de informação. As tabelas dessa seção apresentam as estimativas $\hat{\mathrm{S}}(\mathrm{t})$ e respectivos intervalos de confiança de $95 \%$.

Os resultados da técnica atuarial para os dados do recordatório de 12 meses estão apresentados na Tabela 1 que contém: os intervalos de tempo considerados; o número de crianças em amamentação no início de cada intervalo, o número de crianças que deixaram o leite de peito (falha), o número de observações perdidas de observação (censura), a função de sobrevida estimada $(\hat{S}(t))$, para o instante final do intervalo, o erro padrão de $\hat{S}(t)$, e o intervalo de $95 \%$ de confiança para $\hat{S}(t)$. 
Tabela 1 - Estimativas de $\mathrm{S}(\mathrm{t})$ pela técnica atuarial - recordatório

\begin{tabular}{cccccccc}
\hline $\begin{array}{c}\text { Intervalo } \\
\text { de tempo }\end{array}$ & $\begin{array}{c}\text { Crianças em } \\
\text { amamentação } \\
\text { no início do } \\
\text { intervalo }\end{array}$ & Falhas Censuras & $\hat{\mathrm{S}}(\mathrm{t})$ & $\begin{array}{c}\text { Erro } \\
\text { padrão de } \\
\hat{\mathrm{S}}(\mathrm{t})\end{array}$ & IC 95\% \\
\hline $0-15$ & 360 & 20 & 0 & 0,9444 & 0,0121 & 0,9152 & 0,9638 \\
$16-30$ & 340 & 15 & 0 & 0,9028 & 0,0162 & 0,8633 & 0,9277 \\
$31-60$ & 325 & 36 & 0 & 0,8028 & 0,0218 & 0,7510 & 0,8365 \\
$61-90$ & 289 & 41 & 0 & 0,6889 & 0,0253 & 0,6250 & 0,7242 \\
$91-180$ & 248 & 67 & 0 & 0,5028 & 0,0271 & 0,4473 & 0,5532 \\
$181-270$ & 181 & 45 & 0 & 0,3778 & 0,0263 & 0,3297 & 0,4325 \\
$271-360$ & 136 & 9 & 127 & 0,3309 & 0,0274 & 0,2890 & 0,3961 \\
\hline
\end{tabular}

Note-se que o número de censuras no último intervalo não se refere a observações incompletas, mas a observações de crianças com 360 dias que ainda não deixaram o leite de peito. Refere-se ao tipo de censura tipo I.

Pelo recordatório de 12 meses, a sobrevida no intervalo terminado em 360 dias é $34,23 \%$ e a duração mediana da amamentação é de 90 dias.

O modelo que pode ser utilizado para a modelagem dos dados agrupados, como o produzido pelo recordatório, é o modelo complemento log-log, apresentado na Tabela 2.

Tabela 2 - Resultado da regressão complemento log-log - recordatório

\begin{tabular}{crrrrrr}
\hline intervalos & coeficiente & erro padrão & \multicolumn{1}{c}{ Z } & P $>|\mathrm{z}|$ & \multicolumn{2}{c}{ IC 95\% } \\
\hline $0-15$ & $-2,861929$ & 0,223637 & $-12,80$ & 0 & $-3,300250$ & $-2,423608$ \\
$16-30$ & $-3,098420$ & 0,258221 & $-12,00$ & 0 & $-3,604523$ & $-2,592317$ \\
$31-60$ & $-2,142181$ & 0,166762 & $-12,85$ & 0 & $-2,469029$ & $-1,815333$ \\
$61-90$ & $-1,877331$ & 0,156326 & $-12,01$ & 0 & $-2,183724$ & $-1,570937$ \\
$91-180$ & $-1,155399$ & 0,122675 & $-9,42$ & 0 & $-1,395838$ & $-0,914961$ \\
$181-270$ & $-1,252316$ & 0,149579 & $-8,37$ & 0 & $-1,545485$ & $-0,959146$ \\
$271-360$ & $-2,681392$ & 0,333398 & $-8,04$ & 0 & $-3,334841$ & $-2,027943$ \\
\hline
\end{tabular}

As estimativas de cada intervalo e as correspondentes funções de sobrevida estimadas $\hat{\mathrm{S}}(\mathrm{t})$ são apresentadas na Tabela 3. 
Tabela 3 - Estimativas de S(t) pelo modelo complemento log-log - recordatório

\begin{tabular}{ccccc}
\hline $\begin{array}{c}\text { Intervalo de } \\
\text { tempo }\end{array}$ & $\begin{array}{c}\text { Coeficiente } \\
\text { de cada } \\
\text { intervalo }\end{array}$ & $\hat{\mathrm{S}}(\mathrm{t})$ & \multicolumn{2}{c}{ IC 95\% } \\
\hline $0-15$ & $-2,861929$ & 0,9444 & 0,9152 & 0,9638 \\
$16-30$ & $-3,098420$ & 0,9028 & 0,8492 & 0,9379 \\
$31-60$ & $-2,142181$ & 0,8028 & 0,7216 & 0,8618 \\
$61-90$ & $-1,877331$ & 0,6889 & 0,5862 & 0,7700 \\
$91-180$ & $-1,155399$ & 0,5028 & 0,3927 & 0,6011 \\
$181-270$ & $-1,252316$ & 0,3778 & 0,2677 & 0,4857 \\
$271-360$ & $-2,681392$ & 0,3528 & 0,2347 & 0,4687 \\
\hline
\end{tabular}

Como já era esperado, o modelo complemento log-log apresentou estimativas de $\mathrm{S}(\mathrm{t})$ idênticas à da técnica atuarial quando não existe censuras.

A técnica de Kaplan-Meier produz estimativas de $\mathrm{S}(\mathrm{t})$ em todo o momento que ocorre um evento de falha, o que é especialmente interessante no caso dos dados diários. Na Tabela 4, têm-se as estimativas somente para alguns tempos que são os pontos de corte dos dados recordatórios.

Tabela 4 - Estimativas de Kaplan-Meier - caderno diário

\begin{tabular}{cccccccc}
\hline Tempo & $\begin{array}{c}\text { Crianças em } \\
\text { amamentação }\end{array}$ & $\begin{array}{c}\text { Falhas } \\
\text { acumuladas }\end{array}$ & $\begin{array}{c}\text { Censuras } \\
\text { acumuladas }\end{array}$ & $\hat{\mathrm{S}}(\mathrm{t})$ & $\begin{array}{c}\text { Erro } \\
\text { padrão } \\
\text { de S(t) }\end{array}$ & IC 95\% \\
\hline 0 & 360 & - & - & - & - & - & - \\
15 & 360 & 20 & 0 & 0,9722 & 0,0087 & 0,9490 & 0,9850 \\
30 & 340 & 15 & 0 & 0,9306 & 0,0134 & 0,8990 & 0,9525 \\
60 & 325 & 36 & 0 & 0,8389 & 0,0194 & 0,7967 & 0,8730 \\
90 & 289 & 41 & 0 & 0,7772 & 0,0220 & 0,7305 & 0,8168 \\
180 & 248 & 67 & 0 & 0,5468 & 0,0265 & 0,4934 & 0,5970 \\
270 & 181 & 45 & 0 & 0,4246 & 0,0264 & 0,3724 & 0,4758 \\
360 & 136 & 9 & 127 & 0,3558 & 0,0258 & 0,3056 & 0,4063 \\
\hline
\end{tabular}


Gráfico 1 - Gráfico de Kaplan-Meier - caderno diário

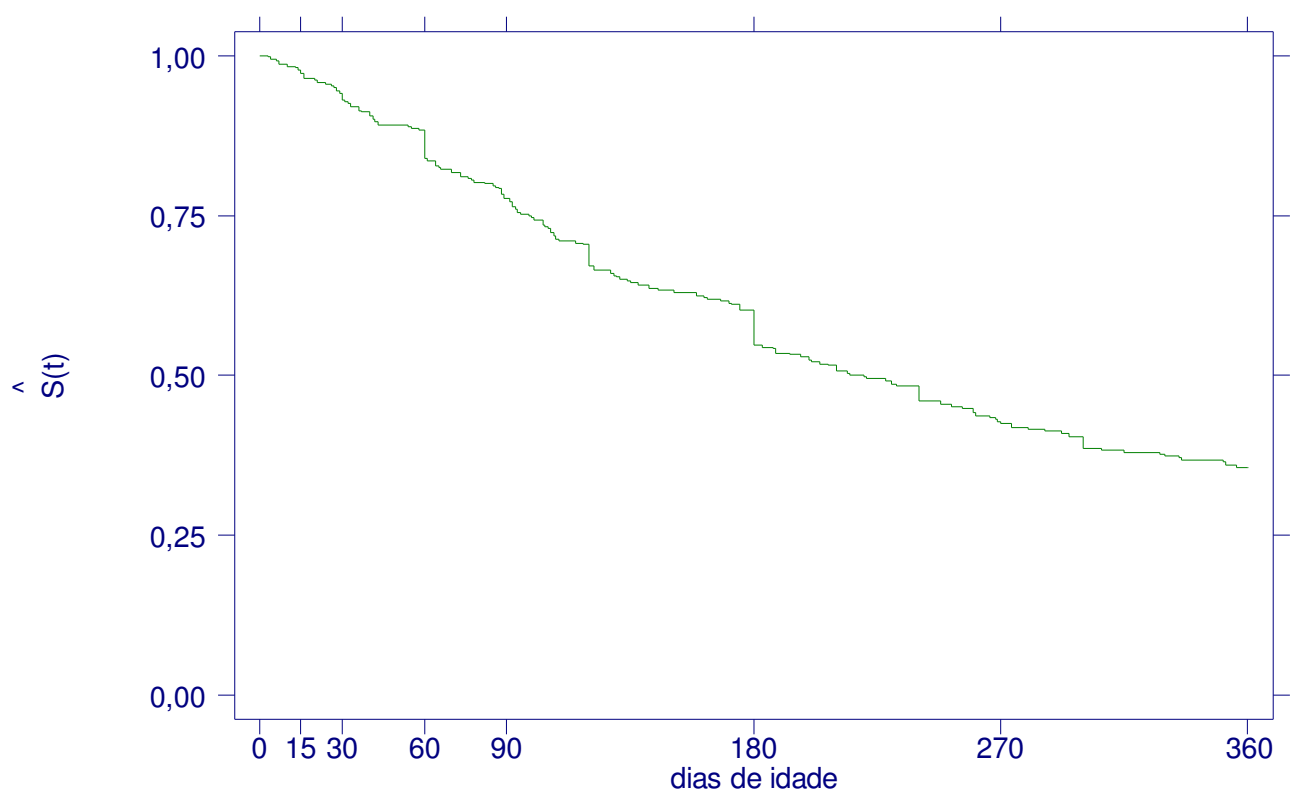

O Gráfico 1 apresenta a curva da proporção de crianças ainda em amamentação no decorrer do tempo, segundo a estimativa de Kaplan-Meier. Pode-se observar que existem algumas quedas mais pronunciadas nos tempos 60, 120, 180 e 240 dias. Note-se que o número de falhas corresponde ao ocorrido no tempo exato que está indicado em cada linha da Tabela 4.

A Tabela 5 e o Gráfico 2 apresentam o conjunto das estimativas de $\mathrm{S}(\mathrm{t})$, segundo as três técnicas.

Tabela 5 - Estimativas de S(t), segundo as técnicas e fontes de informação

\begin{tabular}{cccc}
\hline Intervalo de & \multicolumn{2}{c}{ recordatório } & diário \\
\cline { 2 - 4 } tempo & Técnica atuarial & Complemento log-log & Kaplan-Meier \\
\hline $0-15$ & 0,9444 & 0,9444 & 0,9722 \\
$16-30$ & 0,9028 & 0,9028 & 0,9306 \\
$31-60$ & 0,8028 & 0,8028 & 0,8389 \\
$61-90$ & 0,6889 & 0,6889 & 0,7772 \\
$91-180$ & 0,5028 & 0,5028 & 0,5468 \\
$181-270$ & 0,3778 & 0,3778 & 0,4246 \\
$271-360$ & 0,3309 & 0,3528 & 0,3558 \\
\hline
\end{tabular}

O Gráfico 2 mostra as estimativas para $\mathrm{S}(\mathrm{t})$ segundo as técnicas atuarial para o recordatório e técnica de Kaplan-Meier para o caderno diário. 
Gráfico 2 - Estimativas de $S(t)$, segundo as técnicas e fontes de informação

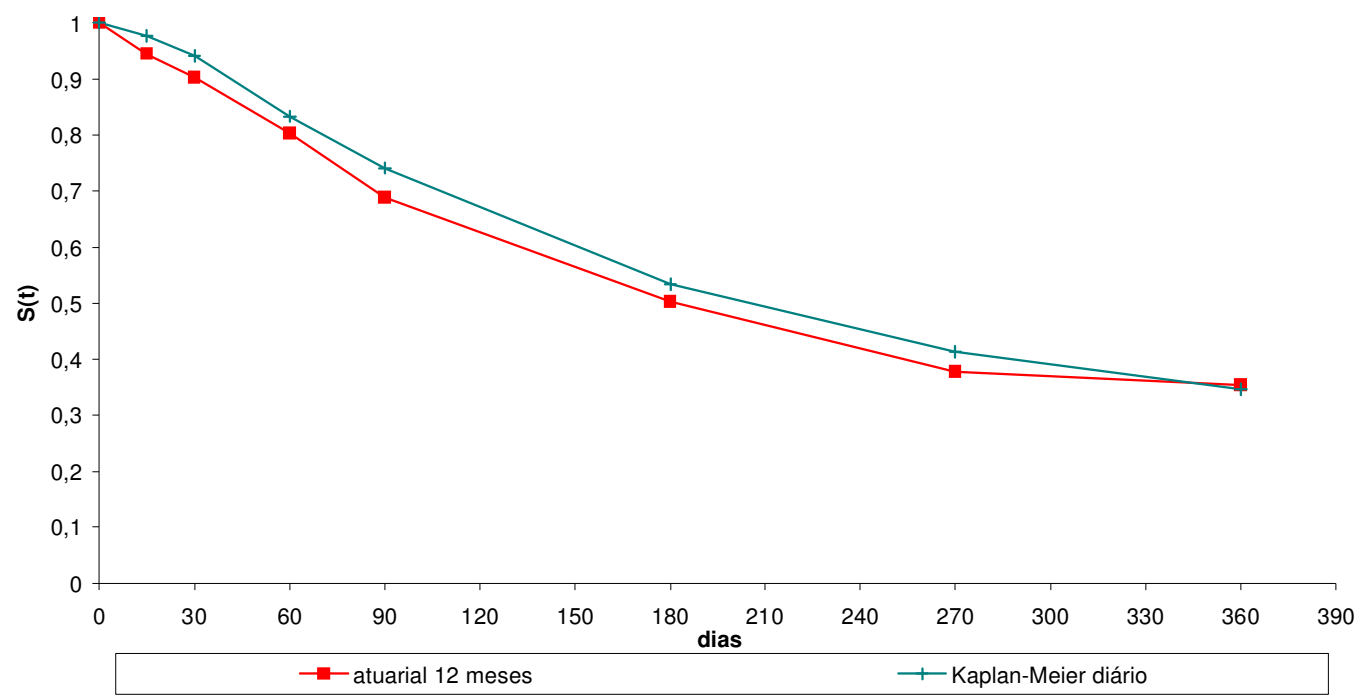

Do início do período de observação até 270 dias, a função de sobrevida estimada apresentada pelo recordatório é menor do que a calculada pelos dados do diário. Aos 360 dias, a estimativa para 12 meses, pela técnica atuarial também está bem próxima da estimativa obtida pelo diário.

\subsubsection{Comentários}

O modelo de regressão com função de ligação complemento log-log é escrito na forma $\ln \left[-\ln \left(1-\theta_{\mathrm{ij}}\right)\right]=\mathbf{x}_{\mathrm{i}}^{\prime} \boldsymbol{\beta}+\tau_{\mathrm{j}}$ e a probabilidade condicional de falha é dada $\operatorname{por} \theta_{\mathrm{ij}}=1-\exp \left\{-\exp \left(\mathbf{x}_{\mathrm{i}} \boldsymbol{\beta}+\tau_{\mathrm{j}}\right)\right\}$.

Quando não são consideradas as covariáveis, ou seja, o vetor $\mathbf{x}_{\mathbf{i}}=\mathbf{0}$, o modelo toma a forma simplificada $\ln \left[-\ln \left(1-\theta_{\mathrm{ij}}\right)\right]=\tau_{\mathrm{j}}$ e $\theta_{\mathrm{ij}}=1-\exp \left\{-\exp \left(\tau_{\mathrm{j}}\right)\right\}$.

Se $\tau_{\mathrm{j}}=\ln \left[-\ln \left(\frac{\mathrm{S}_{0}\left(\mathrm{t}_{\mathrm{j}}\right)}{\mathrm{S}_{0}\left(\mathrm{t}_{\mathrm{j}-1}\right)}\right)\right], \theta_{\mathrm{ij}}=1-\exp \left\{-\exp \left(\tau_{\mathrm{j}}\right)\right\}=1-\frac{\mathrm{S}_{0}\left(\mathrm{t}_{\mathrm{j}}\right)}{\mathrm{S}_{0}\left(\mathrm{t}_{\mathrm{j}-1}\right)}$.

$\theta_{\mathrm{ij}}$ representa a probabilidade do indivíduo i falhar no intervalo j. Note-se que qualquer indivíduo, neste intervalo, tem a mesma probabilidade de falhar no intervalo j. Tem-se, então, a probabilidade com o índice referente ao intervalo j, independente de i para aquele intervalo, $\theta_{\mathrm{j}}$, que pode ser interpretado como a proporção de falhas no intervalo $\mathrm{j}$. 
O estimador de $\theta_{\mathrm{j}}$ é semelhante ao da probabilidade de falhar no intervalo $\mathrm{j}$ na técnica atuarial baseada na proporção de falhas, representada por $\hat{\theta}_{j}^{\mathrm{A}}$, e dada por $\hat{\theta}_{\mathrm{j}}^{\mathrm{A}}=\frac{\mathrm{d}_{\mathrm{j}}}{\mathrm{n}_{\mathrm{j}}-\frac{1}{2} \mathrm{w}_{\mathrm{j}}}$.

Quando se estima $\theta_{\mathrm{j}}^{\mathrm{A}}$, o número de indivíduos que está em risco, no denominador, tem uma parte dos indivíduos censurados retirados, o que não ocorre no modelo complemento log-log que considera a censura no fim do intervalo. Assim, o estimador de $\theta_{\mathrm{j}}^{\mathrm{A}}$ deve ser maior que o estimador de $\theta_{\mathrm{j}}$. Portanto, as estimativas de $\mathrm{S}(\mathrm{t})$ serão menores pela técnica atuarial do que pelo modelo complemento log-log, na presença de censuras e, da mesma forma, serão iguais quando não houver censuras, que é o que ocorreu com os dados apresentados.

Quanto às respostas obtidas pelas fontes de informação, a comparação do tempo de sobrevida entre os recordatórios e o caderno diário permite avaliar diferenças que poderiam expressar possível vício de memória. As estimativas de Kaplan-Meier para o caderno diário são, até 270 dias, sempre maiores do que as outras estimativas produzidas para os recordatórios.

Retornando ao Gráfico 1, a curva de Kaplan-Meier apresenta algumas quedas mais pronunciadas nos tempos 60, 120, 180 e 240 dias, que são múltiplos de 60. Isso é devido, possivelmente, ao fato de algumas mães não terem marcado corretamente o término da amamentação deixando para fazê-lo somente no começo da outra folha, pois cada uma das 6 folhas conta com 60 dias. Isso sugere que a curva, próximo aos dias mencionados, deveria ter um maior número de mães deixando de dar o leite de peito o que significa dizer que a curva mais próxima da realidade deve estar um pouco mais para baixo.

\subsection{Usando cada covariável}

A análise univariada pode ser utilizada para auxiliar na escolha de variáveis para inclusão em um modelo estatístico. Foram escolhidas algumas variáveis para apresentar os gráficos: idade da mãe, condição marital e hábito de fumar da mãe. 


\subsubsection{Caderno diário}

Os Gráficos 3 a 5 apresentam as curvas de Kaplan-Meier para as informações do caderno diário das variáveis escolhidas.

Gráfico 3 - Estimativas de Kaplan-Meier para a escolaridade materna - caderno diário

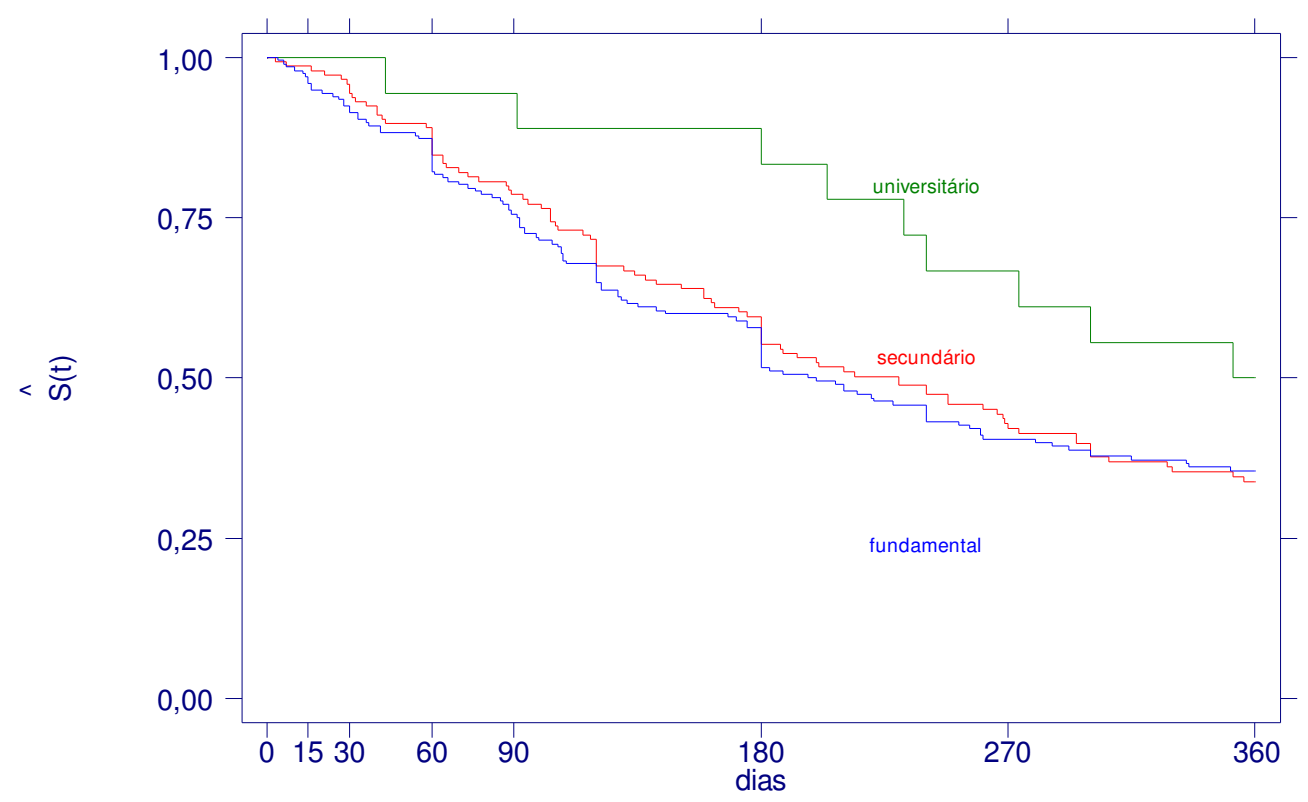

Para as curvas do Gráfico 3, o teste de log-rank indica não haver diferença entre as curvas de escolaridade materna $(\mathrm{p}=0,2218)$. O número de universitários (18) é relativamente pequeno $(5 \%)$. 
Gráfico 4 - Estimativas de Kaplan-Meier para a idade materna - caderno diário

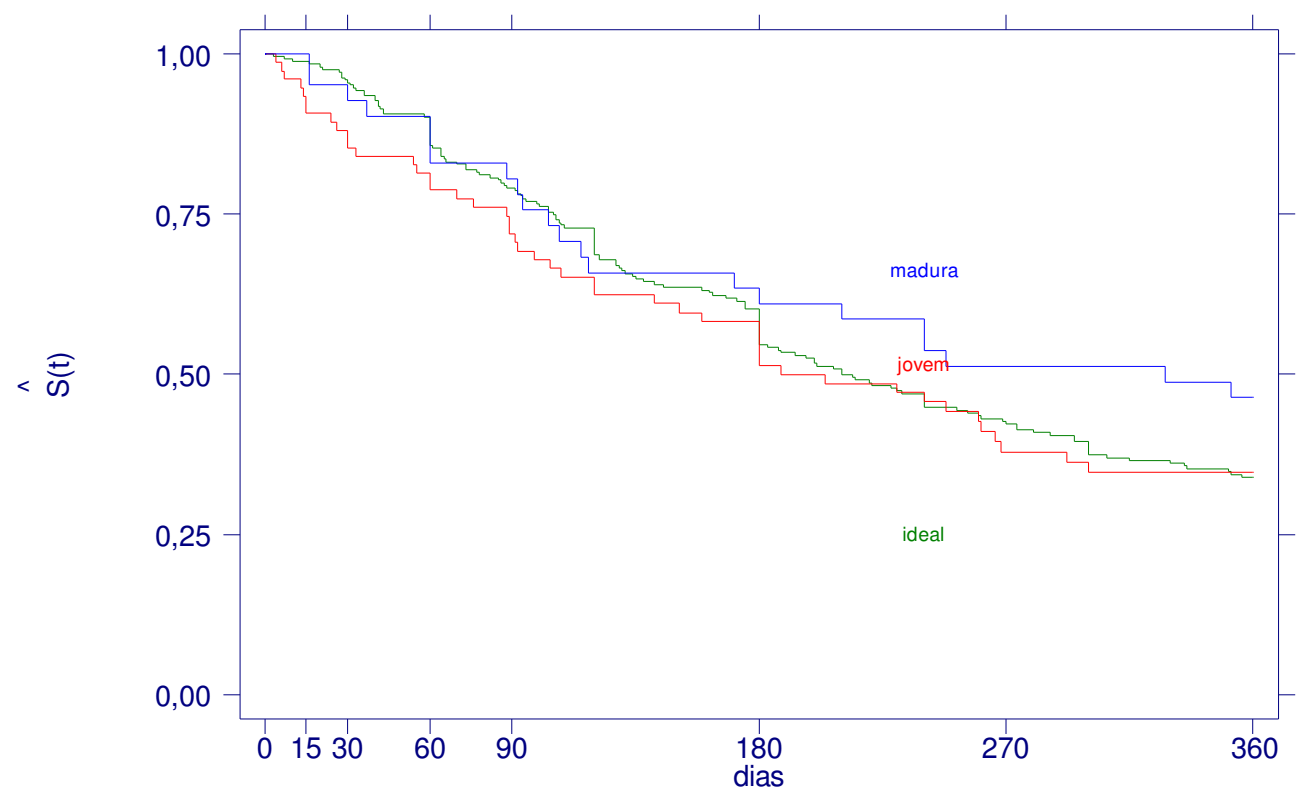

Para as curvas do Gráfico 4, o teste de log-rank indica não haver diferença entre as curvas de idade materna $(\mathrm{p}=0,3515)$.

Gráfico 5 - Estimativas de Kaplan-Meier para hábito de fumar da mãe - caderno diário

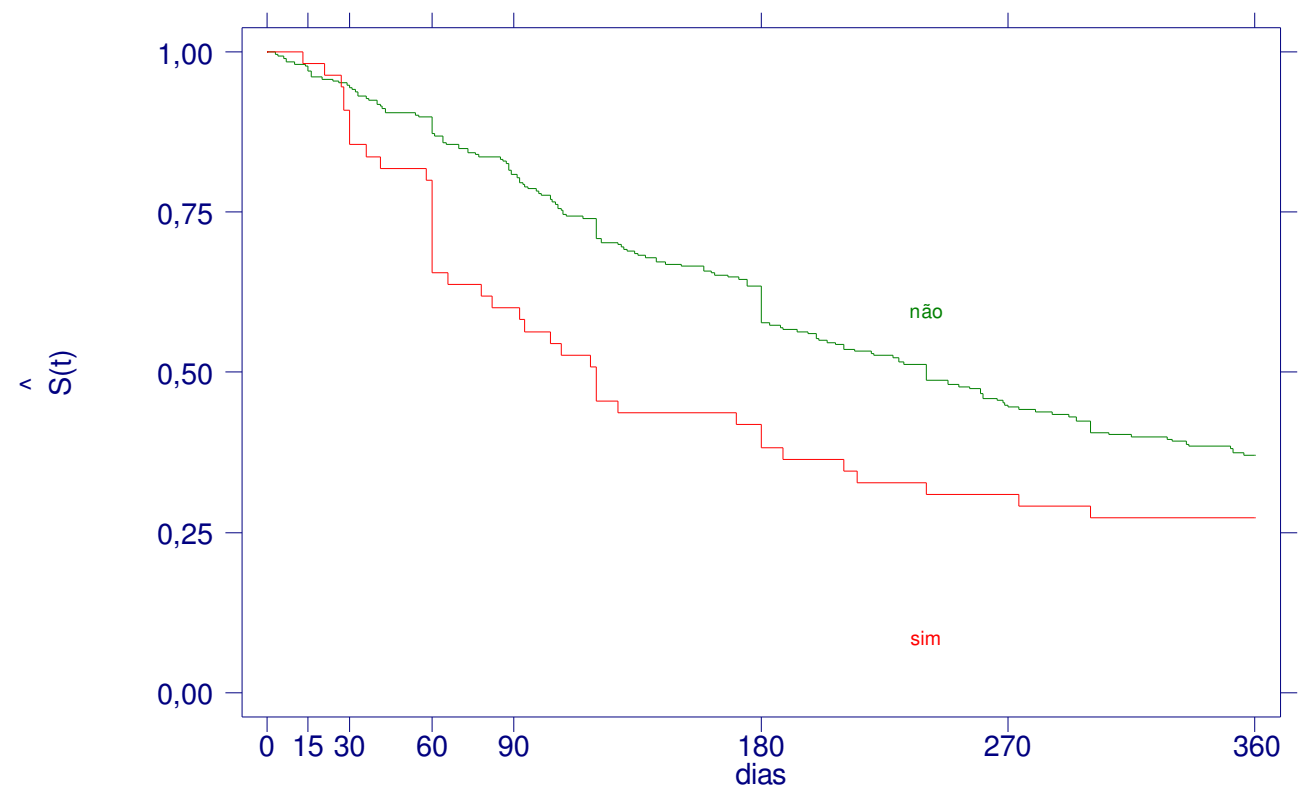


Para as curvas do Gráfico 5, o teste de log-rank indica haver diferença entre as curvas de hábito de fumar ( $\mathrm{p}=0,0156)$.

\begin{tabular}{|c|c|c|c|}
\hline Variáveis & $\%$ de falhas & $\mathrm{S}(360)$ & Log-rank \\
\hline sexo & & & 0,7152 \\
\hline masculino & 35,71 & 0,3364 & \\
\hline feminino & 38,76 & 0,3751 & \\
\hline tipo de parto & & & 0,1867 \\
\hline normal & 35,00 & 0,3295 & \\
\hline fórceps & 31,25 & 0,3051 & \\
\hline cesárea & 45,83 & 0,4442 & \\
\hline raça & & & 0,9050 \\
\hline branca & 35,98 & 0,3447 & \\
\hline não branca & 39,04 & 0,3738 & \\
\hline idade da mãe (anos) & & & 0,4133 \\
\hline até 19 anos & 35,66 & 0,3392 & \\
\hline de 20 ou 34 & 37,33 & 0,3471 & \\
\hline 34 anos e mais & 46,34 & 0,4634 & \\
\hline escolaridade materna & & & 0,2566 \\
\hline nível universitário & 50,00 & 0,5000 & \\
\hline nível secundário & 35,86 & 0,3382 & \\
\hline nível fundamental & 37,06 & 0,3552 & \\
\hline condição marital & & & 0,4487 \\
\hline casada & 37,46 & 0,3613 & \\
\hline não casada & 36,36 & 0,3372 & \\
\hline hábito de fumar & & & 0,0099 \\
\hline não & 39,02 & 0,3704 & \\
\hline $\operatorname{sim}$ & 27,27 & 0,2727 & \\
\hline morar com o pai & & & 0,9772 \\
\hline $\operatorname{sim}$ & 36,61 & 0,3514 & \\
\hline não & 40,00 & 0,3801 & \\
\hline posse de bens & & & 0,1906 \\
\hline $\operatorname{sim}$ & 39,81 & 0,3790 & \\
\hline não & 33,33 & 0,3208 & \\
\hline
\end{tabular}

O Anexo 7 apresenta a análise univariada dos modelos de Cox e complemento log-log com cada uma das variáveis. Nelas, destacamos a presença das variáveis escolaridade da mãe e hábito de fumar da mãe durante a gestação, para os dois modelos.

\subsubsection{Recordatório}

Os gráficos 6 a 8 apresentam as curvas de Kaplan-Meier para as informações do recordatório de 12 meses das variáveis escolhidas. 
Gráfico 6 - Estimativas de Kaplan-Meier para a escolaridade materna - recordatório

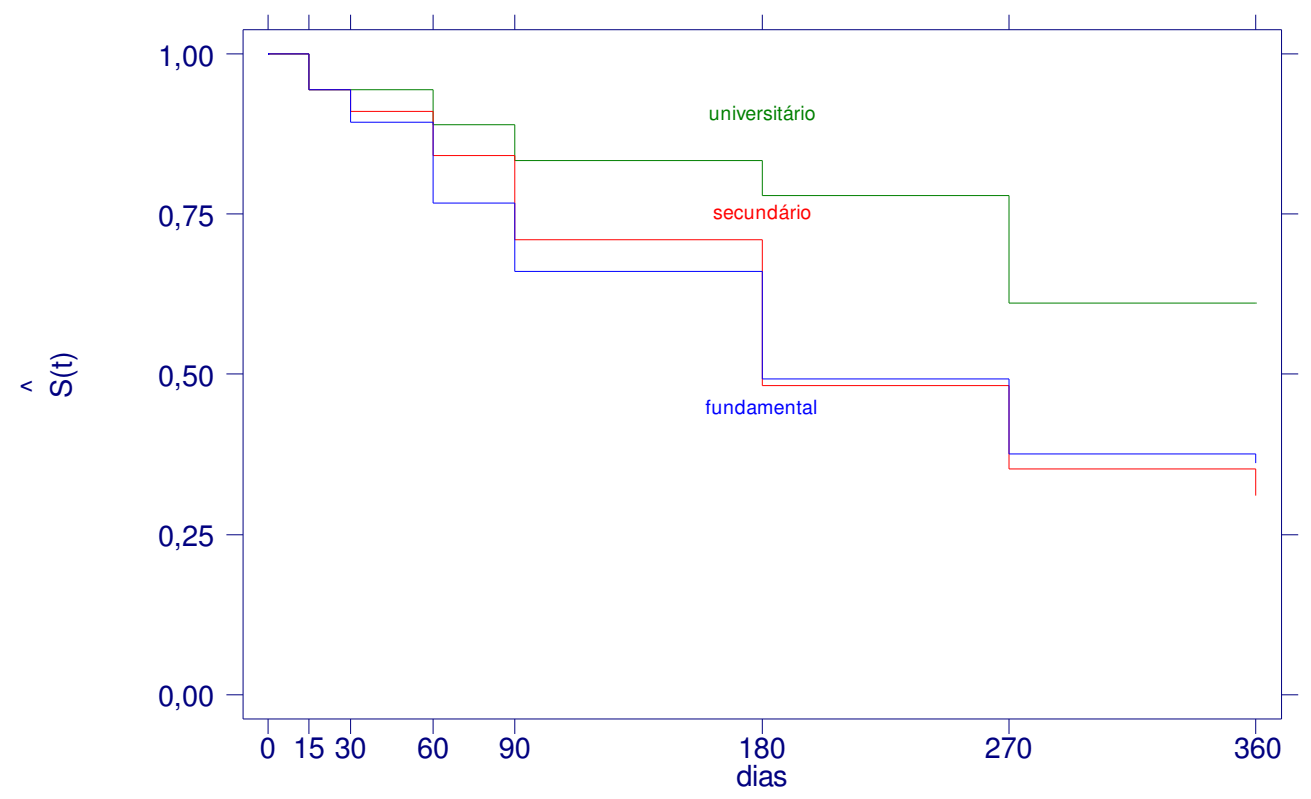

O teste de log-rank indica não haver diferença entre as curvas de escolaridade materna $(\mathrm{p}=0,0889)$.

Gráfico 7 - Estimativas de Kaplan-Meier para a idade materna - recordatório




O teste de log-rank indica não haver diferença entre as curvas de idade materna $(\mathrm{p}=0,3490)$.

Gráfico 8 - Estimativas de Kaplan-Meier para hábito de fumar da mãe - recordatório

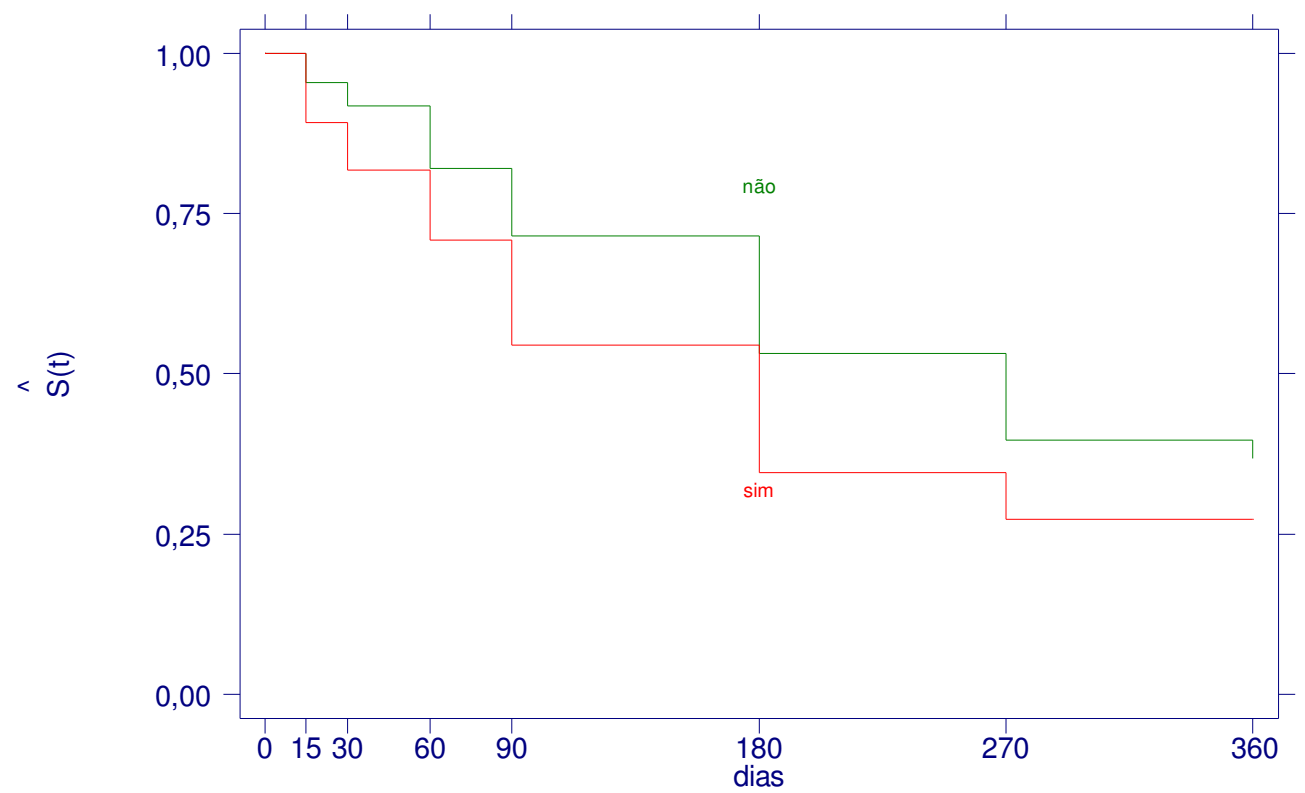

O teste de log-rank indica haver diferença entre as curvas de idade materna $(\mathrm{p}=0,0240)$.

Tabela 7 - Teste de log-rank - recordatório

\begin{tabular}{|c|c|c|c|}
\hline Variáveis & $\%$ de falhas & $S(360)$ & Log-rank \\
\hline sexo & & & 0,5592 \\
\hline masculino & 33,52 & 0,3352 & \\
\hline feminino & 37,08 & 0,3708 & \\
\hline tipo de parto & & & 0,5328 \\
\hline normal & 35,00 & 0,3500 & \\
\hline fórceps & 32,81 & 0,3281 & \\
\hline cesárea & 37,50 & 0,3750 & \\
\hline raça & & & 0,6765 \\
\hline branca & 33,18 & 0,3318 & \\
\hline $\begin{array}{l}\text { não branca } \\
\text { idade da mãe (anos) }\end{array}$ & 38,36 & 0,3836 & 0,3490 \\
\hline até 19 anos & 33,20 & 0,3320 & \\
\hline de 20 ou 34 & 34,67 & 0,3467 & \\
\hline $\begin{array}{l}34 \text { anos e mais } \\
\text { escolaridade materna }\end{array}$ & 48,78 & 0,4878 & 0,0889 \\
\hline nível universitário & 61,11 & 0,6111 & \\
\hline nível secundário & 31,03 & 0,3103 & \\
\hline nível fundamental & 36,04 & 0,3604 & \\
\hline
\end{tabular}


Tabela 7 (continuação) - Teste de log-rank - recordatório

\begin{tabular}{|c|c|c|c|}
\hline Variáveis & $\%$ de falhas & $\mathrm{S}(360)$ & Log-rank \\
\hline condição marital & & & 0,3386 \\
\hline casada & 36,40 & 0,3640 & \\
\hline não casada & 31,17 & 0,3117 & \\
\hline hábito de fumar & & & 0,0240 \\
\hline não & 36,72 & 0,3672 & \\
\hline $\operatorname{sim}$ & 27,27 & 0,2727 & \\
\hline morar com o pai & & & 0,7552 \\
\hline $\operatorname{sim}$ & 35,59 & 0,3672 & \\
\hline não & 33,85 & 0,2727 & \\
\hline posse de bens & & & 0,2835 \\
\hline $\operatorname{sim}$ & 37,04 & 0,3704 & \\
\hline não & 32,64 & 0,3264 & \\
\hline
\end{tabular}

O Anexo 7 apresenta a análise univariada dos modelos de Cox e complemento log-log com cada uma das variáveis. Nelas, destacamos a presença das variáveis escolaridade da mãe e hábito de fumar da mãe durante a gestação, para os dois modelos.

\subsection{Usando as covariáveis em um modelo multivariado}

As variáveis hábito de fumar e escolaridade da mãe foram selecionadas em todos os modelos univariados para entrar no modelo multivariado. $\mathrm{O}$ procedimento de seleção do modelo utilizado se encontra no Anexo 7.

Na Tabela 8, encontra-se o modelo para os dados do caderno diário incluindose todas as variáveis para se observar os valores da razão de riscos (HR). Na Tabela 9 está o resultado após o procedimento de seleção do modelo. 
Tabela 8 - Estimativas dos parâmetros para todas as variáveis, segundo os modelos de Cox e complemento log-log - caderno diário

\begin{tabular}{|c|c|c|c|c|c|c|c|c|c|c|}
\hline \multirow[b]{2}{*}{ Variáveis } & \multirow[b]{2}{*}{$\begin{array}{c}\text { Total } \\
(n=360)\end{array}$} & \multirow[b]{2}{*}{$\%$} & \multicolumn{4}{|c|}{ Cox - diário } & \multicolumn{4}{|c|}{ Complemento log-log - diário } \\
\hline & & & $\begin{array}{c}\mathrm{HR} \\
\text { ajustado }\end{array}$ & IC 9 & & $\mathrm{p}^{*}$ & $\begin{array}{c}\mathrm{HR} \\
\text { ajustado }\end{array}$ & $\mathrm{ICS}$ & & $\mathrm{p}^{*}$ \\
\hline masculino & 182 & 50,6 & 1 & & & & 1 & & & \\
\hline $\begin{array}{l}\text { feminino } \\
\quad \text { tipo de parto }\end{array}$ & 178 & 49,4 & 0,9441 & 0,7212 & 1,2359 & 0,676 & 0,9248 & 0,7050 & 1,2130 & 0,572 \\
\hline normal & 200 & 55,6 & 1 & & & & 1 & & & \\
\hline fórceps & 64 & 17,8 & 1,2050 & 0,8350 & 1,7389 & 0,319 & 1,2023 & 0,8307 & 1,7401 & 0,329 \\
\hline cesárea & 96 & 26,6 & 0,8133 & 0,5827 & 1,1360 & 0,225 & 0,7980 & 0,5704 & 1,1165 & 0,188 \\
\hline raça & & & & & & & & & & \\
\hline branca & 214 & 59,4 & 1 & & & & 1 & & & \\
\hline $\begin{array}{l}\text { não branca } \\
\text { idade da mãe (anos) }\end{array}$ & 146 & 40,6 & 1,0496 & 0,7916 & 1,3917 & 0,737 & 1,0616 & 0,7979 & 1,4123 & 0,682 \\
\hline entre 20 e 34 & 244 & 67,8 & 1 & & & & 1 & & & \\
\hline 20 ou menos & 75 & 20,8 & 1,1331 & 0,8483 & 1,5134 & 0,398 & 1,1566 & 0,8635 & 1,5492 & 0,329 \\
\hline $\begin{array}{l}34 \text { ou mais } \\
\text { escolaridade materna }\end{array}$ & 41 & 11,4 & 1,1331 & 0,8483 & 1,5134 & 0,398 & 1,1566 & 0,8635 & 1,5492 & 0,329 \\
\hline nível universitário & 18 & 5,0 & 1 & & & & 1 & & & \\
\hline nível secundário & 145 & 40,3 & 1,5464 & 0,7672 & 3,1171 & 0,223 & 1,6205 & 0,8028 & 3,2707 & 0,178 \\
\hline nível fundamental & 197 & 54,8 & 1,4785 & 0,7280 & 3,0027 & 0,279 & 1,5499 & 0,7633 & 3,1468 & 0,225 \\
\hline
\end{tabular}


Tabela 8 (continuação) - Estimativas dos parâmetros para todas as variáveis, segundo os modelos de Cox e complemento

\begin{tabular}{|c|c|c|c|c|c|c|c|c|c|c|}
\hline \multirow[b]{2}{*}{ Variáveis } & \multirow{2}{*}{$\begin{array}{c}\text { Total } \\
(n=360)\end{array}$} & \multirow[b]{2}{*}{$\%$} & \multicolumn{4}{|c|}{ Cox - diário } & \multicolumn{4}{|c|}{ Complemento log-log - diário } \\
\hline & & & $\begin{array}{c}\text { HR } \\
\text { ajustado }\end{array}$ & $\mathrm{IC}$ & $5 \%$ & $\mathrm{p}^{*}$ & $\begin{array}{c}\text { HR } \\
\text { ajustado }\end{array}$ & IC 9 & & $\mathrm{p}^{*}$ \\
\hline casada & 283 & 78,6 & 1 & & & & 1 & & & \\
\hline $\begin{array}{l}\text { não casada } \\
\quad \text { hábito de fumar }\end{array}$ & 77 & 21,4 & 1,6741 & 0,8802 & 3,1843 & 0,116 & 1,8715 & 0,9781 & 3,5808 & 0,058 \\
\hline não & 305 & 84,7 & 1 & & & & 1 & & & \\
\hline $\begin{array}{l}\operatorname{sim} \\
\quad \text { morar com o pai }\end{array}$ & 55 & 15,3 & 1,4856 & 1,0289 & 2,1451 & 0,035 & 1,5086 & 1,0409 & 2,1863 & 0,030 \\
\hline $\operatorname{sim}$ & 295 & 81,9 & 1 & & & & 1 & & & \\
\hline não & 65 & 18,1 & 0,6093 & 0,3013 & 1,2321 & 0,168 & 0,5384 & 0,2644 & 1,0963 & 0,080 \\
\hline $\begin{array}{l}\text { posse de bens } \\
\text { sim }\end{array}$ & 216 & 60,0 & 1 & & & & 1 & & & \\
\hline não & 144 & 40,0 & 1,1226 & 0,8389 & 1,5424 & 0,436 & 1,1519 & 0,8584 & 1,5457 & 0,346 \\
\hline
\end{tabular}

* Teste de Wald 
As estimativas da razão das funções de risco e seus intervalos, para todas as variáveis, são próximas entre os dois modelos aplicados ao caderno diário.

Na Tabela 9, após o procedimento de seleção, a variável que permanece em ambos os modelos é hábito de fumar da mãe. Os coeficientes são muito semelhantes, assim como os limites dados pelos intervalos de confiança.

Tabela 9 - Estimativas dos parâmetros para a variável hábito de fumar, segundo os modelos de Cox e complemento log-log - caderno diário

\begin{tabular}{|c|c|c|c|c|c|c|c|c|c|c|}
\hline \multirow{3}{*}{$\begin{array}{c}\text { hábito de } \\
\text { fumar }\end{array}$} & \multirow{3}{*}{$\begin{array}{c}\text { Total } \\
(\mathrm{n}=360)\end{array}$} & \multirow{3}{*}{$\%$} & \multicolumn{8}{|c|}{ caderno diário } \\
\hline & & & \multicolumn{4}{|c|}{ Cox } & \multicolumn{4}{|c|}{ Complemento log-log } \\
\hline & & & HR & IC 9 & & $\mathrm{p}^{*}$ & HR & IC 9 & & $\mathrm{p}^{*}$ \\
\hline não & 305 & 84,7 & 1 & & & & 1 & & & \\
\hline $\operatorname{sim}$ & 55 & 15,3 & 1,4732 & 1,0297 & 2,1077 & 0,034 & 1,4475 & 1,0195 & 2,0552 & 0,039 \\
\hline
\end{tabular}

* Teste de Wald

Segundo o modelo de Cox, quem teve o hábito de fumar durante a gravidez apresenta um risco de deixar de dar o leite de peito 1,47 (IC95\% 1,03-2,11) vezes o de quem não fumou ou, equivalentemente, o risco de deixar de dar o leite de peito de quem fumou durante a gravidez é $47 \%$ maior ao risco de quem não fumou. O modelo complemento log-log apresentou estimativas muito próximas (1,45; IC95\% 1,01$2,05)$ ou, equivalentemente, $45 \%$ maior. Assim, nas duas modelagens para o caderno diário, os valores de HR e seus intervalos de confiança permitem dizer que o fato de a mãe fumar durante a gravidez representa um risco de desmame da criança maior do que quem não fumou.

A Tabela 10 apresenta os valores estimados da função de sobrevida, em determinados tempos, segundo os modelos complemento log-log e de Cox, segundo categorias da variável hábito de fumar. Pode ser observado que os valores nos dois modelos, segundo as categorias, praticamente se superpõem. 
Tabela 10 - Estimativas da sobrevida pelos modelos segundo categorias de hábito de fumar - caderno diário

\begin{tabular}{crrrrr}
\hline \multirow{2}{*}{ Tempo } & \multicolumn{4}{c}{ Hábito de fumar } \\
\cline { 2 - 6 } & \multicolumn{2}{c}{ Cox } & $\begin{array}{c}\text { Complemento } \\
\text { log-log }\end{array}$ & Cox & $\begin{array}{c}\text { Complemento } \\
\text { log-log }\end{array}$ \\
\cline { 2 - 6 } & 1 & 1 & 1 & 1 \\
15 & 0,9783 & 0,9705 & 0,9681 & 0,9818 \\
30 & 0,9456 & 0,9443 & 0,9207 & 0,8545 \\
60 & 0,8796 & 0,8718 & 0,8275 & 0,6545 \\
90 & 0,7875 & 0,8088 & 0,7029 & 0,6000 \\
180 & 0,5978 & 0,5772 & 0,4679 & 0,3818 \\
270 & 0,4369 & 0,4451 & 0,2945 & 0,3091 \\
360 & 0,3672 & 0,3170 & 0,2278 & 0,2440 \\
\hline
\end{tabular}

O Gráfico 9 apresenta as estimativas, para o modelo de Cox do caderno diário, da variável hábito de fumar e os valores observados por meio da técnica KaplanMeier.

Gráfico 9 - Sobrevida, segundo categorias de hábito de fumar, estimadas pelo modelo de Cox e pelo método Kaplan-Meier - caderno diário

○ Kaplan-Meier: fumo = não

$\square$ Cox: fumo $=$ não

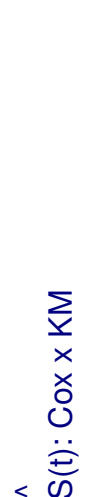



Pelo gráfico, pode ser notado que, para quem não fumou durante a gravidez, o estimador de Kaplan-Meier está próximo aos do de Cox em todos o período de tempo 
de acompanhamento. De forma contrária, para aqueles que fumaram, os valores observados estão por vezes acima e por outras abaixo do valor fornecido pelo modelo. A maior diferença ocorre entre 60 e 180 dias, período em que o modelo apresenta probabilidades maiores de sobrevida do que o observado. Isso indica que existe um problema na suposição de proporcionalidade dos riscos.

O Gráfico 10 apresenta as estimativas, para o modelo complemento log-log, da variável hábito de fumar e os valores observados.

Gráfico 10 - Sobrevida segundo categorias de hábito de fumar, estimadas pelo modelo complemento log-log e pela técnica atuarial - caderno diário

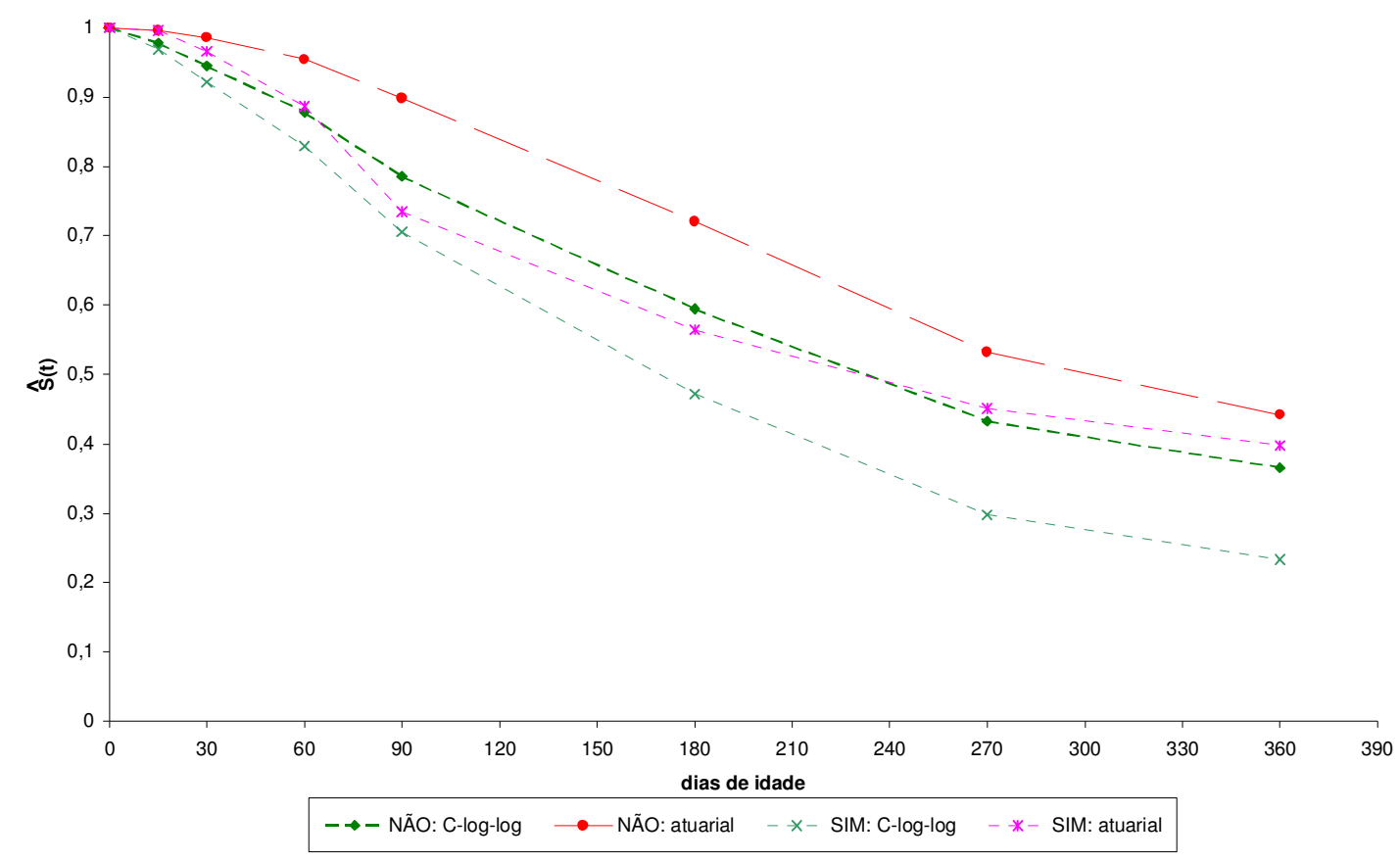

Pode ser observado no Gráfico 10 que os valores ajustados tanto para quem fumou como para quem não fumou durante a gravidez não estão muito próximas dos valores observados, mas os valores observados das duas categorias se aproximam bastante no período final.

$\mathrm{Na}$ Tabela 11, encontra-se o modelo incluindo-se todas as variáveis e na Tabela 12 o resultado após o procedimento de seleção do modelo, detalhado no Anexo 7, para os dados do recordatório. 
Tabela 11 - Estimativas dos parâmetros para todas as variáveis, segundo os modelos de Cox e complemento log-log - recordatório

\begin{tabular}{|c|c|c|c|c|c|c|c|c|}
\hline \multirow[b]{2}{*}{ Variáveis } & \multicolumn{4}{|c|}{ Cox - recordatório } & \multicolumn{4}{|c|}{ Complemento log-log - recordatório } \\
\hline & $\begin{array}{c}\mathrm{HR} \\
\text { (ajustado) }\end{array}$ & IC & & $\mathrm{p}^{*}$ & $\begin{array}{c}\mathrm{HR} \\
\text { (ajustado) }\end{array}$ & IC & $5 \%$ & $\mathrm{p}^{*}$ \\
\hline masculino & 1 & & & & 1 & & & \\
\hline $\begin{array}{l}\text { feminino } \\
\quad \text { tipo de parto }\end{array}$ & 0,8860 & 0,6805 & 1,1536 & 0,369 & 0,8831 & 0,6730 & 1,1418 & 0,329 \\
\hline normal & 1 & & & & 1 & & & \\
\hline fórceps & 1,1929 & 0,8176 & 1,7403 & 0,360 & 1,2252 & 0,8390 & 1,7893 & 0,293 \\
\hline cesárea & 1,0060 & 0,7333 & 1,3802 & 0,970 & 1,0200 & 0,7420 & 1,4021 & 0,903 \\
\hline raça & & & & & & & & \\
\hline $\begin{array}{l}\text { branca } \\
\text { não branca }\end{array}$ & $\begin{array}{r}1 \\
0,9514\end{array}$ & 0,7208 & 1,2557 & 0,725 & $\begin{array}{r}1 \\
0,9617\end{array}$ & 0,7273 & 1,2717 & 0,784 \\
\hline $\begin{array}{l}\text { ldade da mae (anos) } \\
\text { entre } 20 \text { e } 34\end{array}$ & 1 & & & & 1 & & & \\
\hline 20 ou menos & 0,9893 & 0,6980 & 1,4023 & 0,952 & 0,9948 & 0,7016 & 1,4107 & 0,977 \\
\hline $\begin{array}{l}34 \text { ou mais } \\
\text { escolaridade materna }\end{array}$ & 0,8308 & 0,5154 & 1,3389 & 0,446 & 0,8062 & 0,4994 & 1,3014 & 0,378 \\
\hline nível universitário & 1 & & & & 1 & & & \\
\hline nível secundário & 2,0119 & & & 0,0 & 2,0168 & 0,9128 & 4,4 & 0,083 \\
\hline nível fundamental & 1,8515 & 0,8351 & 4,1046 & 0,129 & 1,8717 & 0,8436 & 4,1530 & 0,123 \\
\hline
\end{tabular}


Tabela 11 (continuação) - Estimativas dos parâmetros para todas as variáveis, segundo os modelos de Cox e complemento log-log - recordatório

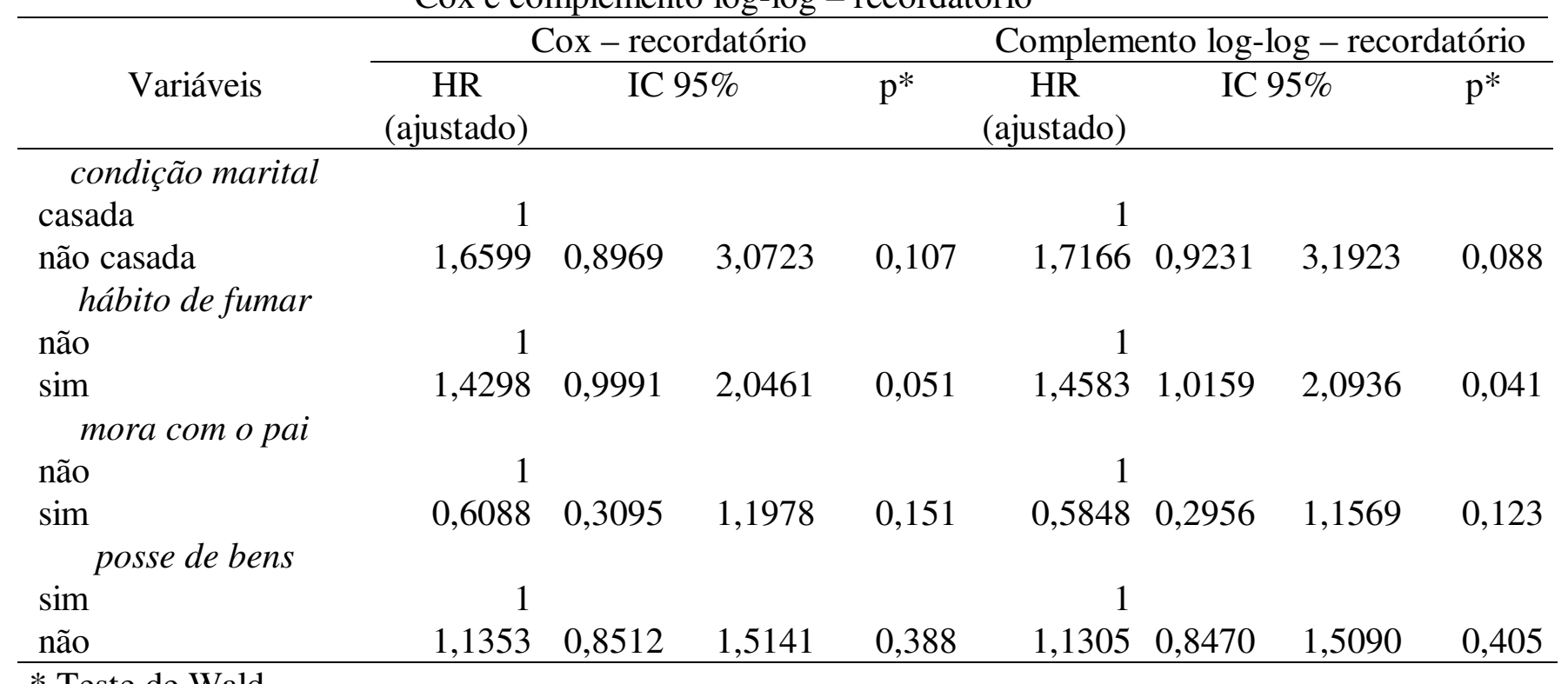

* Teste de Wald 
As variáveis apresentaram estimativas de razão de riscos semelhantes. Após o procedimento de seleção do modelo (passos no Anexo 7), a única variável que permanece é hábito de fumar da mãe (Tabela 12).

Tabela 12 - Estimativas dos parâmetros para a variável hábito de fumar, segundo os modelos de Cox e complemento log-log - recordatório.

\begin{tabular}{|c|c|c|c|c|c|c|c|c|c|c|}
\hline \multirow{3}{*}{$\begin{array}{c}\text { hábito de } \\
\text { fumar }\end{array}$} & \multirow{3}{*}{$\begin{array}{c}\text { Total } \\
(\mathrm{n}=360)\end{array}$} & \multirow{3}{*}{$\%$} & \multicolumn{8}{|c|}{ recordatório } \\
\hline & & & \multicolumn{4}{|c|}{ Cox } & \multicolumn{4}{|c|}{ Complemento log-log } \\
\hline & & & HR & $\mathrm{ICS}$ & & $\mathrm{p}^{*}$ & HR & IC & & $\mathrm{p}^{*}$ \\
\hline não & 305 & 84,7 & 1 & & & & 1 & & & \\
\hline $\operatorname{sim}$ & 55 & 15,3 & 1,4594 & 1,0377 & 2,0526 & 0,030 & 1,4763 & 1,0134 & 2,0159 & 0,026 \\
\hline
\end{tabular}

Segundo o modelo de Cox, verifica-se que quem teve o hábito de fumar durante a gravidez apresenta um risco de deixar de dar o leite de peito 1,46 (IC95\% $1,04-2,05)$ vezes o de quem não fumou ou, equivalentemente, $46 \%$ maior. O modelo complemento log-log apresentou estimativas muito próximas (1,48, IC95\% 1,012,02) ou, equivalentemente, $48 \%$ maior.

O Gráfico 11 apresenta as estimativas para o modelo de Cox do caderno diário, da variável hábito de fumar e os valores observados por meio da técnica KaplanMeier. 
Gráfico 11 - Sobrevida, segundo categorias de hábito de fumar, estimadas pelo modelo de Cox e pelo método Kaplan-Meier - recordatório

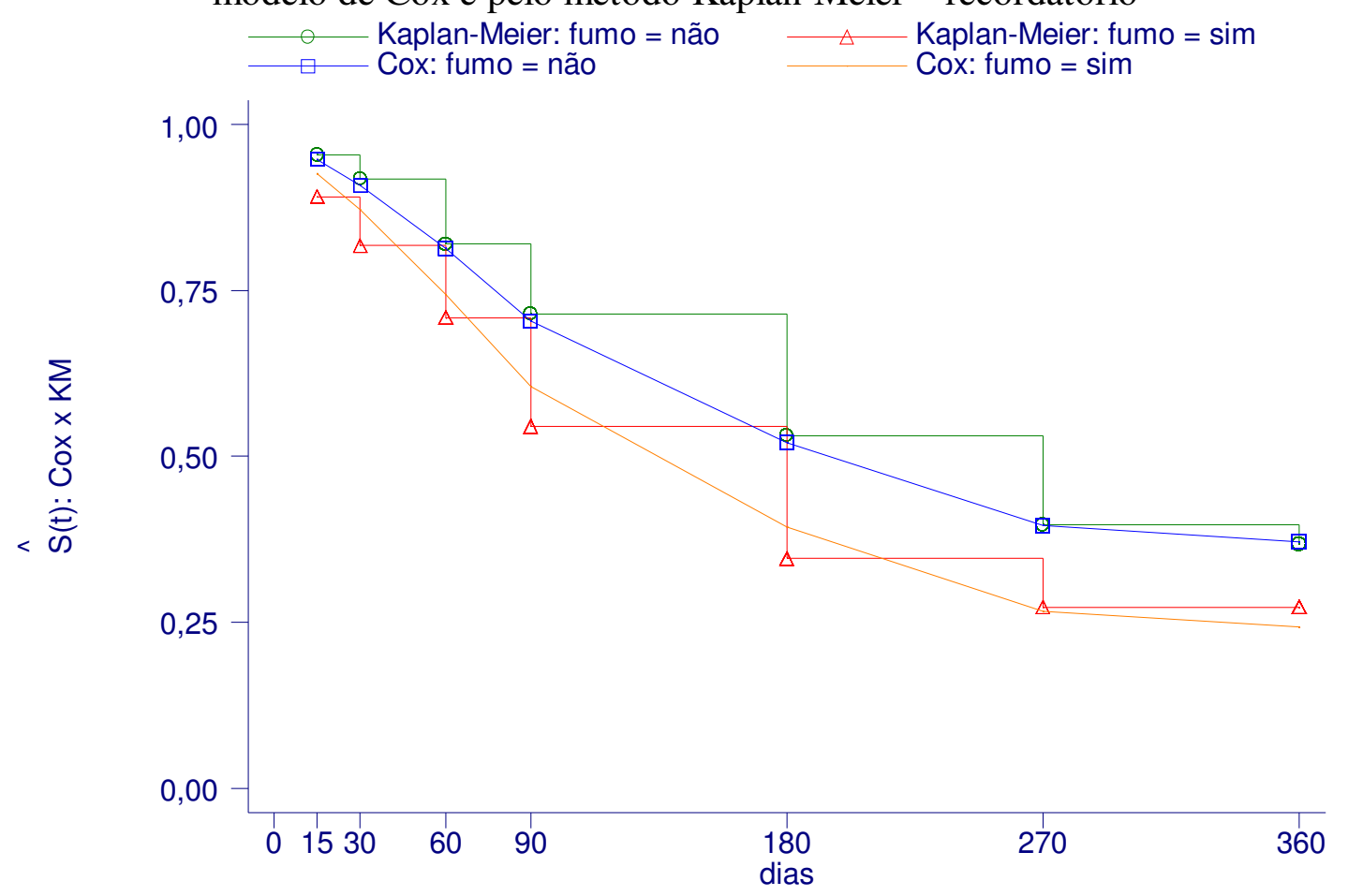

Pelo gráfico, os valores observados das probabilidades segundo os modelos de Cox e Kaplan-Meier estão próximos em todos o período de tempo de acompanhamento. Isso indica que proporcionalidade dos riscos está satisfeita.

O Gráfico 12 apresenta os valores ajustados para $\hat{\mathrm{S}}(\mathrm{t})$ pelo modelo complemento log-log para o recordatório, além das estimativas da técnica atuarial. De forma diferente no caso do caderno diário, os riscos não fogem à proporcionalidade ao longo do tempo. 
Gráfico 12 - Sobrevida segundo categorias de hábito de fumar, estimada pelo modelo complemento log-log e atuarial - recordatório

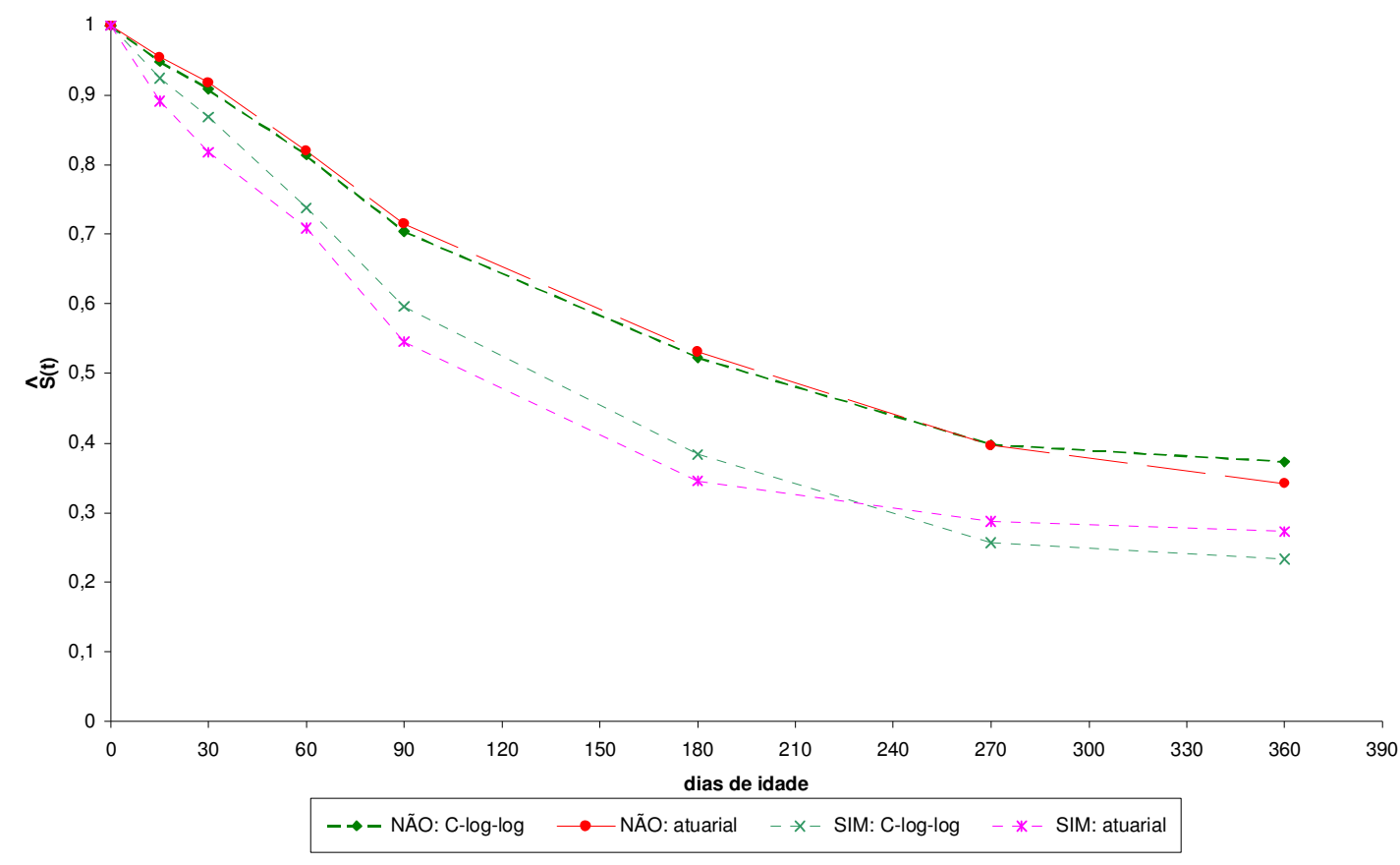

\subsubsection{Comentários}

As covariáveis utilizadas nos modelos, todas categóricas por natureza ou categorizadas, foram definidas de forma que o valor zero indicasse a categoria de referência. Ambos os modelos permitem a interpretação dos parâmetros por meio da razão de riscos (HR).

O ajuste do modelo de Cox aos dados do caderno diário é direta, bastando definir os tempos de desmame, a variável que indica a falha/censura e quais covariáveis utilizar.

Para se ajustar o modelo complemento log-log, os dados do caderno diário tiveram que ser agrupados em intervalos de tempo. Portanto, o tempo original é alterado e isso é justamente o que ocorre quando se trabalha com a aplicação de um recordatório em que a informação é obtida em intervalos. Para se ajustar o modelo é necessário replicar os indivíduos e suas covariáveis, no banco de dados. O número de linhas a mais no banco de dados corresponde ao número de intervalos pelos quais o indivíduo passou. 
Os resultados dos dois modelos, aplicados à informação do caderno diário, apresentam resultados bastante próximos. Ambos indicam a variável hábito de fumar da mãe como importante para se compreender o desmame. Os valores das estimativas da razão de riscos e dos intervalos de confiança também são bastante próximos.

O modelo complemento log-log, aplicado aos dados do recordatório, é adequado para os dados de uma pesquisa de coorte retrospectiva. O tempo fornecido nesse tipo de pesquisa é basicamente de origem intervalar.

O ajuste do modelo complemento log-log aos dados do caderno diário serve para avaliar, com uma mesma técnica, se os dados fornecidos pelos recordatórios possuem semelhança aos do caderno diário. Os resultados da Tabela 11 mostram que as estimativas são praticamente iguais entre os modelos, e a seleção posterior dos modelos finais aponta para a mesma variável. Além desse ajuste, o modelo de Cox, mais apropriado ao caderno diário, apresentou resultados semelhantes aos do modelo complemento log-log (Tabela 8). 


\section{Discussão}

Devido ao fato de cada um dos cadernos conter 60 dias para anotação, existe uma tendência de registro do evento em múltiplos de 60. A anotação dos eventos pode estar sendo completada pela mãe no momento da entrevista e implica um viés do entrevistador.

O viés de recordação, ou de memória, pode estar presente em um estudo de abordagem retrospectiva. Aparentemente, não deve existir diferença na resposta das mães para os diversos níveis das variáveis. A comparação entre as duas abordagens, utilizando uma mesma técnica, pode apontar diferenças que podem estar representando esse viés. Partindo da suposição que a abordagem prospectiva é a mais próxima da medida real, as diferenças que surgem entre esta e os recordatórios podem ser devidas à precisão das medidas e/ou a vieses, sendo o mais importante deles, o de memória.

A idéia de se trabalhar inicialmente sem as covariáveis foi a de analisar o efeito somente das informações dos dois tipos de estudo no tempo de amamentação. Cada tipo de estudo apresenta vantagens e desvantagens, sendo que é importante notar que associado ao estudo de coorte retrospectiva está o fator de memória da mãe. Nessa análise, nota-se que os estimadores apresentam resultados próximos ao do KaplanMeier, indicando que os dois recordatórios forneceram resultados numericamente concordantes com o do caderno diário e semelhantes entre si o que reforça que o recordatório pode ser confiável para avaliar o tempo de amamentação.

Deve-se lembrar que as censuras foram dadas por motivo de fim de estudo e não de perda e, na ausência de censuras, o estimador atuarial é idêntico ao do modelo complemento log-log. No último intervalo do recordatório, quando ocorrem as censuras, o modelo complemento log-log fornece estimativa mais alta que a da técnica atuarial.

A técnica atuarial é bastante simples e não pressupõe riscos proporcionais mas não tem estrutura para se medir o efeito de mais de uma covariável, enquanto que o modelo complemento log-log permite a inclusão de diversas covariáveis no modelo. 
Existem pequenas diferenças entre as estimativas para os recordatórios e para o caderno diário. As diferenças encontradas entre as medidas calculadas para os recordatórios e o caderno diário podem ser frutos de falha de memória da mãe. A imprecisão da informação obtida é inerente a um estudo de coorte retrospectiva. Apesar das diferenças, pode-se ter uma boa idéia do desmame no decorrer do tempo por meio dos recordatórios.

As quedas bruscas na função de sobrevida pelo Kaplan-Meier mostram que as entrevistas domiciliares têm um papel ainda mais importante a cumprir para se detectar e corrigir falhas na pesquisa. Para se tentar melhorar o preenchimento do caderno diário, as visitas domiciliares podem ser mais freqüentes. Porém, o aumento de visitas, além de encarecer uma pesquisa, pode aumentar a influência da pesquisa no preenchimento da amamentação.

Quando são consideradas as covariáveis, foram aplicados os modelos de Cox e complemento log-log para as informações do caderno diário. As estimativas dos efeitos de cada covariável são bem parecidas entre os modelos. As estimativas fornecem uma noção de quais variáveis podem ser importantes na amamentação. Isso não significa que devem ser utilizados estudos de coorte retrospectiva para se medir os efeitos de covariáveis no lugar de estudos de coorte, mas eles podem ser úteis para ajudar a identificar covariáveis importantes. Deve-se notar, ainda, que a construção de uma coorte retrospectiva não é fácil, pois depende da identificação e localização de todas as mães em todo o período de estudo. A falta de informações pode produzir um estudo que mais se aproxima de um estudo de corte transversal.

Nessa análise, a falta de proporcionalidade dos riscos ocorre para os dois modelos. Caso fossem utilizados modelos que comportem variáveis tempodependentes, os resultados para os dois modelos poderiam ser diferentes mas, com a semelhança aqui apresentada, não se acredita que houvesse muita alteração.

Ao se utilizar o modelo de Cox e complemento log-log aos dados do recordatório, as estimativas do risco de falhas foram bastante semelhantes entre si. Assim, os modelos apresentaram resultados semelhantes tanto com o dado retrospectivo como o do prospectivo. 
Observando-se apenas o modelo complemento log-log, os dados do caderno diário apresentaram estimativas muito parecidas aos do recordatório indicando que as duas fontes de informação apresentam certa concordância.

A mesma semelhança entre as estimativas é encontrada quando se utiliza o modelo de Cox para as duas fontes.

Em geral, as estimativas das funções de sobrevida fornecidas pelos dois modelos finais são bastante parecidas. Mais ainda, somente uma e a mesma variável permaneceu no modelo final para todas as técnicas, com estimativas muito próximas, reforçando semelhança entre as várias abordagens. Esta variável, hábito de fumar da mãe, aparece como fator de risco em diversos artigos normalmente acompanhadas de outros fatores (Levy 2002; Gigante 2000; Najdawi 1999; Rutishauser 1992). 


\section{Conclusão}

O modelo de Cox apresentou estimativas semelhantes tanto para a coorte retrospectiva quanto para a coorte prospectiva.

O modelo complemento log-log apresentou estimativas semelhantes tanto para a coorte retrospectiva quanto para a coorte prospectiva.

Os resultados do modelo de Cox e modelo complemento log-log apresentaram estimativas semelhantes para os dados da coorte retrospectiva.

Os resultados do modelo de Cox e modelo complemento log-log apresentaram estimativas semelhantes para os dados da coorte prospectiva.

$\mathrm{O}$ risco de uma criança deixar mais precocemente o leite de peito naquelas com mães que fumaram durante a gravidez é maior comparado ao risco para crianças com mães que não fumaram. 


\section{Referências}

Abada TSJ, Trovato F, Lalu N. Determinants of breastfeeding in the Philippines: a survival analysis. Social Science and Medicine 2001, 52: 71-81.

Assis AMO, Prado MS, Freitas MC, Silva RCR, Ramos LB, Machado AD. Prática do aleitamento materno em comunidades rurais do semi-árido baiano. Revista de Saúde Pública 1994, 28(5): 380-4.

Breslow NE. A generalized Kruskal-Wallace test for comparing k samples subject to unequal patterns of censorship. Biometrika 1970; 57: 579-594.

Breslow NE. Covariance analysis of censored survival data. Biometrics 1974; 30: 89100.

Carstensen B. Regression models for interval censored data: application to HIV infection in Danish homosexual men. Statistics in Medicine 1996; 15: 2177-2189.

Chalita LVAS, Colossimo EA, Demétrio CGB. Likelihood approximation and discrete models for interval-censored data under Cox regression model. UNESP NOV 1999. Relatório Técnico 99-01.

Collett D. Modelling Survival Data in Medical Research. London: Chapman Hill; 1994.

Corrente JE, Chalita LVAS, Moreira JA. Choosing between Cox proportional hazards and logistic models for interval-censored data via bootstrap. Journal of Applied Statistics JAN 2003, 30 (1): 37-47

Cox DR. Regression models and life-tables (with discussion). Journal of the Royal Statistical Society 1972, 34 (Series B): 187-200.

Cox DR, Oakes D. Analysis of Survival Data. London: Chapman and Hall, 1984.

Escamilla RP, Lutter CK, Wickham $\mathrm{C}$ et al. Identification of risk factors for short breastfeeding in Mexico City through survival analysis. Ecol Food and Nutrition 1997, 36(1): 43-64.

Farrington CP. Interval censored survival data: a generalized linear model approach. Statistics in Medicine 1996; 15: 283-292.

Gehan EA. A generalized Wilcoxon test for comparing arbitrarily singly-censored samples. Biometrics 1965; 52: 203-223. 
Gigante DP, Victora CG, Barros FC. Nutrição materna e duração da amamentação em uma coorte de nascimento de Pelotas, RS. Revista de Saúde Pública 2000, 34(3): 259-65.

Hardy EE et al. A prática de amamentação no município de Paulínia, Estado de São Paulo, Brasil. Revista de Saúde Pública 1982, 16: 337-45.

Hess KR. Graphical methods for assessing violations of the proportional hazards assumption in Cox regression. Statistics in Medicine 1995, 14: 1707-1723.

Hitchcock NE et al. The growth of breast fed and artificially fed infants from birth to twelve months. Acta Paediatrica Scandinavica 1985; 74: 240-5.

Hosmer DW, Lemeshow S. Applied Survival Analysis: regression modeling of time to event data. New York: John Wiley and Sons; 1999.

Kaplan EL, Meier P. Nonparametric estimation from incomplete observations. Journal of Chronic Diseases 1955; 1: 12-32.

Kalbfleisch JD, Prentice RL. The statistical analysis of failure time data. New York: Wiley; 1980.

Klein JP, Moeschberger ML. Survival Analysis: techniques for censored and truncated data. New York: Springer; 1997.

Kleinbaum DG, Kupper LL, Morgenstern H. Epidemiologic research. New York: Van Nostrand Reinhold; 1982.

Kosterman R, Hawkins JD, Guo J, Catalano RF, Abbott RD. The dynamics of alcohol and marijuana initiation: Patterns and predictors of first use in adolescence. American Journal of Public Health MAR 2000, 90 (3): 360-366.

Kummer SC, Giugliani ERJ, Susin LO et al. Evolução do padrão de aleitamento materno. Revista de Saúde Pública 2000, 34(2): 143-8;

Lancelot R, Lesnoff M, McDermott JJ. Use of Akaike information criteria for model selection and inference. An application to assess prevention of gastrointestinal parasitism and respiratory mortality of Guinean goats in Kolda, Senegal. Preventive Veterinary Medicine NOV 15 2002, 55 (4): 217-240.

Lawless JF. Statistical models and methods for lifetime data. New York: John Wiley \& Sons, Inc.; 1982.

Lee ET. Statistical methods for survival data analysis. New York: John Wiley \& Sons, Inc.; 1992. 
Levy SM, Slager SL, Warren JJ et al. Association of pacifier use, digit sucking, and child care attendance with cessation of breastfeeding. Journal of Family and Practice MAY 2002, 51(5): U15-U19.

Lilienfeld AM. Foundations of epidemiology. New York: Oxford University Press; 1976.

Comissão Nacional de Ética em Pesquisa. Normas para pesquisa envolvendo seres humanos (Res. CNS 196/96 e outras) = Rules on research involving human subjects / Conselho Nacional de Saúde. Brasília: Ministério da Saúde; 2000.

McCullagh P, Nelder JA. Generalized linear models. $2^{\text {nd }}$. ed. London: Chapman Hill; 1989.

OPAS/OMS. Indicadores para evaluar las practicas de lactancia maternal. OMS/CED/SER/91. 14. Genebra; 1991.

Passos MC, Lamounier JA, Silva CAM et al. Práticas de amamentação no município de Ouro Preto, MG, Brasil. Revista de Saúde Pública 2000; 34(6): 617-22.

Pereira MG. Epidemiologia: teoria e prática. Rio de Janeiro: Guanabara Koogan; 1999.

Peto R, Peto J. Asymptotically efficient rank invariance test procedures (with discussion). Journal of the American Statistical Association 1972; 72: 854-858.

Prentice RL, Gloecker LA. Regression analysis of grouped survival data with application to breast cancer data. Biometrics 1978, 34: 57-67.

Radrigan M et al. Alimentación en el primer año de vida. Ver. Chil. Pediatr. 1989, 60 (Suppl): 9-19.

Rea MF, Venâncio SI, Batista LE, Santos RG, Greiner T. Possibilidades e limitações da amamentação entre mulheres trabalhadoras formais. Revista de Saúde Pública 1997, 31(2): 149-56.

Rothman KJ, Greenland S. Modern Epidemiology. $2^{\text {nd }}$. ed. Philadelphia: Lippincott Raven; 1998.

Rutishauser IHE, Carlin JB. Body mass index and duration of breast feeding: a survival analysis during the first six months of life. Journal of Epidemiology and Community Health 1992, 46: 559-565.

Scott JA, Aitkin I, Binns CW et al. Factors associated with the duration of breastfeeding among women in Perth, Australia. Acta Paediatric APR 1999, 88(4): 416-421. 
Szklo M, Nieto FJ. Epidemiology: beyond the basics. Maryland: Aspen; 2000.

STATACORP. Stata statistical software: release 7.0. College Station (TX): Stata Corporation; 2001.

Therneau TM, Grambsch PM. Modeling survival data: extending the Cox model. New York: Springer; 2000.

Weiderpass E, Barros FC, Victora CG, Tomasi E, Halpern R. Incidência e duração da amamentação conforme o tipo de parto: estudo longitudinal no sul do Brasil. Revista de Saúde Pública 1998; 32(3): 225-31. 
Anexos 
Anexo 1 - Termo de consentimento 
TERMO DE CONSENTIMENTO PARA PARTICIPAÇÃO NA PESQUISA ALIMENTAÇÃO NO PRIMEIRO ANO DE VIDA

(de acordo com a Resolução 196 de 10/10/1996 do Conselho Nacional de Saúde)

$\mathrm{Eu}$ livremente,

permito que meu(minha) filho(a) participe da pesquisa "Alimentação no primeiro ano de vida" sob responsabilidade dos pesquisadores José Maria Pacheco de Souza, Professor Titular da Faculdade de Saúde Pública da USP, Sonia Buongermino de Souza, Professora Doutora da Faculdade de Saúde Pública da USP, Suely Godoy Agostinho Gimeno, Professora Doutora da Universidade Federal de São PauloEscola Paulista de Medicina- e Arnaldo Augusto Franco de Siqueira, Professor Titular da Faculdade de Saúde Pública da USP.

\section{Fui informado(a) sobre o seguinte:}

Objetivo da Pesquisa: Verificar a prática alimentar no primeiro ano de vida e sua relação com o crescimento e o desenvolvimento da criança.

Participação: Responder às perguntas necessárias e permitir que sejam feitas medidas de peso, de comprimento, de perímetros cefálico e torácico, a cada visita domiciliar, ao longo do primeiro ano de vida.

Riscos: Não haverá riscos para a integridade física, mental ou moral de meu(minha) filho(a).

Benefícios: As informações obtidas nesta pesquisa poderão ser úteis cientificamente e de ajuda para todos.

Privacidade: Os dados individualizados serão confidenciais. Os resultados coletivos serão divulgados nos meios científicos.

Contatos com os pesquisadores: Terei acesso a telefone para esclarecimento de dúvidas ou reclamações.

Desistência: Poderei desistir a qualquer momento da minha participação, sem qualquer conseqüência para mim.

Assinatura 
Anexo 2 - Formulário 1 


\section{FORMULÁRIO 1}

IDENTIF ICAÇÃO

\begin{tabular}{|c|c|}
\hline 1. $\mathrm{NOME}$ DA $\mathrm{MA \tilde {A }}$ & \\
\hline 2. NOME DA CRIANÇA & \\
\hline 3. ENDEREÇO & \\
\hline 4. $\mathrm{N}^{\circ}$ DO FORMULÁRIO & $I \_1 \_I$ \\
\hline 5. $\mathrm{N}^{\circ}$ DA CRIANÇA & -1 \\
\hline 6. DATA & 1 \\
\hline 7. ENTREVISTADORA & 1 \\
\hline 8. $\mathrm{N}^{\circ}$ DO REGISTRO HOSPITALAR & -1 \\
\hline $\begin{array}{ll}\text { 9. RELAÇÃO DA MÃE COM A USP } \\
\text { Servidor não docente(0) } \\
\text { Dep. de não docente(2) } & \text { Dep. de docente (3) } \\
\text { Aluno(4) } & \text { Não USP (5) } \\
\end{array}$ & 1 \\
\hline $\begin{array}{l}\text { 10. RELAÇÃO DO PAI COM A USP } \\
\text { Servidor não docente(0) Servidor docente (1) } \\
\text { Dep. de não docente(2) Dep. de docente (3) } \\
\text { Aluno(4) } \\
\text { Não USP (5) }\end{array}$ & 1 \\
\hline
\end{tabular}

\section{CARACTERÍSTICAS DA CRIANÇA}

\begin{tabular}{|l|l|}
\hline 11. DATA DE NASCIMENTO & I_ \\
\hline 12. SEXO Masculino(0) & \\
\hline 13. COR/RAÇA/ETNIA Branca(0) Preta (1) \\
Parda/Mulata (2) Amarela/Oriental (3)
\end{tabular}

\section{CONDIÇÕES DA GESTAÇÃO E PARTO}

I_l_l_ l I

\begin{tabular}{|c|c|}
\hline 19. TEMPO DE GESTAÇÃO (semanas) & $I_{1} I_{2}$ \\
\hline 20. GANHO DE PESO DA MÃE NA GESTAÇÃO $\quad(\mathrm{kg})$ & 1 \\
\hline 21. NÚMERO DE CONSULTAS NO PRÉ-NATAL & -1 \\
\hline 22. PARTO Normal(0) Fórceps(1) Cesárea(2) & \\
\hline 23. NÚMERO DE GESTAÇÕES ANTERIORES & 1 \\
\hline $\begin{array}{l}\text { 24. HÁBITO DE FUMAR DA MÃE ANTES DA GESTAÇÃO } \\
\text { Não(00) Número de cigarros por dia( ) }\end{array}$ & 1 \\
\hline $\begin{array}{l}\text { 25. HÁBITO DE FUMAR DA MÃE DURANTE A } \\
\text { GESTAÇ̃̃O } \\
\quad \text { Não(00) } \\
\text { Número de cigarros por dia( ) }\end{array}$ &  \\
\hline $\begin{array}{l}\text { 26. HÁBITO DE BEBER DA MÃE ANTES DA GESTAÇÃO } \\
\text { Não(0) Ocasionalmente(1) } \\
\text { Semanalmente(2) } \quad \text { Diariamente (3) }\end{array}$ & 1 \\
\hline $\begin{array}{l}\text { 27. HÁBITO DE BEBER DA MÃE DURANTE A } \\
\text { GESTAÇÃO } \\
\text { Não (0) } \\
\text { Semanalmente (2) } \begin{array}{l}\text { Ocasionalmente (1) } \\
\text { Diariamente (3) }\end{array}\end{array}$ & 1 \\
\hline
\end{tabular}


CARACTERÍSTICAS FAMILIARES

\begin{tabular}{|c|c|}
\hline $\begin{array}{ll}\text { 28. } & \text { CONDIÇÃO MARITAL DA MÃE } \\
\text { Solteira (0) } & \text { Casada (1) } \\
\text { Viúva(2) } & \text { Separada (3) } \\
\end{array}$ & $1 \ldots 1$ \\
\hline $\begin{array}{ccc}\text { 29. MÃE MORA COM PAI DA CRIANÇA } \\
\text { Não }(0) & \text { Sim }(1) & \\
\end{array}$ & $1 \ldots 1$ \\
\hline 30. IDADE DA MÃE & $1 \ldots$ \\
\hline 31. IDADE DO PAI & 1 \\
\hline $\begin{array}{l}\text { 32. LOCAL DE NASCIMENTO DA MÃE } \\
\text { S.Paulo(0) Grande S.Paulo(1) } \\
\text { Est.S.Paulo(2) Outro Estado(3) } \\
\text { Outro país(4) }\end{array}$ & 1 \\
\hline $\begin{array}{l}\text { 33. LOCAL DE NASCIMENTO DO PAI } \\
\text { S.Paulo(0) Grande S.Paulo(1) } \\
\text { Est.S.Paulo(2) Outro Estado(3) } \\
\text { Outro país(4) }\end{array}$ & 1 \\
\hline $\begin{array}{c}\text { 34. ESCOLARIDADE DA MÃE } \\
\operatorname{Grau}() \text { Série( ) } \\
\end{array}$ & 1 \\
\hline $\begin{array}{c}\text { 35. ESCOLARIDADE DO PAI } \\
\text { Grau( ) Série( ) }\end{array}$ & 1 \\
\hline 36. OCUPAÇÃO DA MÃE & 1 \\
\hline 37. OCUPAÇÃO DO PAI & 1 \\
\hline
\end{tabular}




\begin{tabular}{|c|c|}
\hline 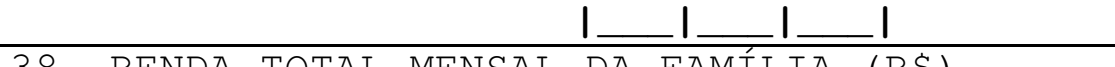 & \\
\hline 38. RENDA TOTAL MENSAL DA FAMILIA (R\$) & $I_{-} I_{ـ} I_{\ldots} I_{-}$ \\
\hline 39. $\mathrm{N}^{\circ}$ DE CRIANÇAS RESIDENTES NA CASA & I. \\
\hline $\begin{array}{l}\text { 40. } \text { N }^{\circ} \text { DE CRIANÇAS QUE VÃO À CRECHE OU } \\
\text { BERÇÁRIO }\end{array}$ & 1 \\
\hline 41. NÚMERO DE CRIANÇAS QUE VÃO À ESCOLA & $I_{2}$ \\
\hline $\begin{array}{l}\text { 42. NÚMERO DE CRIANÇAS QUE FICAM EM OUTROS } \\
\text { LOCAIS, EM CONTATO COM OUTRAS CRIANÇAS } \\
\text { (VIZINHO, PARENTE, IGREJA). } \\
\text { LOCAL: }\end{array}$ & $1 \ldots$ \\
\hline 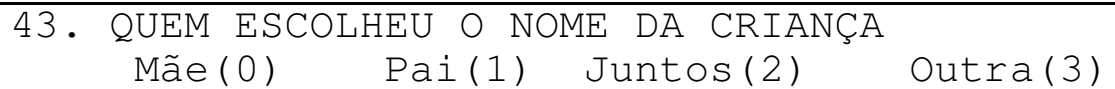 & -1 \\
\hline 44. NÚMERO DE FUMANTES RESIDENTES NA CASA & \\
\hline $\begin{array}{l}\text { 45. O PAI FUMA? } \\
\text { Não(00) No Cigarros p/dia( ) }\end{array}$ & $I_{\ldots} I_{\ldots} I_{1}$ \\
\hline $\begin{array}{l}\text { 46. HÁBITO DE BEBER DO PAI } \\
\text { Não(0) Ocasionalmente (1) } \\
\text { Semanalmente (2) } \quad \text { Diariamente (3) }\end{array}$ & 1 \\
\hline 47. NÚMERO DE IRMÃOS VIVOS DA CRIANÇA & -1 \\
\hline $\begin{array}{l}\text { 48. IDADE DO IRMÃO MAIS VELHO, EM ANOS } \\
\text { INTEIROS }\end{array}$ & $I_{\ldots} I_{\ldots} I_{1}$ \\
\hline 49. AMAMENTOU SÓ NO PEITO ATÉ ( ) MESES & 1 \\
\hline 50. AMAMENTOU NO PEITO ATÉ ( ) MESES & -1 \\
\hline 51. QUAL A RAZÃO DO DESMAME DO PEITO & 1 \\
\hline $\begin{array}{l}\text { 52. IDADE DO IRMÃO MAIS NOVO, EM ANOS } \\
\text { INTEIROS }\end{array}$ & $I_{\ldots} I_{2} I$ \\
\hline 53. AMAMENTOU SÓ NO PEITO ATÉ ( ) MESES & \\
\hline 54. AMAMENTOU NO PEITO ATÉ ( ) MESES & 1 \\
\hline 55. QUAL A RAZÃO DO DESMAME DO PEITO & 1 \\
\hline $\begin{array}{l}\text { 56. DIABETES NA MÃE } \\
\text { Não(0) Sim, tipo I(1) Sim,tipo II(2) Não } \\
\text { sabe(9) }\end{array}$ & 1 \\
\hline $\begin{array}{l}\text { 57. DIABETES NO PAI } \\
\text { Não(0) Sim, tipo I(1) Sim,tipo II(2) Não } \\
\text { sabe(9) }\end{array}$ & 1 \\
\hline $\begin{array}{l}\text { 58. DIABETES EM IRMÃO } \\
\text { Não(0) Sim, tipo I(1) Sim, tipo II(2) Não } \\
\text { sabe(9) }\end{array}$ & 1 \\
\hline
\end{tabular}


Anexo 3 - Formulário 2 
FORMULÁRIO 2

\begin{tabular}{|c|c|}
\hline 1. NOME DA MÃE & \\
\hline \begin{tabular}{|lll} 
2. NOME & DA & CRIANÇA
\end{tabular} & \\
\hline \begin{tabular}{|llll}
$4 . N^{\circ}$ & DO & FORMULÁRIO
\end{tabular} & 2 \\
\hline \begin{tabular}{|llll}
5. & $N^{\circ}$ & DA & CRIANÇA \\
\end{tabular} & -1 \\
\hline 6. DATA & $I_{1}$ \\
\hline 7. ENTREVISTADORA & $-1 \ldots$ \\
\hline 8. $\mathrm{N}^{\circ}$ DO REGISTRO HOSPITALAR & 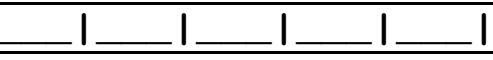 \\
\hline
\end{tabular}

\section{CONDIÇÕES DO DOMICÍLIO}

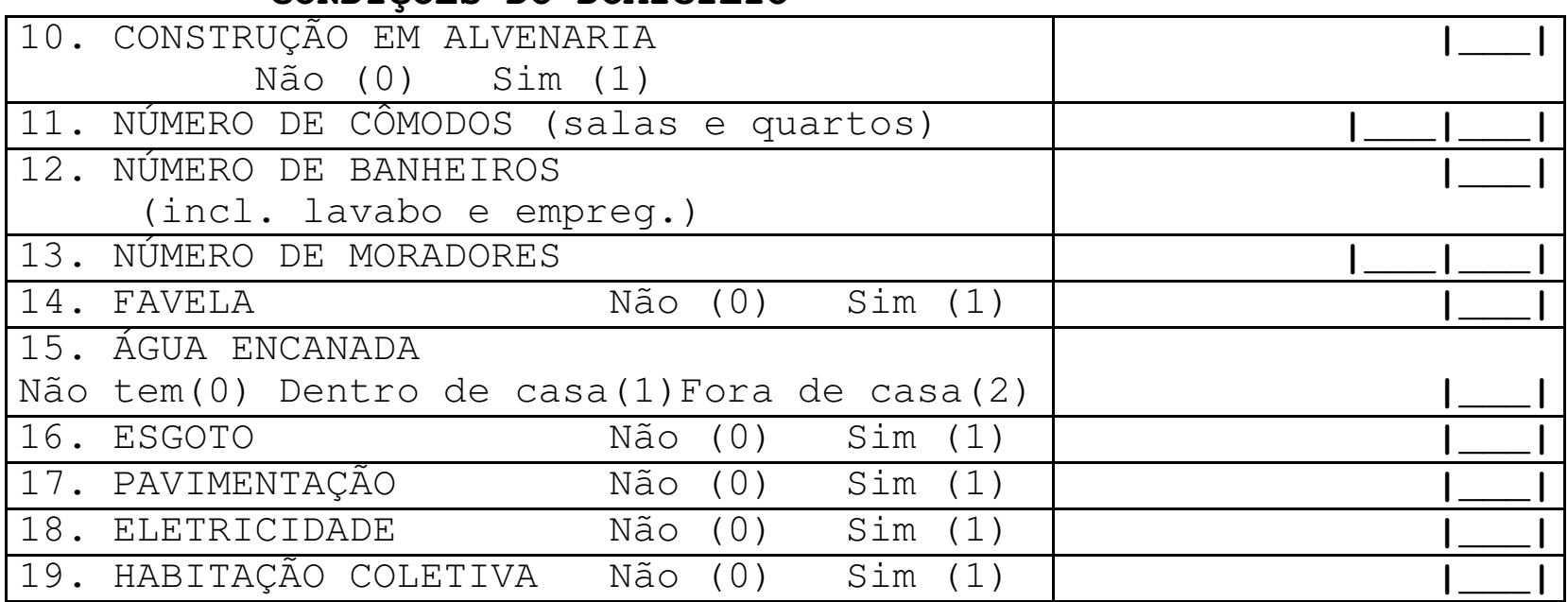

POSSE DE BENS

\begin{tabular}{|c|c|}
\hline 20. NÚMERO DE COMPUTADORES & \\
\hline 21. NÚMERO DE CARROS & \\
\hline 22. NÚMERO DE APARELHOS DE TV & \\
\hline $\begin{array}{l}\text { 23. TEM TV PAGA (NET, TVA)? } \\
\text { Não (0) Sim (1) }\end{array}$ & $I_{-}$ \\
\hline 24. NÚMERO DE TELEFONES/CELULARES (LINHAS) & \\
\hline 25. NÚMERO DE RÁDIOS/SOM & \\
\hline 26. NÚMERO DE VIDEO-CASSETES & $I_{\ldots} 1$ \\
\hline $\begin{array}{c}\text { 27. TEM MÁQ.DE LAVAR ROUPAS? } \\
\text { Não (0) Sim (1) }\end{array}$ & 1 \\
\hline 28. NÚMERO DE GELADEIRAS/FREEZERS & \\
\hline $\begin{array}{l}\text { 29. TEM MÁQ.DE LAVAR LOUÇA? } \\
\text { Não (0) Sim (1) }\end{array}$ & $I_{\ldots} I_{1}$ \\
\hline
\end{tabular}


Anexo 4 - Formulário 3 
FORMULÁRIO 3

\begin{tabular}{|c|c|}
\hline 1. NOME DA MÃE & \\
\hline 2. NOME DA CRIANÇA & \\
\hline 4. $\mathrm{N}^{\circ}$ DO FORMULÁRIO & $1+3 \_1$ \\
\hline 5. $\mathrm{N}^{\circ}$ DA CRIANÇA & -1 \\
\hline 6. DATA & $I_{-}$ \\
\hline 7. ENTREVISTA & \\
\hline 8. ENTREVISTADORA & -1 \\
\hline 9. $\mathrm{N}^{\circ}$ DO REGISTRO HOSPITALAR & -1 \\
\hline 10. IDADE DA CRIANÇA (em dias) & -1 \\
\hline $\begin{array}{ll}\text { 11. HÁBITO DE } & \text { FUMAR } \\
\text { Não(00) } & N^{\circ} \text { de cigarros/dia( ) }\end{array}$ & 1 \\
\hline $\begin{array}{cl}\text { 12. HÁBITO DE BEBER DA MÃE Não(0) } \\
\text { Ocasionalmente (3) } & \text { Semanalmente (2) } \\
\text { Diariamente (1) } & \\
\end{array}$ & 1 \\
\hline CRESCIMENTO / CUIDADOS DE SAÚDE & \\
\hline 13. PESO (gramas) & $I_{\ldots} I_{\ldots} I_{\ldots}$ \\
\hline 14. COMPRIMENTO ( cm) & -1 \\
\hline 15. PERÍMETRO CEFÁLICO ( $\mathrm{cm})$ & -1 \\
\hline 16. PERÍMETRO TORÁCICO $(\mathrm{cm})$ & $1 \ldots$ \\
\hline 17. VACINA BCG Não(000) $\quad$ Sim(DIAS DE IDADE) & -1 \\
\hline 18. VACINA DPT Não(000) $\quad$ Sim(DIAS DE IDADE) & -1 \\
\hline $\begin{array}{l}\text { 19. VACINA SABIN } \\
\text { Não(000) Sim(DIAS DE IDADE) }\end{array}$ & $I_{\ldots} I_{\ldots} I_{\ldots} I_{1}$ \\
\hline $\begin{array}{l}\text { 20. VACINA SARAMPO } \\
\text { Não(000) Sim(DIAS DE IDADE) }\end{array}$ & $I_{\ldots} I_{\ldots} I_{\ldots} I$ \\
\hline $\begin{array}{lccc}\text { 21. HÁ LUGAR DEFINIDO } & \text { PARA O BEBÊE QUANDO SE } \\
\text { ALIMENTA? } & \text { Não(0) } & \text { Sim(1)Qual: } & \\
\end{array}$ & 1 \\
\hline 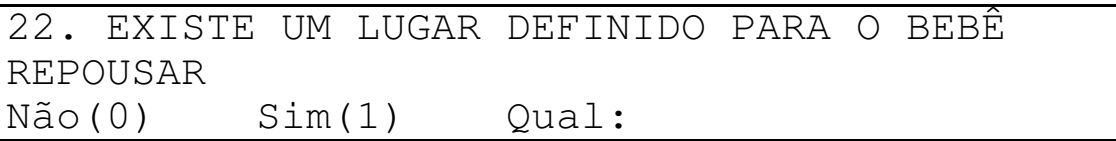 & -1 \\
\hline $\begin{array}{llll}\text { 23. EXISTE UM LUGAR } & \text { DEFINIDO PARA A HIGIENE } \\
\text { DO BEBE } & & & \\
\text { Não(0) } & \text { Sim(1) } & \text { Qual: } & \end{array}$ & 1 \\
\hline $\begin{array}{llllr}\text { 24. EXISTE UM LUGAR DEFINIDO PARA O BEBÊ NO } \\
\text { CONVÍVIO DA FAMÍLIA Não(0) } & \text { Sim(1) } & \text { Qual: } \\
\end{array}$ & 1 \\
\hline $\begin{array}{l}\text { 25. RESPONSÁVEL PELA ALIMENTAÇÃO DA CRIANÇA } \\
\text { Mãe (0) Outro Parente (1) Creche (3) Outros( } 4 \text { ) } \\
\text { Quem? }\end{array}$ & 1 \\
\hline
\end{tabular}


CONSULTAS MÉDICAS

\begin{tabular}{|l|l|}
\hline $\begin{array}{l}\text { 26. NÚMERO DE CONSULTAS MÉDICAS DE ROTINA } \\
\text { (Locais, médicos, endereços, orientações) }\end{array}$ & \\
\hline
\end{tabular}


DESMAME । I । I

\begin{tabular}{|c|c|}
\hline $\begin{array}{l}\text { 28. CONTINUA DANDO SÓ LEITE DE PEITO } \\
\text { Não }(0) \\
\text { Sim }\end{array}$ & $1 \ldots 1$ \\
\hline $\begin{array}{l}\text { 29. CONTINUA DANDO LEITE DE PEITO } \\
\text { Não (0) Sim (1) }\end{array}$ & \\
\hline 30. QUAL ALIMENTO INTRODUZIU PRIMEIRO? & $I_{\ldots} I$ \\
\hline $\begin{array}{l}\text { COMEÇOU A DAR OUTRO (S) ALIMENTO (S) } \\
\text { PORQUE }\end{array}$ & \\
\hline $\begin{array}{l}\text { 31. O LEITE ERA FRACO } \\
\text { Não (0) Sim (1) }\end{array}$ & $I_{\ldots} I_{1}$ \\
\hline 32. NÃO TINHA LEITE $\quad$ Não (0) $\operatorname{Sim}(1)$ & $I_{\ldots} I_{1}$ \\
\hline $\begin{array}{l}\text { 33. O LEITE SECOU } \\
\text { Não (0) Sim (1) }\end{array}$ & 1 \\
\hline $\begin{array}{l}\text { 34. O BEBÊ SENTIA FOME } \\
\begin{array}{ccc}\text { Não } & \text { (0) } & \text { Sim (1) }\end{array}\end{array}$ & 1 \\
\hline $\begin{array}{l}\text { 35. O BEBÊ REJEITAVA O PEITO } \\
\text { Não (0) Sim (1) }\end{array}$ & 1 \\
\hline  & $I_{\ldots} \mathrm{I}$ \\
\hline $\begin{array}{l}\text { 37. O PEITO FICOU MACHUCADO } \\
\text { Não (0) }\end{array}$ & $I_{2} I$ \\
\hline $\begin{array}{l}\text { 38. TINHA DOR AO AMAMENTAR } \\
\text { Não (0) Sim (1) }\end{array}$ & $I_{1} I$ \\
\hline $\begin{aligned} 39 . \text { A MÃE } & \text { FICOU DOENTE } \\
& \text { Não }(0) \quad \operatorname{Sim}(1) \\
& \\
& \text { Dizer a doença. } \ldots \ldots \ldots \ldots \ldots \ldots \ldots \ldots \ldots\end{aligned}$ & 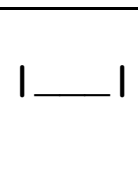 \\
\hline $\begin{array}{l}\text { 40. PRECISOU TRABALHAR } \\
\text { Não }(0) \quad \text { Sim (1) }\end{array}$ & $I_{2} I$ \\
\hline 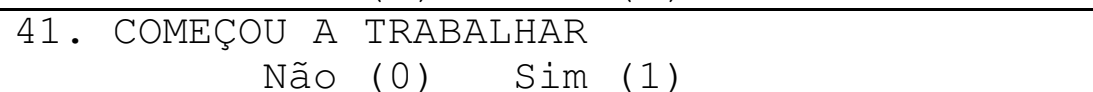 & $I_{2} I$ \\
\hline $\begin{array}{l}\text { 42. VOLTOU A TRABALHAR } \\
\text { Não (0) Sim (1) }\end{array}$ & $I \ldots$ \\
\hline $\begin{array}{c}\text { 43. O BEBÊ FOI PARA A CRECHE } \\
\text { Não (0) } \\
\text { Sim (1) }\end{array}$ & $I_{2} I$ \\
\hline $\begin{array}{l}\text { 44. PRECISOU DEIXAR O BEBÊ COM ALGUÉM } \\
\text { NãO (0) Sim (1) } \\
\text { Quem? }\end{array}$ & 1 \\
\hline $\begin{array}{l}\text { 45. ALGUÉM ORIENTOU A INTRODUÇÃO? } \\
\text { Conta própria (0) Médico (1) Outra (3) } \\
\text { Quem? }\end{array}$ & $\mathrm{I}$ \\
\hline 46. SEDE/CALOR & 1 \\
\hline 47. CÓLICA/PRISÃO DE VENTRE & $1 \ldots$ \\
\hline
\end{tabular}




\begin{tabular}{|c|c|}
\hline OLVIMENTO & \\
\hline (dias de idade) & $I_{2} I_{2} I_{-} I_{1}$ \\
\hline 47. ENGATINHOU (dias de idade) & $I_{1} I_{2}$ \\
\hline 48. ANDOU (dias de idade) & -1 \\
\hline 49. FALOU (dias de idade) & 1 \\
\hline 50. ERUPÇÃO DE DENTE & $I_{2} I_{\ldots} I_{2}$ \\
\hline 51. USA CHUPETA? & -1 \\
\hline
\end{tabular}

\section{MINISTÉRIO DA SAÚDE}

SECRETARIA NACIONAL DE PROGRAMAS ESPECIAIS DE SAÚDE DIVISÃO NACIONAL DE SAÚDE MATERNO-INFANTIL

\section{FICHA DE ACOMPANHAMENTO Nome: DO DESENVOLVIMENTO Registro:}

\begin{tabular}{|c|c|c|c|c|c|c|c|c|c|c|c|}
\hline \multirow{2}{*}{$\begin{array}{c}\text { Época } \\
\text { da Con- } \\
\text { sulta }\end{array}$} & \multirow{2}{*}{ Data de Nascimento } & \multirow{2}{*}{$\begin{array}{c}\text { Marcos do } \\
\text { Desenvolvimento } \\
\text { (Resposta Esperada) }\end{array}$} & \multicolumn{9}{|c|}{ Idade (Meses) } \\
\hline & & & \begin{tabular}{l|l}
1 & 2 \\
\end{tabular} & \begin{tabular}{l|l|l}
2 & 3 & 4 \\
\end{tabular} & & 6 & \begin{tabular}{l|l}
7 & 8 \\
\end{tabular} & & 1 & 12 & \\
\hline \multirow{3}{*}{$\begin{array}{c}1 \\
\text { mês }\end{array}$} & & \begin{tabular}{|l|}
$\begin{array}{l}\text { Abre e fecha os braços em resposta à estimu- } \\
\text { laçâo (Reflexo de Moro). }\end{array}$ \\
\end{tabular} & & & & & & & & & \\
\hline & & $\begin{array}{l}\begin{array}{l}\text { Postura: barriga para cima, pernas e braços fle- } \\
\text { tidos, cabeça lateralizada. }\end{array} \\
\end{array}$ & & & & & & & & & \\
\hline & & Olha para a pessoa que a observa. & & & & & & & & & \\
\hline \multirow{3}{*}{$\stackrel{2}{2}$} & & $\begin{array}{l}\text { Colocada de bruços, levanta a cabeça momenta- } \\
\text { neamente. }\end{array}$ & & & & & & & & & \\
\hline & & Sorri espontaneamente. & & & & & & & & & \\
\hline & & Fixa e acompanha objetos em seu campo visual. & & & & & & & & & \\
\hline \multirow{3}{*}{$\begin{array}{c}4 \\
\text { meses }\end{array}$} & & $\begin{array}{l}\text { Colocada de bruços, levanta e sustenta a cabeça, } \\
\text { apoiando-se no antebraço. }\end{array}$ & & & & & & & & & \\
\hline & & \begin{tabular}{|l|} 
Alcanca e pega objetos pequenos. \\
\end{tabular} & & & & & & & & & \\
\hline & & Emote sons - vocaliza. & & & & & & & & & \\
\hline \multirow{3}{*}{$\begin{array}{c}6 \\
\text { meses }\end{array}$} & & I evantada pelos hrassos, jajuda com a sorps. & & & & & & & & & \\
\hline & & $\begin{array}{l}\text { Segura e transfere objetos de uma mäo para } \\
\text { outra. }\end{array}$ & & & & & & & & & \\
\hline & & $\begin{array}{l}\text { Vira a cabesa na diresáa de uma voz ou objeto } \\
\text { sonoro. }\end{array}$ & & & & & & & & & \\
\hline \multirow{3}{*}{$\underset{\text { meses }}{9}$} & & Senta-se sem apoio. & & & & & & & & & \\
\hline & & Arrasta-se ou engatinha. & & & & & & & & & \\
\hline & & $\begin{array}{l}\text { Responde diferentemente a pessoas familiares e } \\
\text { estranhas. }\end{array}$ & & & & & & & & & \\
\hline \multirow{3}{*}{$\begin{array}{c}12 \\
\text { meses }\end{array}$} & & Anda com apoio. & & & & & & & & & \\
\hline & & $\begin{array}{l}\text { Faz gestos com a mão e cabeça (de tchau, de } \\
\text { não; bate palmas, etc.). }\end{array}$ & & & & & & & & & \\
\hline & & Emprega pelo menos 1 palavra com sentido. & & & & & & & & & \\
\hline \multirow{2}{*}{$\begin{array}{l}\text { Epoca } \\
\text { da Con- } \\
\text { sulta }\end{array}$} & & \multirow{2}{*}{$\begin{array}{c}\text { Marcos do } \\
\text { Desenvolvimento } \\
\text { (Resposta Esperada) }\end{array}$} & \multicolumn{4}{|c|}{ Idade (Meses) } & \multicolumn{5}{|c|}{ Idade (Anos) } \\
\hline & & & \begin{tabular}{|l|l|}
11 & 14 \\
\end{tabular} & 415 & 18 & 21 & 2 & 3 & 4 & & 6 \\
\hline \multirow{3}{*}{$\begin{array}{c}18 \\
\text { meses }\end{array}$} & & Anda sozinha; raramente cai. & & & & & & & & & \\
\hline & & Combina pelo menos 2 palavras. & & & & & & & & & \\
\hline & & Tira qualquer peça do vestuário. & & & & & & & & & \\
\hline
\end{tabular}


Anexo 5 - Questionário recordatório 




CONDIÇÕES SÓCIO-ECONÔMICAS

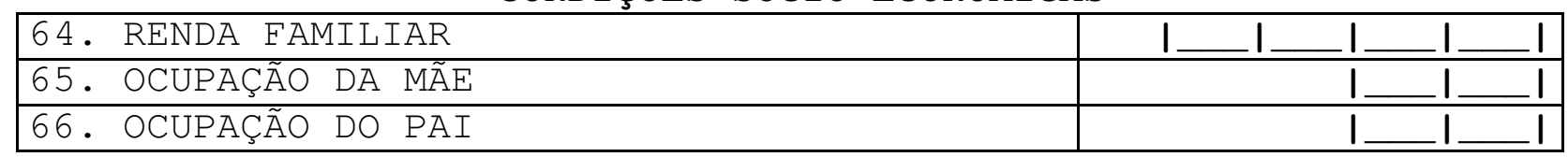


Anexo 6 - Caderno diário 
Anexo 7 - Escolha dos modelos 
Modelo: Cox; fonte de informação: caderno diário

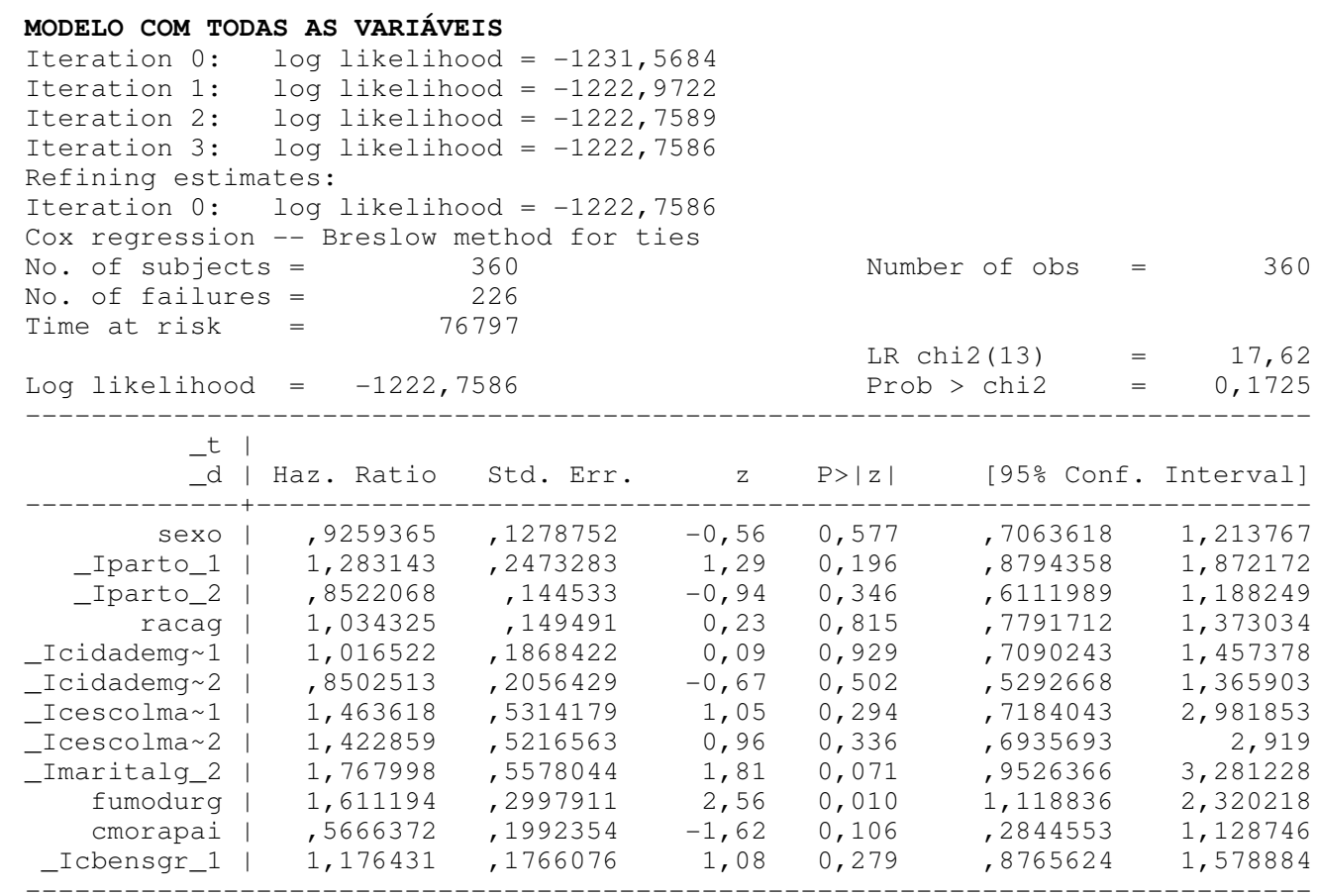

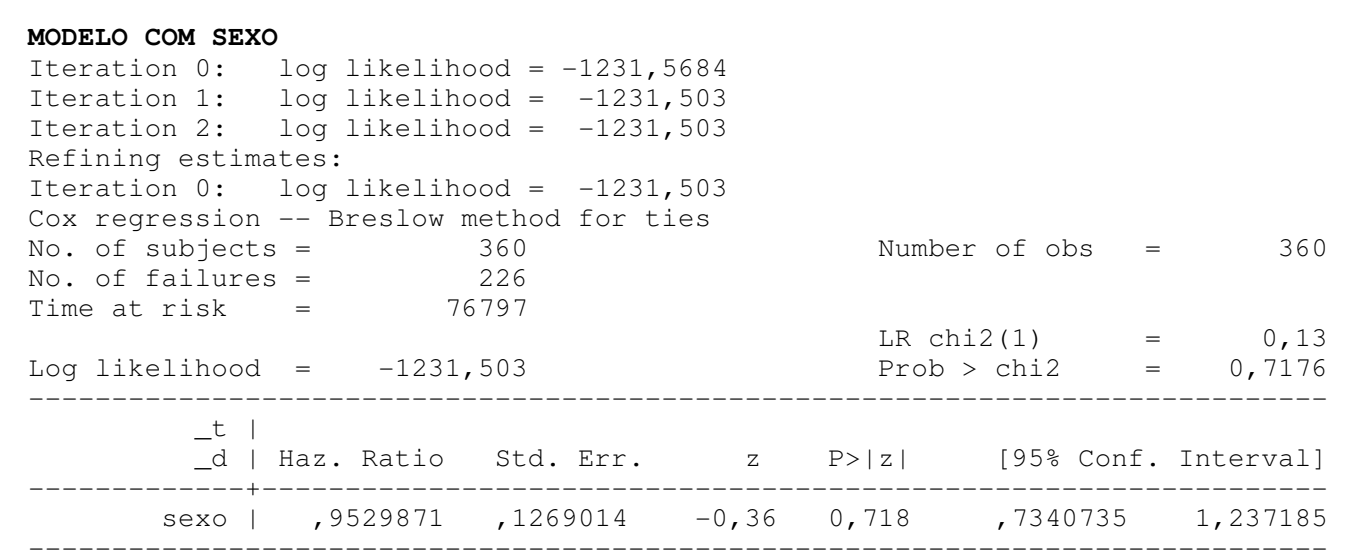

\section{MODELO COM TIPO DE PARTO}

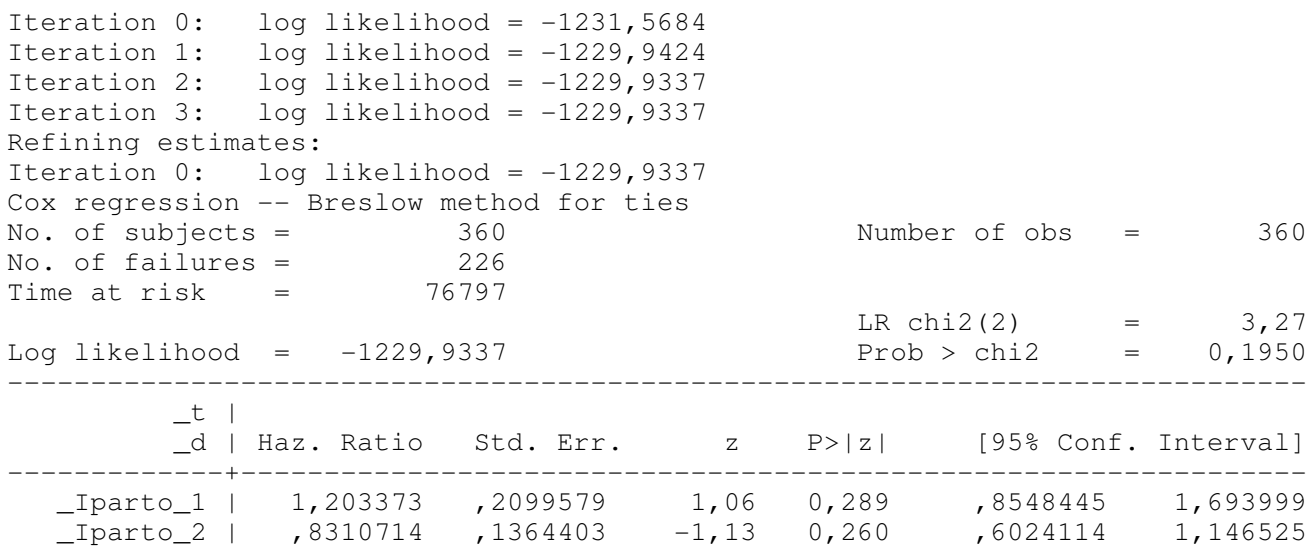




\section{MODELO COM RAÇA}

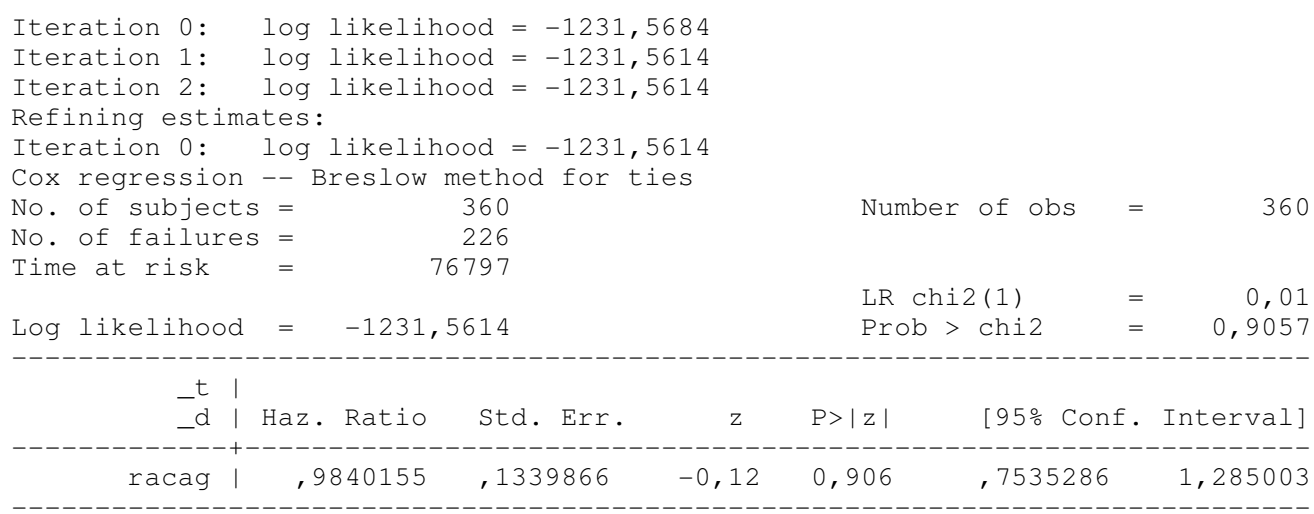

\section{MODELO COM IDADE DA MÃE}

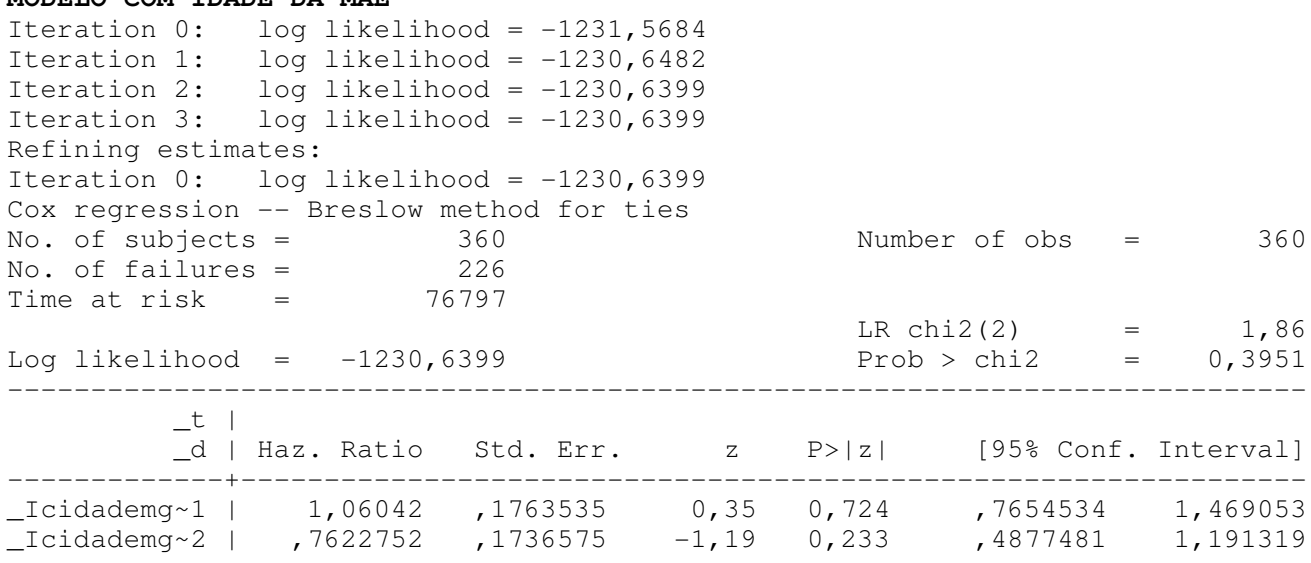

\section{MODELO COM ESCOLARIDADE DA MÃE}

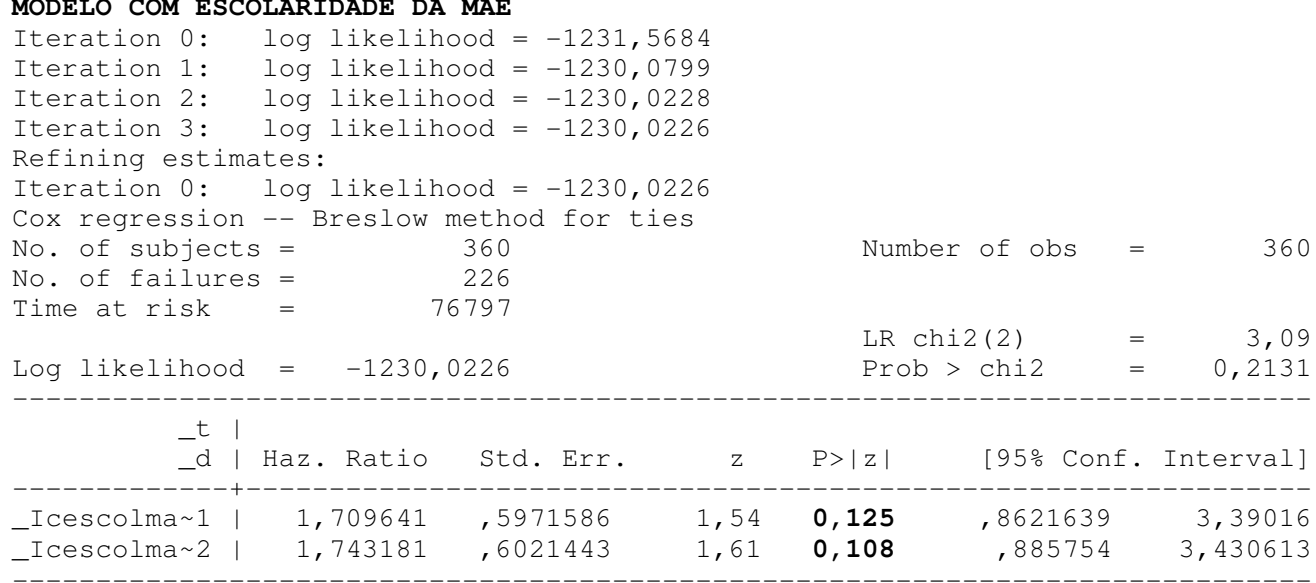

A variável ESCOLARIDADE DA MÃE deve ser selecionada. 
MODELO COM CONDIÇÃO MARITAL DA MÃE

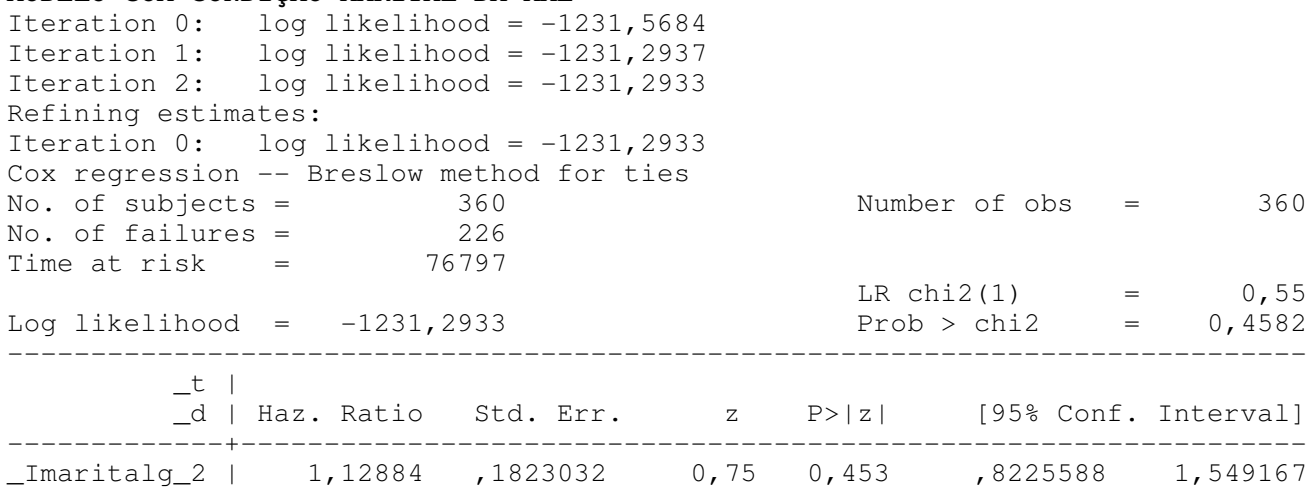

MODELO COM HÁBITO DE FUMAR DA MÃE



A variável HÁBITO DE FUMAR deve ser selecionada.

MODELO COM MORAR O PAI DA CRIANÇA COM A MÃE

Iteration 0: log likelihood $=-1231,5684$

Iteration 1: $\log$ likelihood $=-1231,568$

Iteration 2: $\log$ likelihood $=-1231,568$

Refining estimates:

Iteration 0: $\log$ likelihood $=-1231,568$

Cox regression -- Breslow method for ties

No. of subjects $=\quad 360 \quad$ Number of obs $=360$

No. of failures $=\quad 226$

Time at risk $=76797$

$\begin{array}{llr}\text { Log likelihood = } \quad-1231,568 & \text { LR chi2(1) } & 0,00 \\ & \text { Prob }>\text { chi2 } & =, 9774\end{array}$

- t |
d I Haz. Ratio Std. Err. $\quad$ z


MODELO COM POSSE DE BENS

$\begin{array}{lll}\text { Iteration } 0: & \log \text { likelihood }=-1231,5684 \\ \text { Iteration 1: } & \text { log likelihood }=-1230,7376\end{array}$

Iteration 2: $\quad \log$ likelihood $=-1230,7373$

Refining estimates:

Iteration 0: log likelihood $=-1230,7373$

Cox regression -- Breslow method for ties

$\begin{array}{lll}\text { No. of subjects }= & 360 & \text { Number of obs }= \\ \text { No. of failures }= & 226 & \end{array}$

Time at risk $=\quad 76797$

Log likelihood = -1230,7373 $\begin{array}{ll}\text { LR chi2 }(1) & 1,66 \\ \text { Prob }>\text { chi2 } & =0,1973\end{array}$

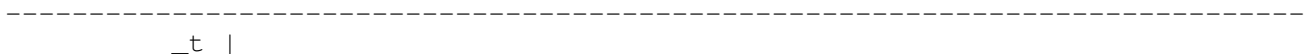

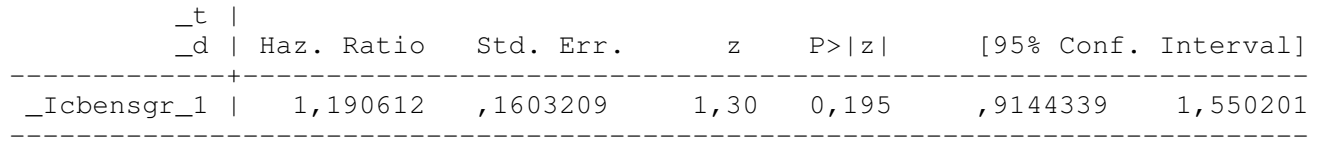

MODELO COM AS VARIÁVEIS SELECIONADAS - ESCOLARIDADE DA MÃE E HÁBITO DE FUMAR

Iteration 0: $\quad \log$ likelihood $=-1231,5684$

Iteration 1: $\quad \log$ likelihood $=-1227,6362$

Iteration 2: $\quad \log$ likelihood $=-1227,4877$

Iteration 3: $\quad$ log likelihood $=-1227,4876$

Refining estimates:

Iteration 0: $\quad$ log likelihood $=-1227,4876$

Cox regression -- Breslow method for ties

No. of subjects $=\quad \begin{array}{cc}360 & \text { Number of obs }=\end{array}$

No. of failures $=\quad 226$

Time at risk $=76797$

$\begin{array}{lll}\text { Log likelihood }=-1227,4876 & \text { LR chi2(3) } & =8,16 \\ \text { Prob }>\text { chi2 } & =0,0428\end{array}$

- t
$-d$

MODELO COM HÁBITO DE FUMAR

Iteration 0: log likelihood $=-1231,5684$

Iteration 1: $\quad \log$ likelihood $=-1228,7519$

Iteration 2: $\quad$ log likelihood $=-1228,6491$

Iteration 3: $\quad \log$ likelihood $=-1228,649$

Refining estimates:

Iteration 0: log likelihood $=-1228,649$

Cox regression -- Breslow method for ties

$\begin{array}{ccc}\text { No. of subjects }= & 360 & \text { Number of obs } \\ \text { No. of failures }= & 226 & \end{array}$

Time at risk = 76797

Log likelihood = -1228,649 $\begin{array}{ll}\text { LR chi2 }(1) & 5,84 \\ \text { Prob }>\text { chi2 } & =0,0157\end{array}$

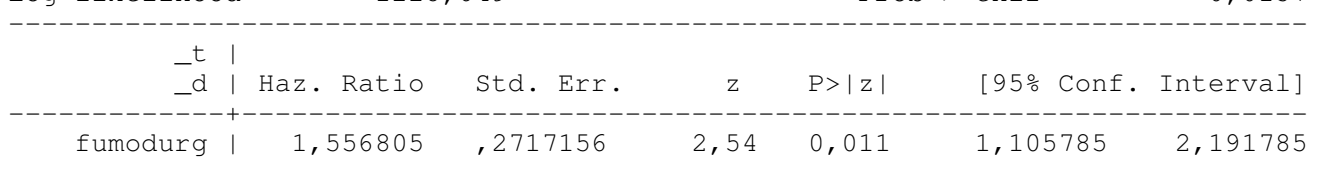

O TESTE DA RAZÃO DE VEROSSIMILHANÇAS, A PARTIR DOS DOIS MODELOS ANTERIORES, INDICA A SAÍDA DA VARIÁVEL ESCOLARIDADE DA MÃE.

$\operatorname{chi2}(2)=2,32$

Prob $>$ chi2 $=0,3131$

DESSA FORMA, O MODELO FINAL FOI O QUE CONTÉM SOMENTE HÁBITO DE FUMAR DA MÃE. 
Modelo: complemento log-log; fonte de informação: caderno diário

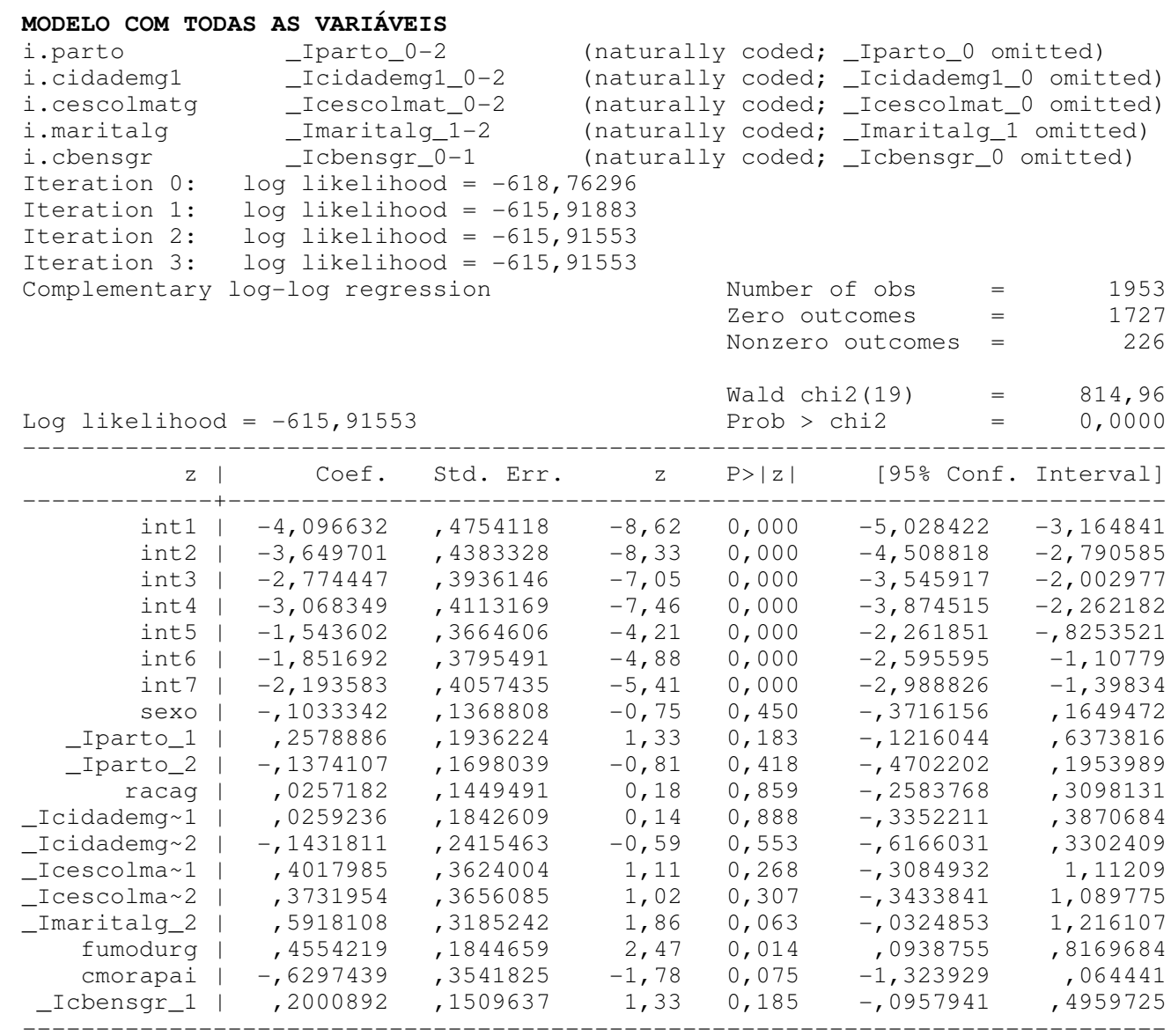

\section{MODELO COM SEXO}

$\begin{array}{lll}\text { Iteration } 0: & \text { log likelihood }=-626,80656 \\ \text { Iteration 1: } & \text { log likelihood }=-624,55677 \\ \text { Iteration 2: } & \text { log likelihood }=-624,55262 \\ \text { Iteration 3: } & \text { log likelihood }=-624,55262\end{array}$

Complementary log-log regression

$\begin{array}{llr}\text { Number of obs } & = & 1953 \\ \text { Zero outcomes } & = & 1727 \\ \text { Nonzero outcomes } & = & 226 \\ \text { Wald chi2(8) } & = & 828,41 \\ \text { Prob chi2 } & = & 0,0000\end{array}$

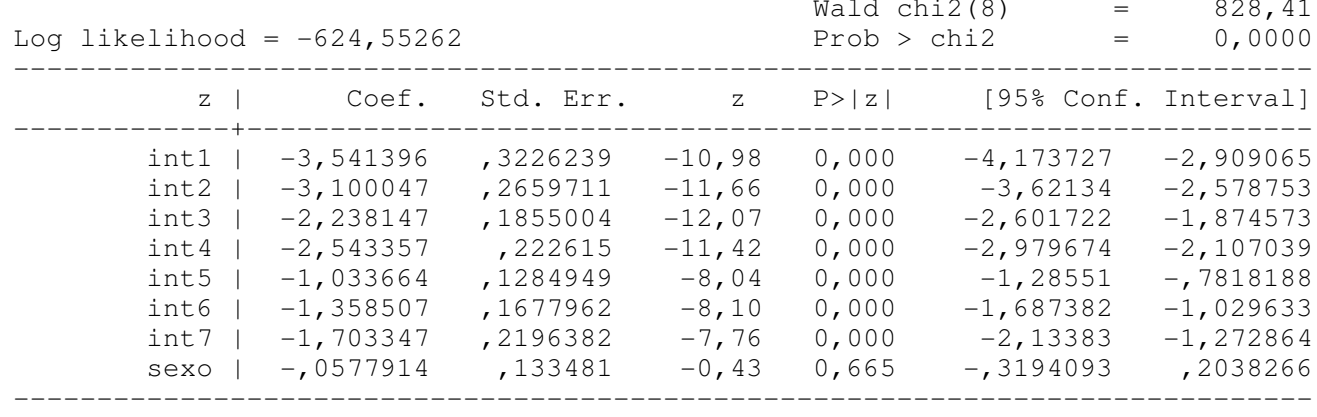


MODELO COM TIPO DE PARTO

Iteration 0: $\log$ likelihood $=-625,50415$

Iteration 1: $\quad \log$ likelihood $=-623,06839$

Iteration 2: $\quad$ log likelihood $=-623,06463$

Iteration 3: log likelihood $=-623,06463$

Complementary log-log regression

Number of obs $=1953$

$\begin{array}{llr}\text { Zero outcomes } & = & 1727 \\ \text { Nonzero outcomes } & = & 226\end{array}$

Wald $\operatorname{chi2}(9)=826,14$

Log likelihood $=-623,06463 \quad$ Prob $>$ chi2 $=0,0000$

$\begin{array}{rrrrrrr}z & \text { l } & \text { Coef. } & \text { Std. Err. } & z & \text { P }>|z| & \text { [95\% Conf. Interval] } \\ \text { int1 | } & -3,562436 & , 321732 & -11,07 & 0,000 & -4,193019 & -2,931853 \\ \text { int2 | } & -3,11887 & , 2647002 & -11,78 & 0,000 & -3,637673 & -2,600067 \\ \text { int3 | } & -2,255987 & , 1833948 & -12,30 & 0,000 & -2,615435 & -1,89654 \\ \text { int4 | } & -2,561054 & , 2205733 & -11,61 & 0,000 & -2,99337 & -2,128739 \\ \text { int5 } & -1,052264 & , 1248175 & -8,43 & 0,000 & -1,296902 & -, 807626 \\ \text { int6 } & -1,376832 & , 1649613 & -8,35 & 0,000 & -1,700151 & -1,053514 \\ \text { int7 } & -1,716642 & , 21801 & -7,87 & 0,000 & -2,143934 & -1,28935 \\ \text {-Iparto_1 } & , 190503 & , 1749099 & 1,09 & 0,276 & -, 1523141 & , 5333202 \\ \text {-Iparto_2 } & -, 1757055 & , 1645259 & -1,07 & 0,286 & -, 4981702 & , 1467593\end{array}$

\section{MODELO COM RAÇA}

Iteration 0: log likelihood $=-626,89311$

Iteration 1: log likelihood $=-624,64426$

Iteration 2: $\quad$ log likelihood $=-624,64011$

Iteration 3: $\quad \log$ likelihood $=-624,64011$

Complementary log-log regression

Number of obs=

Zero outcomes $=\quad 1727$

Nonzero outcomes $=226$

Wald chi2(8) $=828,55$

Log likelihood $=-624,64011 \quad$ Prob $>$ chi2 $=0,0000$

\begin{tabular}{r|rrrrrr} 
z l & \multicolumn{1}{c}{ Coef. } & Std. Err. & z & P $>|z|$ & [95\% Conf. Interval] \\
int1 | & $-3,563317$ &, 3209284 & $-11,10$ & 0,000 & $-4,192325$ & $-2,934308$ \\
int2 | & $-3,122022$ &, 2637409 & $-11,84$ & 0,000 & $-3,63894$ & $-2,605099$ \\
int3 | & $-2,260272$ &, 1819995 & $-12,42$ & 0,000 & $-2,616985$ & $-1,90356$ \\
int4 | & $-2,565462$ &, 2197541 & $-11,67$ & 0,000 & $-2,996172$ & $-2,134752$ \\
int5 & $-1,055578$ &, 1238228 & $-8,52$ & 0,000 & $-1,298266$ &,- 81289 \\
int6 | & $-1,380914$ &, 1640308 & $-8,42$ & 0,000 & $-1,702409$ & $-1,05942$ \\
int7 | & $-1,727098$ &, 2159017 & $-8,00$ & 0,000 & $-2,150257$ & $-1,303938$ \\
racag | &,- 0152844 &, 1364828 & $-0,11$ & 0,911 &,- 2827858 &, 252217
\end{tabular}

\section{MODELO COM IDADE DA MÃE}

Iteration 0: log likelihood $=-625,98904$

Iteration 1: $\quad \log$ likelihood $=-623,68655$

Iteration 2: $\log$ likelihood $=-623,68248$

Iteration 3: $\log l$ ikelihood $=-623,68248$

Complementary log-log regression

$\begin{array}{llr}\text { Number of obs } & = & 1953 \\ \text { Zero outcomes } & = & 1727 \\ \text { Nonzero outcomes } & = & 226 \\ \text { Wald chi2(9) } & = & 827,00 \\ \text { Prob }>\text { chi2 } & = & 0,0000\end{array}$

Log likelihood $=-623,68248$

[95\% Conf. Interval]




MODELO COM ESCOLARIDADE DA MÃE

\begin{tabular}{|c|c|c|c|c|c|c|c|}
\hline teration & ] & & & & & & \\
\hline teration 0: & $\log$ likelih & $=-$ & & & & & \\
\hline teration 1: & $\log$ likelit & od $=-623$, & 003 & & & & \\
\hline teration 2: & log likelit & $o d=-623$, & 588 & & & & \\
\hline teration 3: & log likelit & od $=-623$, & 88 & & & & \\
\hline omplementary & $\log -\log r e g$ & ssion & & Numbe & f obs & $=$ & 1953 \\
\hline & & & & Zero & comes & $=$ & 1727 \\
\hline & & & & Nonze & outcomes & $=$ & 226 \\
\hline & & & & Wald & $2(9)$ & $=$ & 825,91 \\
\hline lihood & $=-623,08$ & & & Prob & hi2 & $=$ & 0,0000 \\
\hline $\mathrm{z}$ & Coef & Std. Err. & z & $\mathrm{P}>|\mathrm{z}|$ & {$[95 \% \mathrm{Cc}$} & inf. & Interval] \\
\hline int 1 & $-4,097919$ &, 4574155 & $-8,96$ & 0,000 & $-4,99443$ & & $-3,201401$ \\
\hline int2 & $-3,655624$ & , 4191015 & $-8,72$ & 0,000 & $-4,4770$ & & $-2,8342$ \\
\hline int 3 & $-2,792721$ & 3727838 & $-7,49$ & 0,000 & $-3,52336$ & & $-2,062078$ \\
\hline int 4 & $-3,096127$ & , 3918683 & $-7,90$ & 0,000 & $-3,8641$ & & $-2,328079$ \\
\hline int 5 & $-1,582051$ &, 3453158 & $-4,58$ & 0,000 & $-2,25885$ & &,- 9052445 \\
\hline int 6 & $-1,902503$ &, 3593481 & $-5,29$ & 0,000 & $-2,60681$ & & $-1,198194$ \\
\hline int 7 & $-2,248988$ & 3856996 & $-5,83$ & 0,000 & $-3,0049$ & & $-1,493031$ \\
\hline $\operatorname{lma} 1$ &, 5378555 &, 3496178 & 1,54 & 0,124 &,- 147382 & & 1,223094 \\
\hline $\operatorname{lma} 2$ &, 5592154 &, 345735 & 1,62 & 0,106 &,- 118412 & & 1,236844 \\
\hline
\end{tabular}

A variável ESCOLARIDADE DA MÃE deve ser selecionada.

\section{MODELO COM CONDIÇÃO MARITAL DA MÃE}

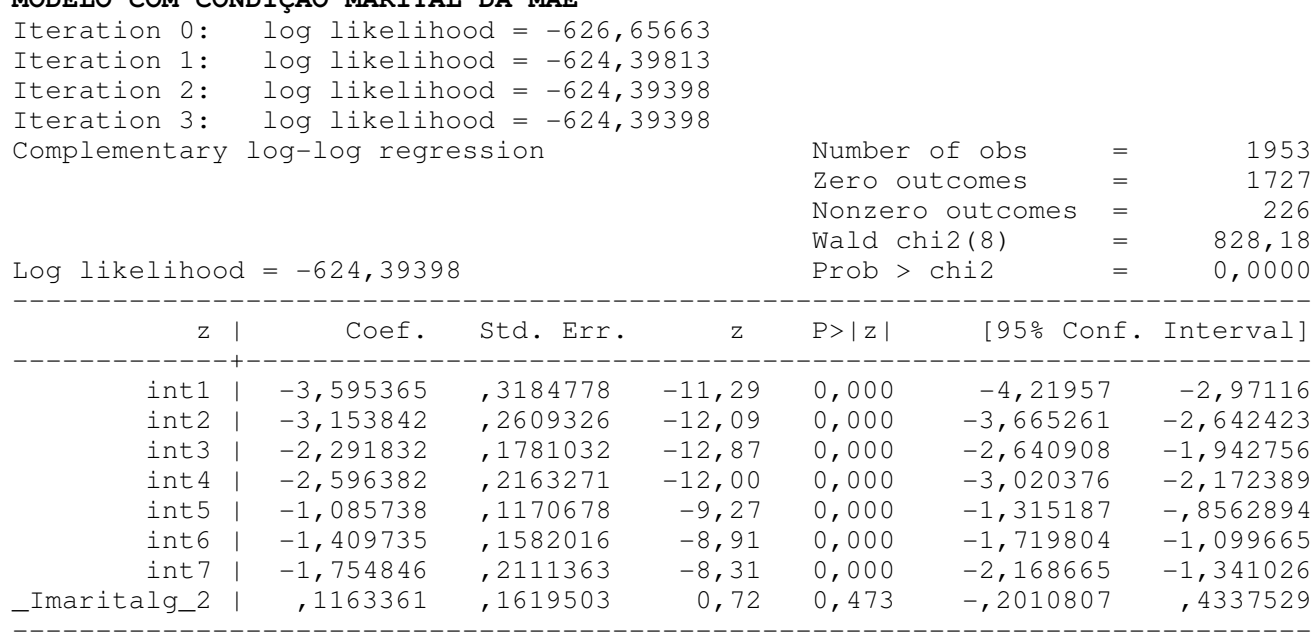

\section{MODELO COM HÁBITO DE FUMAR DA MÃE}

\section{Iteration 0: log likelihood $=-624,20787$ \\ Iteration 1: $\quad \log$ likelihood $=-621,70772$ \\ Iteration 2: log likelihood $=-621,70397$ \\ Iteration 3: $\quad$ log likelihood $=-621,70397$ \\ Complementary log-log regression}

$\begin{array}{llr}\text { Number of obs } & = & 1953 \\ \text { Zero outcomes } & = & 1727 \\ \text { Nonzero outcomes } & = & 226 \\ & & \\ \text { Wald chi2(8) } & = & 824,38 \\ \text { Prob }>\text { chi2 } & = & 0,0000\end{array}$

Log likelihood $=-621,70397$

\begin{tabular}{|c|c|c|c|c|c|c|}
\hline $\mathrm{z}$ & Coef. & Std. Err. & $\mathrm{z}$ & $P>|z|$ & [95\% Conf. & Interval] \\
\hline int 1 & $-3,652182$ &, 3185916 & $-11,46$ & 0,000 & $-4,27661$ & $-3,027754$ \\
\hline int 2 & $-3,20756$ &, 2608947 & $-12,29$ & 0,000 & $-3,718904$ & $-2,696216$ \\
\hline int 3 & $-2,336596$ &, 1772878 & $-13,18$ & 0,000 & $-2,684074$ & $-1,989118$ \\
\hline int 4 & $-2,636525$ &, 2154507 & $-12,24$ & 0,000 & $-3,058801$ & $-2,21425$ \\
\hline int 5 & $-1,123037$ &, 1153724 & $-9,73$ & 0,000 & $-1,349163$ &,- 8969117 \\
\hline int 6 & $-1,448251$ &, 1573743 & $-9,20$ & 0,000 & $-1,756699$ & $-1,139803$ \\
\hline int 7 & $-1,799919$ &, 2111242 & $-8,53$ & 0,000 & $-2,213715$ & $-1,386123$ \\
\hline fumodurg &, 445765 &, 1751304 & 2,55 & 0,011 &, 1025156 &, 7890143 \\
\hline
\end{tabular}

A variável HÁBITO DE FUMAR deve ser selecionada. 
MODELO COM MORAR O PAI DA CRIANÇA COM A MÃE

Iteration 0: log likelihood $=-626,89798$

Iteration 1: $\quad \log$ likelihood $=-624,65055$

Iteration 2: $\quad$ log likelihood $=-624,64639$

Iteration 3: $\quad \log$ likelihood $=-624,64639$

complementary log-log regression

Number of obs $=1953$

Zero outcomes $=1727$

Nonzero outcomes $=226$

$\begin{array}{llll} & \text { Wald chi2 }(8) & = & 828,56 \\ \text { Log likelihood }=-624,64639 & \text { Prob }>\text { chi2 } & = & 0,0000\end{array}$

\begin{tabular}{rrrrrrr} 
z | & Coef. & Std. Err. & $z$ & P $>|z|$ & {$[95 \%$ Conf. Interval] } \\
int1 | & $-3,569403$ &, 3178086 & $-11,23$ & 0,000 & $-4,192297$ & $-2,94651$ \\
int2 | & $-3,127999$ &, 2600931 & $-12,03$ & 0,000 & $-3,637772$ & $-2,618226$ \\
int3 | & $-2,266158$ &, 1768462 & $-12,81$ & 0,000 & $-2,61277$ & $-1,919546$ \\
int4 I & $-2,571371$ &, 2153985 & $-11,94$ & 0,000 & $-2,993544$ & $-2,149197$ \\
int5 | & $-1,061536$ &, 1157793 & $-9,17$ & 0,000 & $-1,288459$ &,- 8346129 \\
int6 | & $-1,386987$ &, 1576325 & $-8,80$ & 0,000 & $-1,695941$ & $-1,078033$ \\
int7 | & $-1,733223$ &, 2108147 & $-8,22$ & 0,000 & $-2,146413$ & $-1,320034$ \\
cmorapai | &,- 0003533 &, 1764757 & $-0,00$ & 0,998 &,- 3462393 &, 3455327 \\
\hline
\end{tabular}

\section{MODELO COM POSSE DE BENS}

Iteration 0: log likelihood $=-625,87363$

Iteration 1: log likelihood $=-623,60206$

Iteration 2: log likelihood $=-623,59789$

Iteration 3: log likelihood $=-623,59789$

Complementary log-log regression

\begin{tabular}{|c|c|c|c|}
\hline & \multicolumn{2}{|c|}{ Number of obs } \\
\hline \multirow{2}{*}{\multicolumn{2}{|c|}{$\begin{array}{l}\text { Zero outcomes } \\
\text { Nonzero outcomes }\end{array}$}} & & 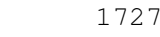 \\
\hline & & $=$ & \\
\hline \multirow{2}{*}{\multicolumn{2}{|c|}{$\begin{array}{l}\text { Wald chi2 }(8) \\
\text { Prob > chi2 }\end{array}$}} & $=$ & \\
\hline & & $=$ & \\
\hline \multicolumn{4}{|c|}{$\mathrm{P}>|\mathrm{z}| \quad[95 \%$ Conf. Interval } \\
\hline 0,000 & $-4,28419$ & & -3 , \\
\hline 0,000 & $-3,73156$ & & $-2,691$ \\
\hline 0,000 & $-2,7081$ & & $-1,987$ \\
\hline 0,000 & $-3,08523$ & & $-2,21$ \\
\hline 0,000 & $-1,38604$ & &,- 8943 \\
\hline 0,000 & $-1,78325$ & & $-1,14$ \\
\hline 0,000 & $-2,23281$ & & $-1,38$ \\
\hline 0,145 &,- 068000 & &, 461 \\
\hline
\end{tabular}

A variável POSSE DE BENS deve ser selecionada. 


\section{MODELO CON DE BENS \\ Iteration 0: $\quad$ log likelihood $=-622,51522$ \\ Iteration 1: log likelihood $=-619,96156$ \\ Iteration 2: $\log$ likelihood $=-619,95782$ \\ Iteration 3: $\log$ likelihood $=-619,95782$ \\ Complementary log-log regression}

Log likelihood $=-619,95782$

\begin{tabular}{|c|c|c|c|c|c|c|c|}
\hline $\mathrm{z}$ & & Coef. & Std. Err. & z & $P>|z|$ & [95\% Conf. & Interval] \\
\hline int 1 & i & $-4,115862$ & 4576238 & $-8,99$ & 0,000 & $-5,012788$ & $-3,218936$ \\
\hline int 2 & | & $-3,671124$ &, 4192995 & $-8,76$ & 0,000 & $-4,492936$ & $-2,84931$ \\
\hline int3 & | & $-2,798192$ &, 3728669 & $-7,50$ & 0,000 & $-3,528998$ & $-2,06738$ \\
\hline int 4 & | & $-3,096384$ &, 3918832 & $-7,90$ & 0,000 & $-3,864461$ & $-2,32830$ \\
\hline int 5 & i & $-1,579211$ &, 3452992 & $-4,57$ & 0,000 & $-2,255985$ &,- 9024371 \\
\hline int 6 & | & $-1,897784$ &, 359301 & $-5,28$ & 0,000 & $-2,602001$ & $-1,193567$ \\
\hline int 7 & i & $-2,249237$ &, 3857162 & $-5,83$ & 0,000 & $-3,005227$ & $-1,49324$ \\
\hline _Icescolma 1 & 1 &, 4468205 &, 3525151 & 1,27 & 0,205 &,- 2440964 & 1,13773 \\
\hline Icescolma 2 & i &, 4011505 & 3574412 & 1,12 & 0,262 &,- 2994215 & 1,101722 \\
\hline fumodurg & i & 4108512 &, 1763511 & 2,33 & 0,020 &, 0652095 &, 7564929 \\
\hline Icbensgr_1 & | &, 1560069 &, 1449432 & 1,08 & 0,282 &,- 1280765 &, 440090 \\
\hline
\end{tabular}

MODELO COM ESCOLARIDADE DA MÃE, HÁBITO DE FUMAR

$\begin{array}{lll}\text { Iteration } 0: & \log \text { likelihood }=-623,07639 \\ \text { Iteration 1: } & \log \text { likelihood }=-620,53806 \\ \text { Iteration 2: } & \log \text { likelihood }=-620,53431 \\ \text { Iteration 3: } & \log \text { likelihood }=-620,53431\end{array}$

Complementary log-log regression

$\begin{array}{llr}\text { Number of obs } & = & 1953 \\ \text { Zero outcomes } & = & 1727 \\ \text { Nonzero outcomes } & = & 226 \\ \text { Wald chi2(10) } & = & 822,36 \\ \text { Prob }>\text { chi2 } & = & 0,0000\end{array}$

Log likelihood $=-620,53431$

Number of obs $\quad=\quad 1953$

Zero outcomes = 1727

Nonzero outcomes $=226$

$\begin{array}{lll}\text { Wald chi2 }(11) & = & 821,51 \\ \text { Prob }>\operatorname{chi2} & = & 0,0000\end{array}$ 


\section{MODELO COM HABITO DE FUMAR}

Iteration 0: log likelihood $=-624,20787$

Iteration 1: $\quad$ log likelihood $=-621,70772$

Iteration 2: $\quad$ log likelihood $=-621,70397$

Iteration 3: $\log$ likelihood $=-621,70397$

Complementary log-log regression

$\begin{array}{llr}\text { Number of obs } & = & 1953 \\ \text { Zero outcomes } & = & 1727 \\ \text { Nonzero outcomes } & = & 226 \\ \text { Wald chi2(8) } & = & 824,38 \\ \text { Prob }>\text { chi2 } & = & 0,0000\end{array}$

Log likelihood $=-621,70397$ [95\% Conf. Interval]

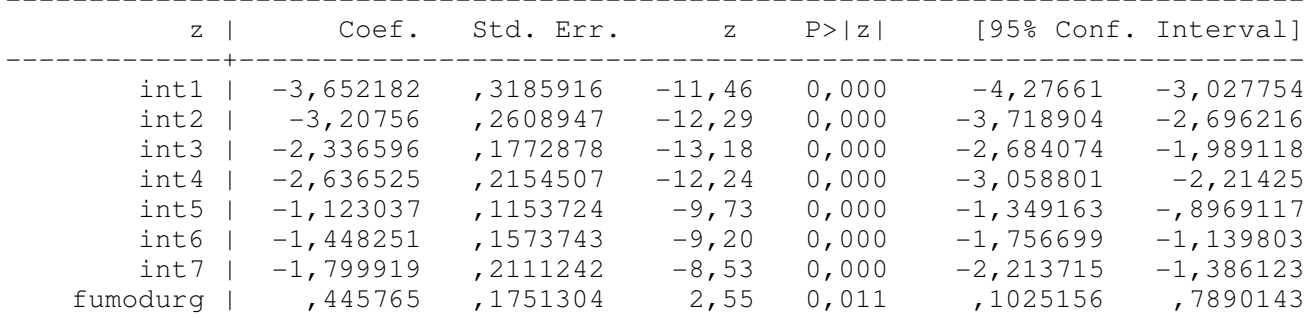

O TESTE DA RAZÃO DE VEROSSIMILHANÇAS, A PARTIR DOS DOIS MODELOS ANTERIORES (UM COM ESCOLARIDADE DA MÃE E HÁBITO DE FUMAR; E O OUTRO MODELO COM HÁBITO DE FUMAR), INDICA A SAÍdA DA VARIÁVEL ESCOLARIDADE DA MÃE.
$\operatorname{chi2}(1)$
2,34
Prob $>$ chi2 $=$
0,3105

DESSA FORMA, O MODELO FINAL É O QUE CONTÉM SOMENTE HÁBITO DE FUMAR DA MÃE. 
Modelo: Cox; fonte de informação: recordatório de 12 meses



MODELO COM SEXO

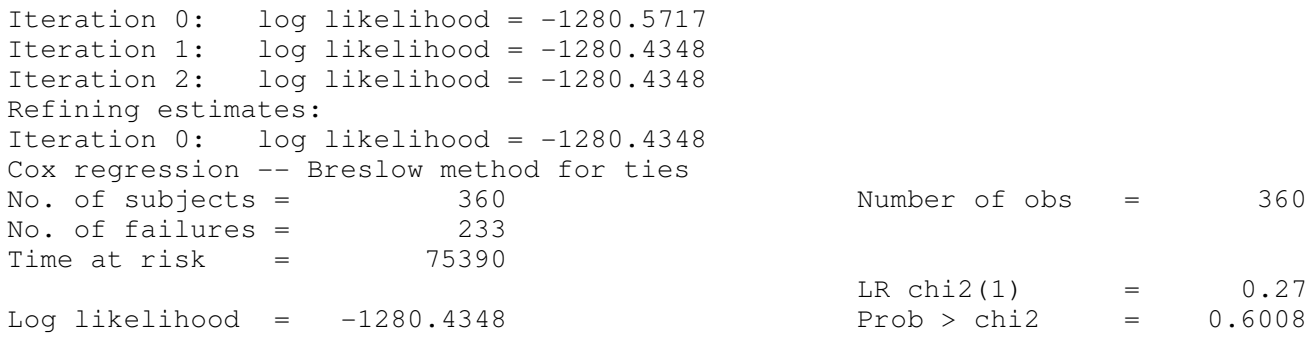

\begin{tabular}{|c|c|c|c|c|c|c|}
\hline \begin{tabular}{l|l}
$-t$ & $\mid$ \\
$-d$ & $\mid$
\end{tabular} & Haz. Ratio & Std. Err. & $\mathrm{z}$ & $P>|z|$ & [95\% Conf. & Interval] \\
\hline sexo & .9337052 & .1224438 & -0.52 & 0.601 & .72208 & 1.207353 \\
\hline
\end{tabular}

MODELO COM TIPO DE PARTO

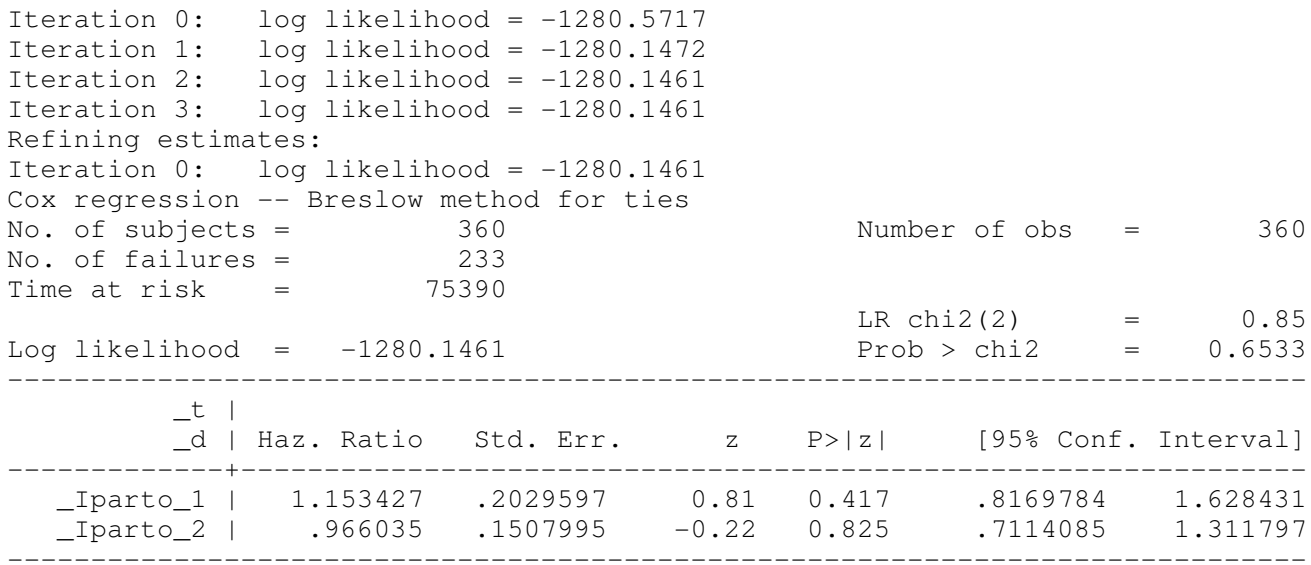




\section{MODELO COM RAÇA}

Iteration 0: $\quad \log$ likelihood $=-1280.5717$

Iteration 1: $\quad \log$ likelihood $=-1280.4677$

Iteration 2: $\quad$ log likelihood $=-1280.4677$

Refining estimates:

Iteration 0: log likelihood $=-1280.4677$

Cox regression -- Breslow method for ties

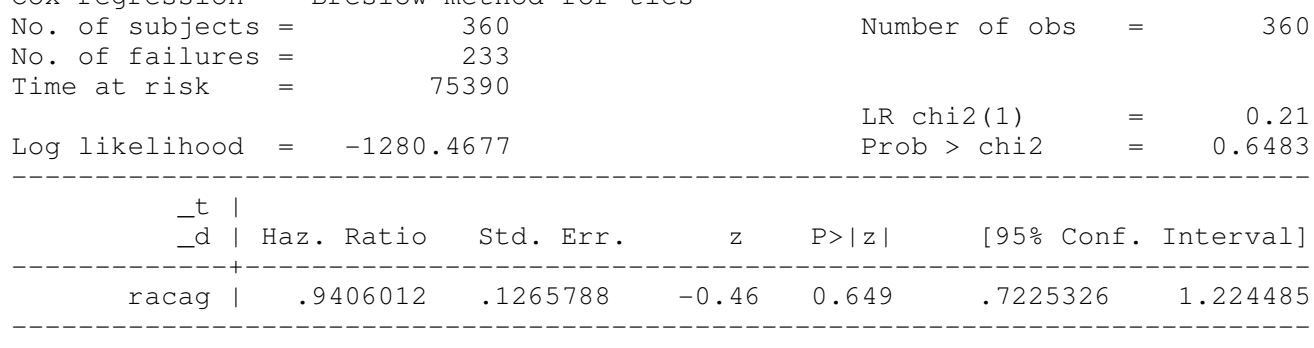

\section{MODELO COM IDADE DA MÃE}

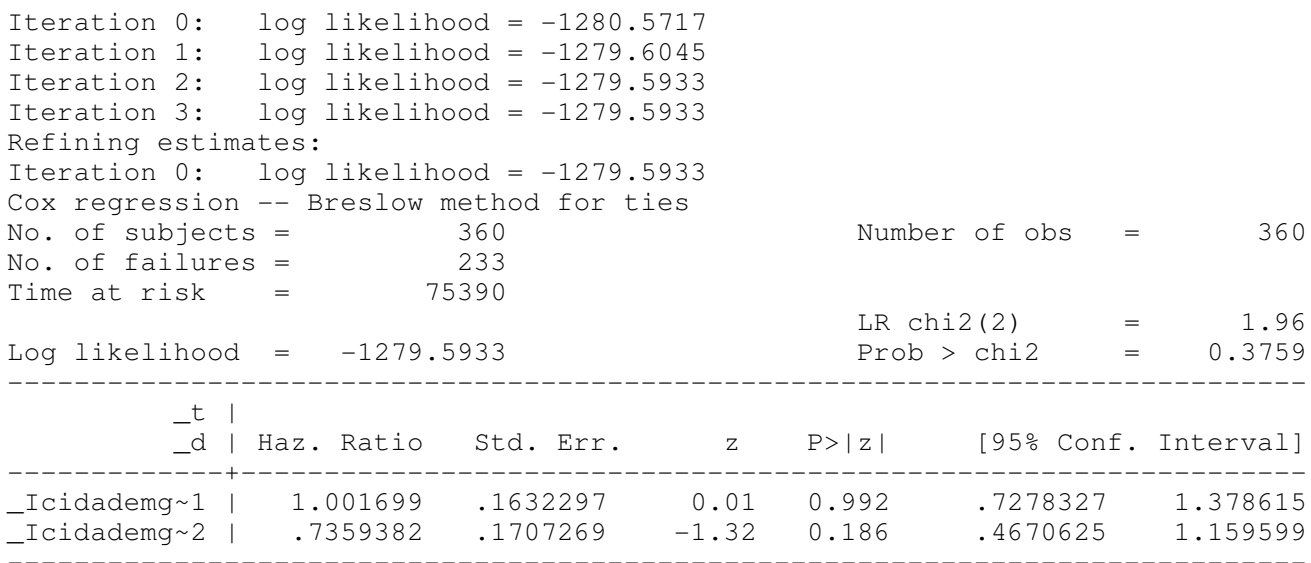

\section{MODELO COM ESCOLARIDADE DA MÃE}



A variável ESCOLARIDADE DA MÃE deve ser selecionada. 
MODELO COM CONDIÇÃO MARITAL DA MÃE

Iteration 0: $\quad \log$ likelihood $=-1280.5717$

Iteration 1: log likelihood $=-1280.1541$

Iteration 2: $\quad$ log likelihood $=-1280.1533$

Refining estimates:

Iteration 0: log likelihood $=-1280.1533$

Cox regression -- Breslow method for ties

No. of subjects $=\quad 360 \quad$ Number of obs $=360$

No. of failures $=\quad 233$

Time at risk $=75390$



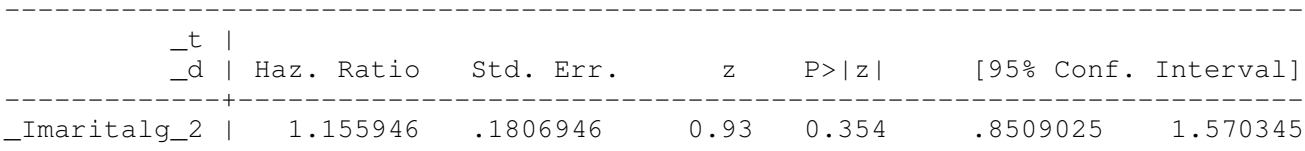

MODELO COM HÁBITO DE FUMAR DA MÃE

Iteration 0: log likelihood $=-1280.5717$

Iteration 1: $\quad \log$ likelihood $=-1278.4533$

Iteration 2: $\quad$ log likelihood $=-1278.4005$

Iteration 3: $\quad \log$ likelihood $=-1278.4005$

Refining estimates:

Iteration 0: $\quad$ log likelihood $=-1278.4005$

Cox regression -- Breslow method for ties

$\begin{array}{ccc}\text { No. of subjects }= & 360 & \text { Number of obs } \\ \text { No. of failures }= & 233 & \end{array}$

Time at risk $=75390$

Log likelihood = $-1278.4005 \quad$ LR chi2(1) $=\begin{aligned} & 4.34 \\ & \text { Prob }>\text { chi2 }=0.0372\end{aligned}$

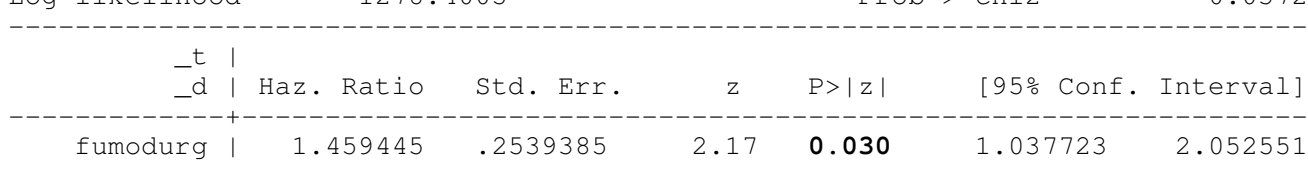

A variável HÁBITO DE FUMAR deve ser selecionada.

MODELO COM MORAR O PAI DA CRIANÇA COM A MÃE

Iteration 0: $\quad$ log likelihood $=-1280.5717$

Iteration 1: $\quad \log$ likelihood $=-1280.5266$

Iteration 2: $\quad \log$ likelihood $=-1280.5265$

Refining estimates:

Iteration 0: $\quad$ log likelihood $=-1280.5265$

Cox regression -- Breslow method for ties

No. of subjects $=\quad 360$

Number of obs $=360$

No. of failures $=233$

Time at risk $=75390$

Log likelihood $=-1280.5265$

LR $\operatorname{chi2}(1)=0.09$

Prob $>$ chi2 $=0.7638$

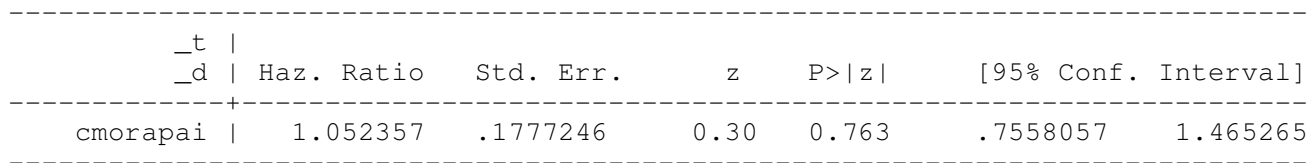


MODELO COM POSSE DE BENS

Iteration 0: log likelihood $=-1280.5717$

Iteration 1: $\quad \log$ likelihood $=-1280.0084$

Iteration 2: $\quad$ log likelihood $=-1280.0082$

Refining estimates:

Iteration 0: log likelihood $=-1280.0082$

Cox regression -- Breslow method for ties

No. of subjects $=\quad 360 \quad$ Number of obs $=360$

$\begin{array}{rrr}\text { No. of failures } & = \\ \text { Time at risk } & =\end{array}$

Log likelihood = -1280.0082 $\begin{array}{ll}\text { LR chi2 }(1) & =1.13 \\ \text { Prob }>\text { chi2 } & =0.2884\end{array}$



MODELO COM AS VARIÁVEIS SELECIONADAS - ESCOLARIDADE DA MÃE E HÁBITO DE FUMAR

Iteration 0: log likelihood $=-1280.5717$

Iteration 1: $\quad \log$ likelihood $=-1276.2152$

Iteration 2: $\quad$ log likelihood $=-1276.0045$

Iteration 3: $\quad \log$ likelihood $=-1276.0033$

Iteration 4: log likelihood $=-1276.0033$

Refining estimates:

Iteration 0: $\quad$ log likelihood $=-1276.0033$

Cox regression -- Breslow method for ties

No. of subjects $=\quad 360 \quad$ Number of obs $=360$

No. of failures $=\quad 233$

Time at risk $=75390$

Log likelihood $=-1276.0033=9.14$

Log likelihood $=-1276.0033 \quad$ Prob $>$ chi2 $=0.0275$

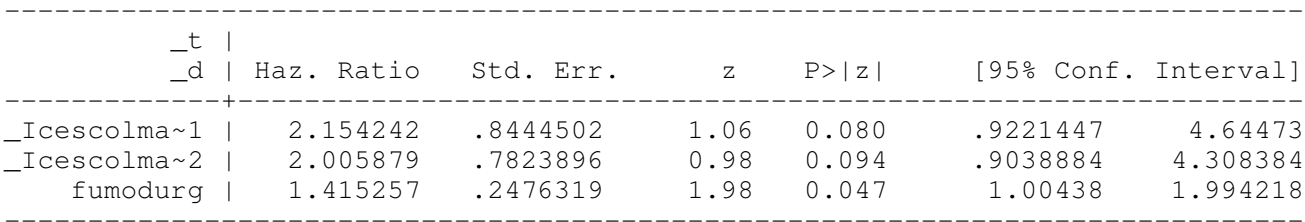

MODELO COM HÁBITO DE FUMAR

Iteration 0: log likelihood $=-1280.5717$

Iteration 1: $\quad$ log likelihood $=-1278.4533$

Iteration 2: $\quad \log$ likelihood $=-1278.4005$

Iteration 3: $\quad \log$ likelihood $=-1278.4005$

Refining estimates:

Iteration 0: log likelihood $=-1278.4005$

Cox regression -- Breslow method for ties

No. of subjects $=360$

No. of failures $=233$

Time at risk $=75390$

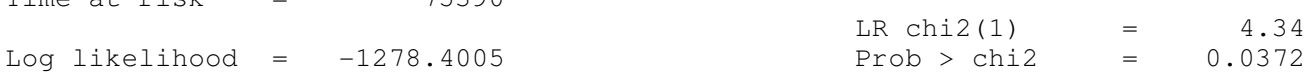

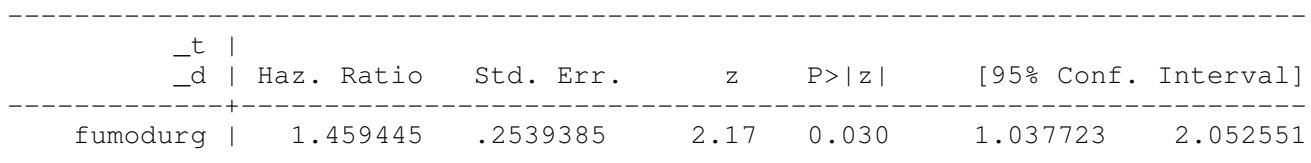

O TESTE DA RAZÃO DE VEROSSIMILHANÇAS, A PARTIR DOS DOIS MODELOS ANTERIORES, INDICA A SAÍDA DA VARIÁVEL ESCOLARIDADE DA MÃE.

$\begin{array}{lr}\text { chi2 }(2) & 4,79 \\ \text { Prob }>\text { chi2 } & =\end{array}$

DESSA FORMA, O MODELO FINAL FOI O QUE CONTÉM SOMENTE HÁBITO DE FUMAR DA MÃE. 
Modelo: complemento log-log; fonte de informação: recordatório de 12 meses

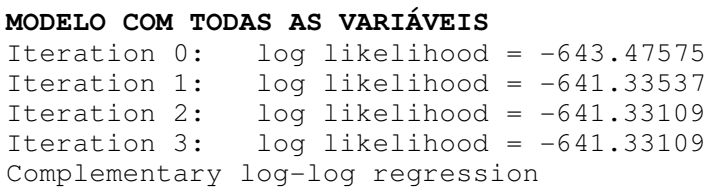

\begin{tabular}{|c|c|c|c|c|c|c|c|}
\hline $\mathrm{z}$ & & Coef. & Std. Err. & $\mathrm{z}$ & $P>|z|$ & [95\% Conf. & Interval] \\
\hline int 1 & | & -3.581534 & .4563244 & -7.85 & 0.000 & -4.475914 & -2.687155 \\
\hline int2 & i & -3.813361 & .4737243 & -8.05 & 0.000 & -4.741843 & -2.884878 \\
\hline int 3 & i & -2.84949 & .4298639 & -6.63 & 0.000 & -3.692007 & -2.006972 \\
\hline int 4 & i & -2.574228 & .4248166 & -6.06 & 0.000 & -3.406853 & -1.741603 \\
\hline int 5 & i & -1.836242 & .4114628 & -4.46 & 0.000 & -2.642694 & -1.029789 \\
\hline int 6 & 1 & -1.917258 & .4188643 & -4.58 & 0.000 & -2.738217 & -1.096299 \\
\hline int 7 & i & -3.339939 & .51435 & -6.49 & 0.000 & -4.348046 & -2.331831 \\
\hline sexo & i & -.1317099 & .1348716 & -0.98 & 0.329 & -.3960534 & .1326336 \\
\hline _Iparto_1 & i & .2031216 & .1932203 & 1.05 & 0.293 & -.1755832 & .5818265 \\
\hline -Iparto_2 & i & .0197828 & .1623617 & 0.12 & 0.903 & -.2984403 & .338006 \\
\hline racag & i & -.0390183 & .1425543 & -0.27 & 0.784 & -.3184196 & .240383 \\
\hline _Icidademg 1 & 1 & -.0051703 & .1781842 & -0.03 & 0.977 & -.354405 & .3440643 \\
\hline Icidademg 2 & i & -.2154283 & .2443146 & -0.88 & 0.378 & -.6942762 & .2634196 \\
\hline Icescolma 1 & i & .7015329 & .4044555 & 1.73 & 0.083 & -.0911854 & 1.494251 \\
\hline Icescolma 2 & i & .6268465 & .4066282 & 1.54 & 0.123 & -.1701301 & 1.423823 \\
\hline _Imaritalg_2 & i & .5403683 & .3165276 & 1.71 & 0.088 & -.0800143 & 1.160751 \\
\hline fumodurg & i & .377305 & .1844792 & 2.05 & 0.041 & .0157324 & .7388776 \\
\hline cmorapai & 1 & -.536432 & .348061 & -1.54 & 0.123 & -1.218619 & .1457551 \\
\hline _Icbensgr_1 & i & .1226829 & .1473323 & 0.83 & 0.405 & -.1660831 & .4114488 \\
\hline
\end{tabular}

\section{MODELO COM SEXO}

Iteration 0: $\quad \log$ likelihood $=-650.80357$

Iteration 1: $\log$ likelihood $=-649.02923$

Iteration 2: $\quad$ log likelihood $=-649.02444$

Iteration 3: $\log$ likelihood $=-649.02444$

Complementary log-log regression

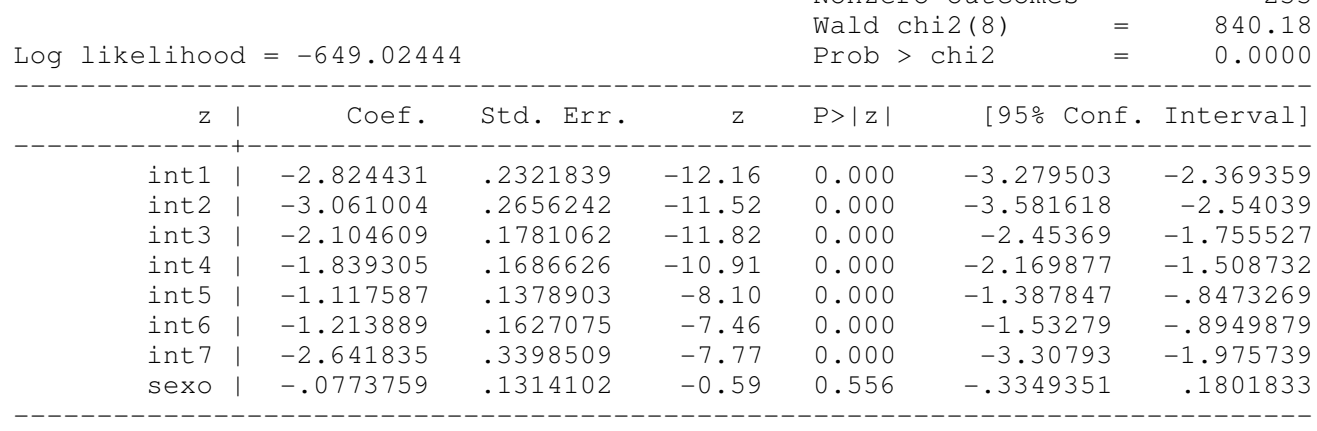

Number of obs = $\quad 1879$

Nonzero outcomes $=233$

$\begin{array}{lll}\text { Wald chi2 }(19) & = & 827.39 \\ \text { Prob }>\text { chi2 } & = & 0.0000\end{array}$

$0.000-4.475914-2.687155$

$0.000-4.741843-2.884878$

$\begin{array}{lll}0.000 & -3.692007 & -2.006972\end{array}$

$-3.406853-1.741603$

$0.000-4.348046-2.331831$

$0.293-.1755832 \quad .5818265$

$\begin{array}{lll}0.903 & -.2984403 & .338006 \\ 0.784 & -.3184196 & .240383\end{array}$

$\begin{array}{lll}0.7847 & -.3184196 & .240383 \\ 0.977 & -.354405 & .3440643\end{array}$

.2634196

$0.083-.0911854-1.494251$

$0.088-.0800143$

$0.041-.0157324-.7388776$
Zero outcomes $\quad=\quad 1646$

$0.000-2.738217-1.096299$

$0.329-.3960534 \quad .1326336$

$0.405-.1660831 \quad .4114488$

\section{s.}


MODELO COM TIPO DE PARTO

\begin{tabular}{|c|c|c|c|c|c|c|c|}
\hline & & & & & & & \\
\hline teration 0: & log likelit & $o d=-650$ & 0796 & & & & \\
\hline teration 1 : & log likelih & od $=-648$. & 8255 & & & & \\
\hline Iteration 2: & log likelih & $o d=-648$. & 7789 & & & & \\
\hline teration 3: & log likelit & od $=-648$ & 7789 & & & & \\
\hline omplementary & $\log -\log r e g r$ & ssion & & Numbe & f obs & $=$ & 1879 \\
\hline & & & & Zero & comes & $=$ & 1646 \\
\hline & & & & Nonze & outcomes & $=$ & 233 \\
\hline & & & & Wald & $2(9)$ & $=$ & 839.67 \\
\hline lihood & $x=-648.677$ & & & Prob & hi2 & $=$ & 0.0000 \\
\hline $\mathrm{z}$ & Coef. & Std. Err. & $\mathrm{z}$ & $\mathrm{P}>|\mathrm{z}|$ & {$[95 \% \mathrm{C}$} & $h f$. & Interval] \\
\hline int 1 & -2.882017 & .2315596 & -12.45 & 0.000 & -3.3358 & & -2.428169 \\
\hline int2 & -3.117137 & .2649724 & -11.76 & 0.000 & -3.6364 & & -2.5978 \\
\hline int 3 & -2.15918 & .1768077 & -12.21 & 0.000 & -2.5057 & & -1.812643 \\
\hline int 4 & -1.893796 & .1668586 & -11.35 & 0.000 & -2.2208 & & -1.566759 \\
\hline int 5 & -1.172866 & .1355284 & -8.65 & 0.000 & -1.4384 & & -.9072353 \\
\hline int 6 & -1.270116 & .1604912 & -7.91 & 0.000 & -1.5846 & & -.9555587 \\
\hline int 7 & -2.699217 & .3387752 & -7.97 & 0.000 & -3.3632 & & -2.03523 \\
\hline _Iparto_1 & .1591283 & .1763449 & 0.90 & 0.367 & -.18650 & & .5047578 \\
\hline Iparto_2 & -.0369993 & .1564017 & -0.24 & 0.813 & -.3435 & & .2695424 \\
\hline
\end{tabular}

\section{MODELO COM RAÇA}

$\begin{array}{lll}\text { Iteration } 0: & \log \text { likelihood }=-650.86807 \\ \text { Iteration 1: } & \log \text { likelihood }=-649.10165 \\ \text { Iteration 2: } & \text { log likelihood }=-649.09683 \\ \text { Iteration 3: } & \text { log likelihood }=-649.09683\end{array}$

Complementary log-log regression

Log likelihood $=-649.09683$

\begin{tabular}{|c|c|c|c|c|c|c|}
\hline z & Coef. & Std. Err. & z & $\mathrm{P}>|\mathrm{z}|$ & [95\% Conf. & Interval] \\
\hline int 1 & -2.838086 & .2296417 & -12.36 & 0.000 & -3.288176 & -2.387997 \\
\hline int 2 & -3.07484 & .2633243 & -11.68 & 0.000 & -3.590946 & -2.558734 \\
\hline int 3 & -2.118371 & .1747132 & $-12 \cdot 12$ & 0.000 & -2.460803 & -1.775939 \\
\hline int 4 & -1.853679 & .1646693 & -11.26 & 0.000 & -2.176424 & -1.530933 \\
\hline int 5 & -1.131975 & .1329562 & -8.51 & 0.000 & -1.392565 & -.8713856 \\
\hline int 6 & -1.228071 & .158721 & -7.74 & 0.000 & -1.539159 & -.9169838 \\
\hline int 7 & -2.655831 & .3380681 & -7.86 & 0.000 & -3.318432 & -1.99323 \\
\hline racag & -.0604956 & .1348425 & -0.45 & 0.654 & -.324782 & .2037908 \\
\hline
\end{tabular}

Number of obs $\quad=\quad 1879$ Zero outcomes $=1646$ Nonzero outcomes $=233$

Wald chi2 (8) $=840.30$ $\begin{array}{lll}\text { Prob }>\text { chi2 } & = & 840.30 \\ & & 0.0000\end{array}$

\section{MODELO COM IDADE DA MÃE}

Iteration 0: log likelihood $=-649.83593$

Iteration 1: $\log$ likelihood $=-648.0381$

Iteration 2: log likelihood $=-648.03331$

Iteration 3: $\quad \log$ likelihood $=-648.03331$

Complementary log-log regression

Number of obs = $\quad 1879$

Zero outcomes = $\quad 1646$

Nonzero outcomes = 233

Wald $\operatorname{chi}(9) \quad=\quad 838.45$

Prob > chi2 $=0.0000$

\begin{tabular}{|c|c|c|c|c|c|c|}
\hline z & Coef. & Std. Err. & z & $P>|z|$ & [95\% Conf. & Interval \\
\hline int 1 & -2.830393 & .227643 & -12.43 & 0.000 & -3.276566 & -2.384221 \\
\hline int 2 & -3.066886 & .2616331 & -11.72 & 0.000 & -3.579678 & -2.554095 \\
\hline int 3 & -2.110756 & .1718211 & -12.28 & 0.000 & -2.447519 & -1.773993 \\
\hline int 4 & -1.845473 & .1616488 & -11.42 & 0.000 & -2.162299 & -1.528647 \\
\hline int 5 & -1.121192 & .1300896 & -8.62 & 0.000 & -1.376163 & -.8662214 \\
\hline int 6 & -1.213786 & .1564348 & -7.76 & 0.000 & -1.520393 & -.9071796 \\
\hline int 7 & -2.63828 & .3367457 & -7.83 & 0.000 & -3.298289 & -1.97827 \\
\hline Icidademg 1 & .0044791 & .1632901 & 0.03 & 0.978 & -.3155637 & .3245218 \\
\hline Icidademg 2 & -.3330578 & .2322458 & -1.43 & 0.192 & -.7882513 & .1221357 \\
\hline
\end{tabular}


MODELO COM ESCOLARIDADE DA MÃE

\begin{tabular}{|c|c|c|c|c|c|c|c|}
\hline & & & & & & & \\
\hline Iteration 0: & $\log$ likelih & $\mathrm{dd}=-648$ & 067 & & & & \\
\hline Iteration 1: & log likelih & $\mathrm{d} d=-646$ & 832 & & & & \\
\hline Iteration 2: & log likelih & $\mathrm{d} d=-646$ & 353 & & & & \\
\hline Iteration 3: & log likelih & $\mathrm{od}=-646$. & 53 & & & & \\
\hline Complementary & $\log -\log r e g r$ & ssion & & Numbe & $f o b s$ & $=$ & 1879 \\
\hline & & & & Zero & comes & $=$ & 1646 \\
\hline & & & & Nonze & outcomes & $=$ & 233 \\
\hline & & & & Wald & $2(9)$ & $=$ & 835.06 \\
\hline og likelihoo & $=-646.3335$ & & & Prob & hi2 & $=$ & 0.0000 \\
\hline z & Coef. & Std. Err. & z & $P>|z|$ & {$[95 \% \mathrm{C}$} & af. & Interval] \\
\hline int 1 & -3.629963 & .4368437 & -8.31 & 0.000 & -4.4861 & & -2.773765 \\
\hline int 2 & -3.865932 & .4553484 & -8.49 & 0.000 & -4.7583 & & -2.973466 \\
\hline int 3 & -2.908772 & .4100108 & -7.09 & 0.000 & -3.7123 & & -2.105166 \\
\hline int 4 & -2.641989 & .4051948 & -6.52 & 0.000 & -3.4361 & & -1.847822 \\
\hline int 5 & -1.913283 & .3915391 & -4.89 & 0.000 & -2.6806 & & -1.14588 \\
\hline int 6 & -2.003156 & .3988723 & -5.02 & 0.000 & -2.7849 & & -1.221381 \\
\hline int 7 & -3.428865 & .4972847 & -6.90 & 0.000 & -4.4035 & & -2.454205 \\
\hline escolma 1 & .826654 & .3914428 & 2.11 & 0.035 & .05944 & & 1.593868 \\
\hline I cescolma 2 & .7725684 & .3887042 & 1.99 & 0.047 & .01072 & & 1.534415 \\
\hline
\end{tabular}

A variável ESCOLARIDADE DA MÃE deve ser selecionada.

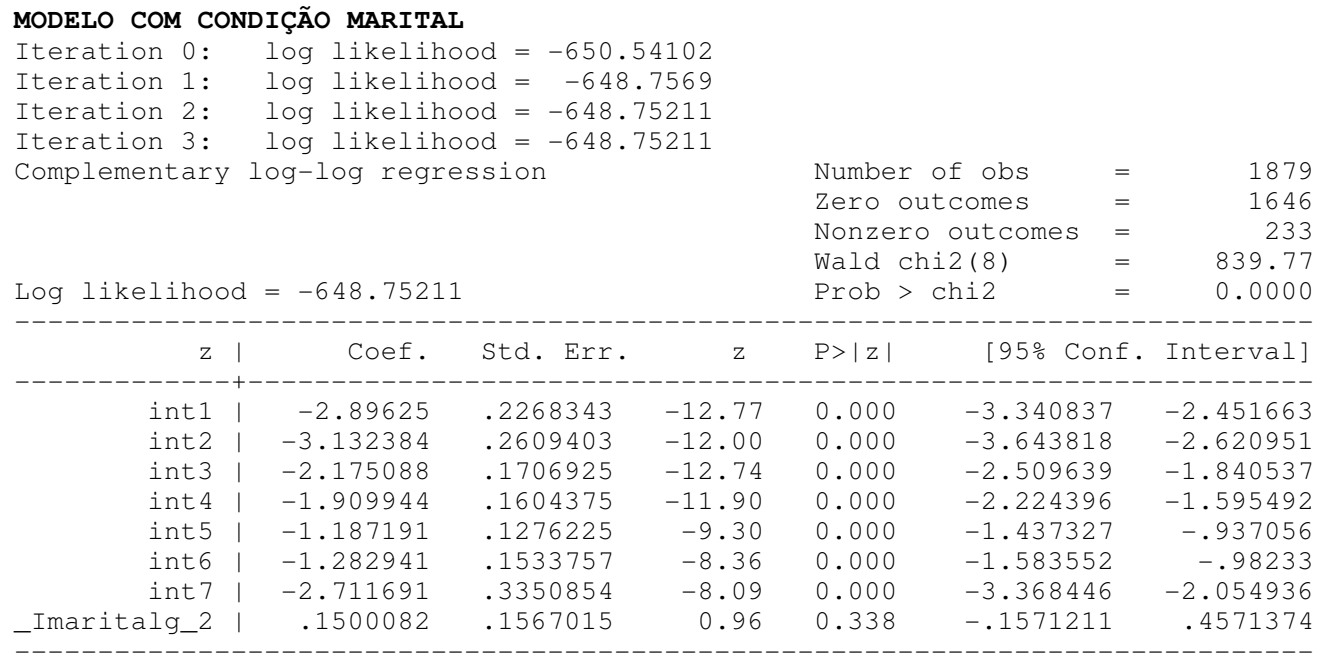

\section{MODELO COM HÁBITO DE FUMAR DA MÃE}

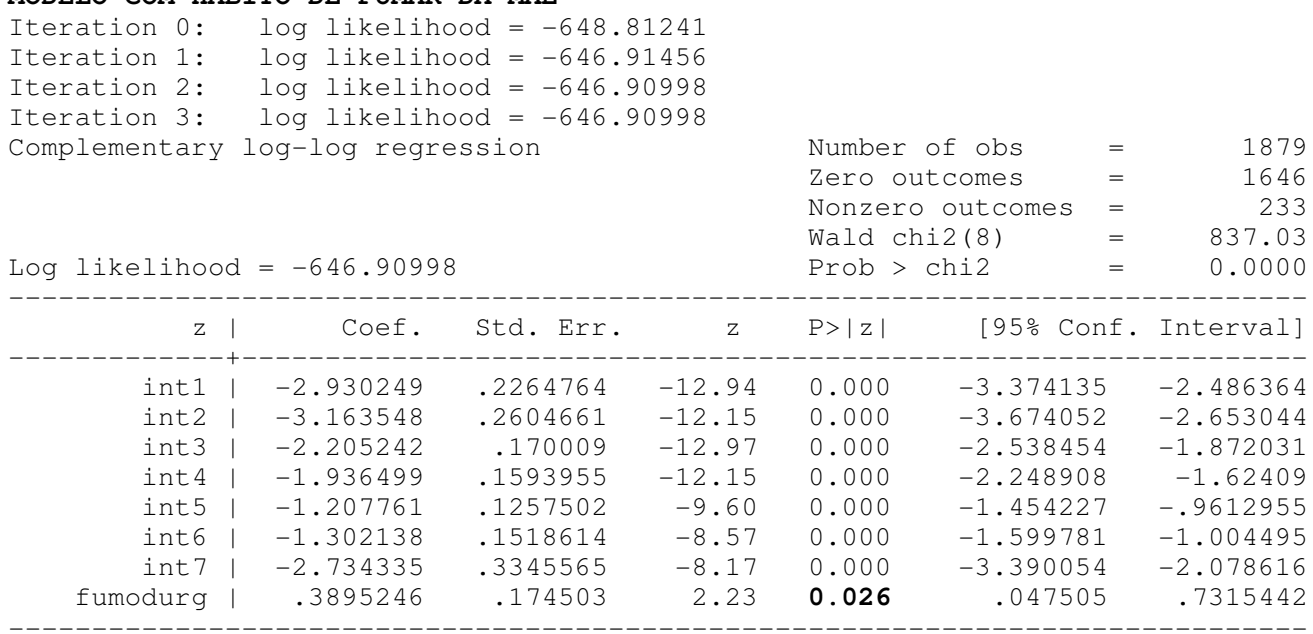

A variável HÁBITO DE FUMAR deve ser selecionada. 
MODELO COM MORAR O PAI DA CRIANÇA COM A MÃE

Iteration 0: log likelihood $=-650.92441$

Iteration 1: log likelihood $=-649.15615$

Iteration 2: $\quad$ log likelihood $=-649.15134$

Iteration 3: $\quad \log$ likelihood $=-649.15134$

complementary log-log regression

\begin{tabular}{|c|c|c|c|}
\hline $\mathrm{mb}$ & obs & $=$ & \\
\hline ero o & comes & $=$ & 164 \\
\hline onzer & butcomes & $=$ & \\
\hline ald & & $=$ & \\
\hline Prob > & ii2 & $=$ & \\
\hline$>12$ & {$[95 \% \mathrm{Col}$} & onf. & \\
\hline & -3.3 & & \\
\hline & -3.6 & & \\
\hline .000 & -2.48398 & & -1.81 \\
\hline مिمि & -2.199 & & \\
\hline .000 & -1.41285 & & -.91 \\
\hline & -1.56080 & & -.9 \\
\hline .0 & -3.3469 & & -2.0 \\
\hline 0.759 & -.279808 & & .383 \\
\hline
\end{tabular}

\section{MODELO COM POSSE DE BENS}

Iteration 0: log likelihood $=-650.43954$
Iteration 1: log likelihood $=-648.64548$
Iteration 2: log likelihood $=-648.64071$
Iteration 3: log likelihood $=-648.64071$
Complementary log-log regression
Log likelihood $=-648.64071$



MODELO COM VARIÁVEIS SELECIONADAS - ESCOLARIDADE DA MÃE E HÁBITO DE FUMAR

\section{Iteration 0: log likelihood $=-646.38896$ \\ Iteration 1: log likelihood $=-644.41766$ \\ Iteration 2: $\quad \log$ likelihood $=-644.4131$ \\ Iteration 3: $\quad \log$ likelihood $=-644.4131$ \\ Complementary log-log regression}

$\begin{array}{llr}\text { Number of obs } & = & 1879 \\ \text { Zero outcomes } & = & 1646 \\ \text { Nonzero outcomes } & = & 233 \\ \text { Wald chi2 }(10) & = & 832.25 \\ \text { Prob > chi2 } & = & 0.0000\end{array}$

\begin{tabular}{|c|c|c|c|c|c|c|c|}
\hline $\mathrm{z}$ & | & Coef. & Std. Err. & z & $P>|z|$ & [95\% Conf. & Interval] \\
\hline int 1 & i & -3.640414 & .4369749 & -8.33 & 0.000 & -4.496869 & -2.783959 \\
\hline int2 & | & -3.873587 & .4554372 & -8.51 & 0.000 & -4.766228 & -2.980947 \\
\hline int3 & i & -2.914927 & .4100913 & -7.11 & 0.000 & -3.718691 & -2.111163 \\
\hline int 4 & | & -2.644742 & .4052386 & -6.53 & 0.000 & -3.438995 & -1.850489 \\
\hline int 5 & | & -1.910092 & .3915209 & -4.88 & 0.000 & -2.677459 & -1.142725 \\
\hline int 6 & | & -1.998083 & .3988237 & -5.01 & 0.000 & -2.779763 & -1.216403 \\
\hline int 7 & | & -3.426818 & .4972639 & -6.89 & 0.000 & -4.401437 & -2.452199 \\
\hline _Icescolma 1 & | & .7823366 & .3922625 & 1.99 & 0.086 & .0135163 & 1.551157 \\
\hline Icescolma 2 & | & .7113256 & .3902607 & 1.82 & 0.098 & -.0535714 & 1.476223 \\
\hline fumodurg & | & .3572137 & .1754492 & 2.04 & 0.042 & .0133395 & .7010879 \\
\hline
\end{tabular}




\section{MODELO COM HABITO DE FUMAR}

Iteration 0: log likelihood $=-648.81241$

Iteration 1: $\quad$ log likelihood $=-646.91456$

Iteration 2: log likelihood $=-646.90998$

Iteration 3: $\log$ likelihood $=-646.90998$

Complementary log-log regression

$\begin{array}{llr}\text { Number of obs } & = & 1879 \\ \text { Zero outcomes } & = & 1646 \\ \text { Nonzero outcomes } & = & 233 \\ \text { Wald chi2 }(8) & = & 837.03 \\ \text { Prob }>\text { chi2 } & = & 0.0000\end{array}$

Log likelihood $=-646.90998$

0.0000

\begin{tabular}{|c|c|c|c|c|c|c|c|}
\hline z & I & Coef. & Std. Err. & z & $\mathrm{P}>|\mathrm{z}|$ & [95\% Conf. & Interval] \\
\hline int 1 & 1 & -2.930249 & .2264764 & -12.94 & 0.000 & -3.374135 & -2.486364 \\
\hline int2 & i & -3.163548 & .2604661 & -12.15 & 0.000 & -3.674052 & -2.653044 \\
\hline int 3 & i & -2.205242 & .170009 & -12.97 & 0.000 & -2.538454 & -1.872031 \\
\hline int 4 & i & -1.936499 & .1593955 & -12.15 & 0.000 & -2.248908 & -1.62409 \\
\hline int 5 & i & -1.207761 & .1257502 & -9.60 & 0.000 & -1.454227 & -.9612955 \\
\hline int 6 & 1 & -1.302138 & .1518614 & -8.57 & 0.000 & -1.599781 & -1.004495 \\
\hline int 7 & i & -2.734335 & .3345565 & -8.17 & 0.000 & -3.390054 & -2.078616 \\
\hline fumodurg & i & .3895246 & .174503 & 2.23 & 0.026 & .047505 & .7315442 \\
\hline
\end{tabular}

O TESTE DA RAZÃO DE VEROSSIMILHANÇAS, A PARTIR DOS DOIS MODELOS ANTERIORES (UM COM HÁBITO DE FUMAR E ESCOLARIDADE DA MÃE E O OUTRO SOMENTE COM HÁBITO DE FUMAR), INDICA A SAÍdA DA VARIÁVEL ESCOLARIDADE DA MÃE.

$\begin{array}{llr}\operatorname{chi}(1) & = & 4,99 \\ \text { Prob }>\operatorname{chi2}= & 0,0823\end{array}$

DESSA FORMA, O MODELO FINAL FOI O QUE CONTÉM SOMENTE HÁBITO DE FUMAR DA MÃE. 
Anexo 8 - Programa no STATA para o modelo complemento log-log e alterações no banco de dados 
Programa para preparar os dados para rodar o modelo complemento log-log.

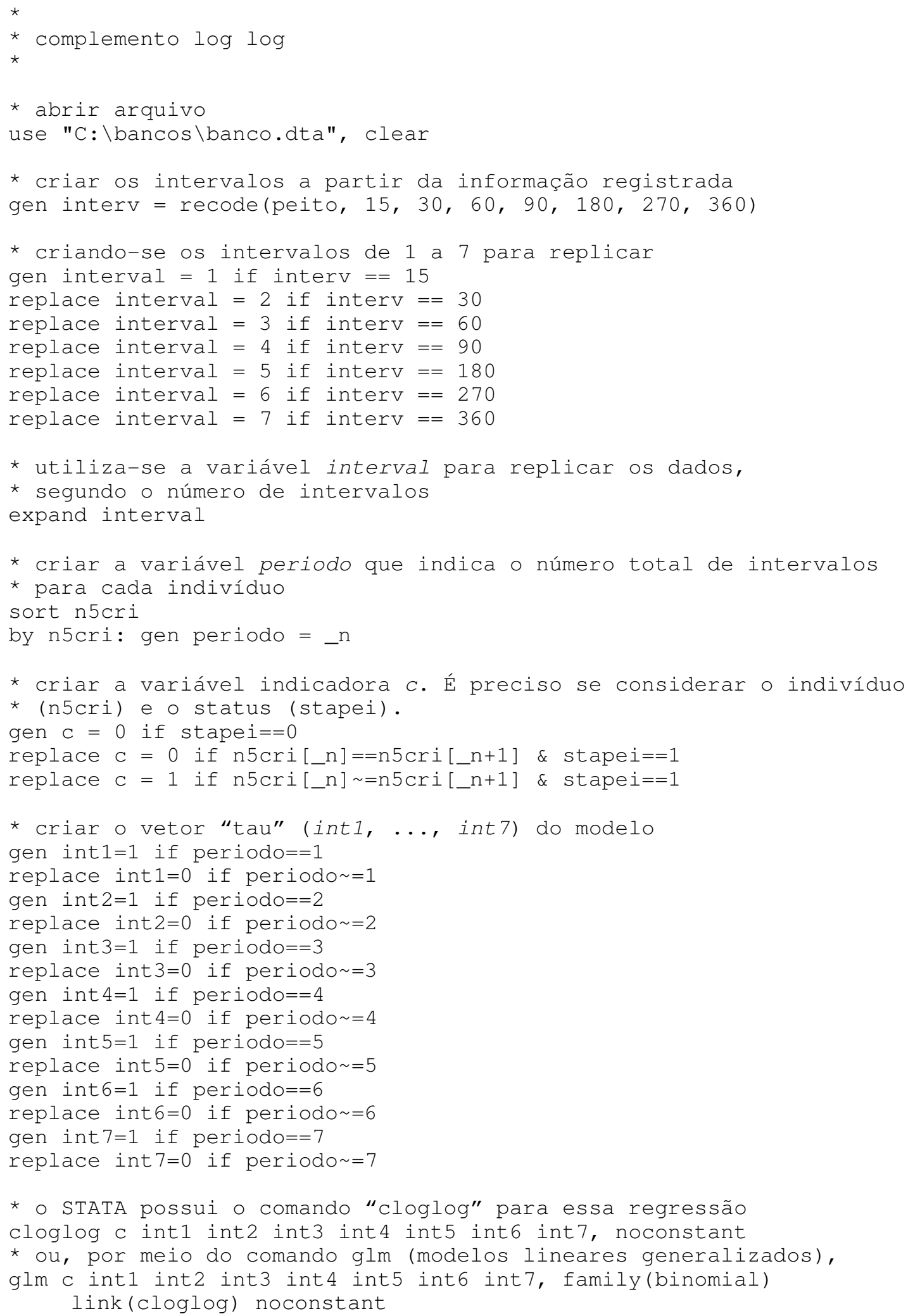

* o STATA possui o comando "cloglog" para essa regressão cloglog $c$ int1 int2 int3 int4 int5 int6 int7, noconstant * ou, por meio do comando glm (modelos lineares generalizados), glm c int1 int2 int3 int4 int5 int6 int7, family(binomial) link (cloglog) noconstant 
O Exemplo a seguir apresenta um fragmento do banco de dados após executar o programa no software STATA.

\section{Exemplo. banco de dados após o programa}

\begin{tabular}{cccccccccc}
\hline id & interval & periodo & c & int1 & int2 & int3 & int4 & int5 & int6 \\
\hline 55 & 1 & 1 & 1 & 1 & 0 & 0 & 0 & 0 & 0 \\
64 & 2 & 1 & 0 & 1 & 0 & 0 & 0 & 0 & 0 \\
64 & 2 & 2 & 1 & 0 & 1 & 0 & 0 & 0 & 0 \\
21 & 3 & 1 & 0 & 1 & 0 & 0 & 0 & 0 & 0 \\
21 & 3 & 2 & 0 & 0 & 1 & 0 & 0 & 0 & 0 \\
21 & 3 & 3 & 1 & 0 & 0 & 1 & 0 & 0 & 0 \\
2 & 4 & 1 & 0 & 1 & 0 & 0 & 0 & 0 & 0 \\
2 & 4 & 2 & 0 & 0 & 1 & 0 & 0 & 0 & 0 \\
2 & 4 & 3 & 0 & 0 & 0 & 1 & 0 & 0 & 0 \\
2 & 4 & 4 & 0 & 0 & 0 & 0 & 1 & 0 & 0 \\
7 & 5 & 1 & 0 & 1 & 0 & 0 & 0 & 0 & 0 \\
7 & 5 & 2 & 0 & 0 & 1 & 0 & 0 & 0 & 0 \\
7 & 5 & 3 & 0 & 0 & 0 & 1 & 0 & 0 & 0 \\
7 & 5 & 4 & 0 & 0 & 0 & 0 & 1 & 0 & 0 \\
7 & 5 & 5 & 1 & 0 & 0 & 0 & 0 & 1 & 0 \\
1 & 6 & 1 & 0 & 0 & 0 & 0 & 0 & 0 & 0 \\
1 & 6 & 2 & 0 & 0 & 1 & 0 & 0 & 0 & 0 \\
1 & 6 & 3 & 0 & 0 & 0 & 1 & 0 & 0 & 0 \\
1 & 6 & 4 & 0 & 0 & 0 & 0 & 1 & 0 & 0 \\
1 & 6 & 5 & 0 & 0 & 0 & 0 & 0 & 1 & 0 \\
1 & 6 & 6 & 0 & 0 & 0 & 0 & 0 & 0 & 1 \\
\hline
\end{tabular}

A criança 55 deixou o leite de peito $(c=1)$ no intervalo 1 .

A criança 64 não deixou o leite de peito $(\mathrm{c}=0)$ no intervalo 1 (periodo=1) mas deixou o leite de peito $(\mathrm{c}=1)$ no intervalo 2 (periodo=2).

A criança 21 deixou o leite de peito $(c=1)$ no intervalo 3 e não deixou $(c=0)$ até o intervalo 2 (periodo=2).

A criança 2 deixou o leite de peito $(c=1)$ no intervalo 4 e não deixou $(c=0)$ até o intervalo 3 (periodo=3).

A criança 7 deixou o leite de peito $(c=1)$ no intervalo 5 e não deixou $(c=0)$ até o intervalo 4 (periodo $=4$ ).

A criança 1 não deixou o leite de peito $(c=0)$ até o intervalo 6 , quando houve censura por terminar o seguimento. 
Anexo 9 - Parecer do Comitê de Ética em Pesquisa da FSP - COEP 